UNIVERSIDADE DE SÃO PAULO

HOSPITAL DE REABILITAÇÃO DE ANOMALIAS CRANIOFACIAIS

\begin{abstract}
EFEITOS DA RINOSSEPTOPLASTIA SOBRE AS DIMENSÕES INTERNAS NASAIS E RESSONÂNCIA DA FALA EM INDIVÍDUOS COM FISSURA DE LÁBIO E PALATO UNILATERAL REPARADA: ANÁLISE POR RINOMETRIA ACÚSTICA E NASOMETRIA.
\end{abstract}

CARLOS EDUARDO BERTIER

Tese apresentada ao Hospital de Reabilitação de Anomalias Craniofaciais da Universidade de São Paulo para obtenção do Título de Doutor em Ciências da Reabilitação, Área de Concentração: Distúrbios da Comunicação Humana. 


\section{EFEITOS DA RINOSSEPTOPLASTIA SOBRE AS DIMENSÕES INTERNAS NASAIS E RESSONÂNCIA DA FALA EM INDIVÍDUOS COM FISSURA DE LÁBIO E PALATO UNILATERAL REPARADA: ANÁLISE POR RINOMETRIA ACÚSTICA E NASOMETRIA.}

CARLOS EDUARDO BERTIER

Orientadora: Prof ${ }^{a}$. Dr ${ }^{a}$. Inge Elly Kiemle Trindade

Tese apresentada ao Hospital de Reabilitação de Anomalias Craniofaciais da Universidade de São Paulo para obtenção do Título de Doutor em Ciências da Reabilitação, Área de Concentração: Distúrbios da Comunicação Humana. 
Rua Silvio Marchione, 3-20

Caixa postal: 1501

17012-900 Bauru/SP - Brasil

(14) $3235-8000$

Profa. Dra Suely Vilela - Reitora da USP

Prof. Dr. José Alberto de Souza Freitas - Superintendente HRAC-USP

Autorizo, exclusivamente, para fins acadêmicos e científicos, a reprodução total ou parcial deste trabalho.

\section{Carlos Eduardo Bertier}

Bauru, de de

\section{Bertier, Carlos Eduardo}

Efeitos da rinosseptoplastia sobre as dimensões internas nasais e ressonância da fala em indivíduos com fissura de lábio e palato unilateral reparada: análise por rinometria acústica e nasometria / Carlos Eduardo Bertier. Bauru, 2006.

94f.: il.; $29,7 \mathrm{~cm}$

Tese Doutorado em Distúrbios da Comunicação Humana - HRAC/USP.

Orientadora: Prof ${ }^{\mathrm{a}}$. Dr ${ }^{\mathrm{a}}$. Inge Elly Kiemle Trindade Descritores:1. rinoplastia 2. septo nasal 3. cavidade nasal $\begin{array}{llll}4 \text {. rinometria acústica } & 5 \text {. nasometria } & 6 \text {. fissura palatina }\end{array}$ 7. fissura labial. 


\section{FOLHA DE APROVAÇAO}

Tese apresentada e defendida por

e aprovada pela Comissão Julgadora em

Prof.(a) $\operatorname{Dr}(a)$.

Instituição

Prof.(a) $\operatorname{Dr}(a)$.

Instituição

Prof.(a) $\operatorname{Dr}(a)$.

Instituição

Prof.(a) Dr(a).

Instituição

Prof $^{\mathrm{a}}$. Dr ${ }^{\mathrm{a}}$. Inge Elly Kiemle Trindade

HRAC-USP/Bauru - Orientadora

Prof $^{a}$. Dr ${ }^{a}$. Inge Elly Kiemle Trindade

Presidente da Comissão de Pós-Graduação do HRAC-USP

Data de depósito da Tese junto à SPG 


\section{MINI-CURRÍCULO}

Nome

04 de Maio de 1962

Americana/SP

$1986-1988$

$1988-1991$

$1988-1991$

$1988-1991$

1992 até a presente data

$1996-2001$

\section{Carlos Eduardo Bertier}

Nascimento

1981 - 1986 Graduação em Medicina. Universidade Severino Sombra, em Vassouras - RJ.

Especialização em Cirurgia Geral no Hospital São Francisco de Assis em Belo Horizonte - MG.

Especialização em Cirurgia Plástica Estética e Reparadora, no Hospital João XXIII da Fundação Hospitalar do Estado de Minas Gerais.

Especialização em Cirurgia Plástica Estética e Reparadora na Clínica Perfil de Cirurgia Plástica em Belo Horizonte - MG.

Especialização em Cirurgia Plástica Estética e Reparadora no Hospital da Baleia Fundação Benjamim Guimarães em Belo Horizonte - MG.

Médico na área de Cirurgia Plástica, do, Hospital de Reabilitação de Anomalias Craniofaciais, da Universidade de São Paulo em Bauru - SP.

Curso de Pós-Graduação em Cirurgia, nível de Mestrado, na Universidade Estadual Paulista Júlio de Mesquita Filho de Botucatu - SP. 
À DEUS,

... pela presença constante em minha vida

.. pela força para enfrentar as dificuldades

... pela quietude para

alcançar a paz 
Aos pacientes e seus familiares,

... razão maior do nosso

aprimoramento

... agradeço a todos que

participaram desta pesquisa, sem os quais não seria possível sua concretização

... o meu profundo muito obrigado pela disponibilidade 


\begin{abstract}
À minha mãe Therezinha, meus irmãos Cláudio e Luiz Gonzaga,
\end{abstract}

Aos meus sobrinhos, Juliana, Reinaldo, Mariana, Vitor e Marcelo,

... pelo amor, paciência e compreensão

$$
\text { pelos sacrifícios }
$$
partilhados nos momentos de ausência

mas sobretudo, pela inesgotável fonte de estímulo para o meu aprimoramento 


\begin{abstract}
À minha Orientadora e Presidente da Comissão de Pós-Graduação do Hospital de Reabilitação de Anomalias Craniofaciais da Universidade de São Paulo,
\end{abstract}

$$
\text { Prof }^{a} \text {. Dr }{ }^{a} \text {. Inge Elly Kiemle }
$$

Trindade,

o meu respeito, a minha admiração e gratidão por ter compartilhado com disponibilidade, paciência e dedicação os seus conhecimentos. 
Ao Superintendente do Hospital de Reabilitação de Anomalias Craniofaciais da Universidade de São Paulo,

Prof. Dr. José Alberto de Souza Freitas,

- meu respeito, a minha admiração pela dedicação ao ser humano, a minha amizade e por ter acreditado no meu trabalho durante todos estes anos no Centrinho. 

Meus sinceros agradecimentos,

Dra . Ana Claudia Martins Sampaio,

- meu carinho e respeito. Agradeço pela dedicação disponibilidade, prestatividade e paciência demonstrada neste trabalho. 


\section{AGRADECIMENTOS}

À família Zambonato Freitas, $\mathrm{Dr}^{\mathrm{a}}$. Sueli, $\mathrm{Dr}{ }^{a}$. Patrícia, Dr. Rogério, Dra . Priscila, Dr. Ricardo e Guilherme, pela amizade e incentivo.

À Ana Paula Fukushiro, pela amizade e contribuições.

À Dra . Renata Paciello Yamashita, pela amizade e contribuições.

Ao Prof. Dr. José Roberto Pereira Lauris, pela contribuição na análise estatística.

Ao Prof. Dr. Marcos Virmond, pela amizade e pelas contribuições no exame de qualificação deste.

À $\mathrm{Dr}^{a}$. Gisele Dalben, pela amizade e contribuições.

Ao Márcio Henrique Andrade, pela amizade, pela dedicação e contribuição na organização deste.

Aos amigos cirurgiões do HRAC-USP, Dr. Eudes, Dr. José Sérgio, Dr. Marcos Lupércio, Dra. Telma, Dr. Luis Garla, Dr. Ricardo Duarte, Dr. Ricardo Mondelli, Dr. Vitor, pela convivência e colaboração.

Aos amigos Dr. Carlos Alberto Aielo, Dr. Roberto Macoto, Dr Ayrton Marques e $\mathrm{Dr}^{\mathrm{a}}$. Cristiane.

À Ana Grigoli, Denise e Ana Regina, pela contribuição na organização bibliográfica. USP .

Aos amigos do setor de Fisiologia do HRAC- 
À equipe de profissionais e funcionários do Centro Cirúrgico.

À equipe de Anestesiologistas, Enfermagem e Auxiliares de Enfermagem.

Aos amigos do setor de Fotografia do HRACUSP .

Aos amigos da Reprografia do HRAC-USP.

À todos os profissionais e funcionários do HRAC-USP e todos aqueles que colaboraram de forma direta ou indiretamente na realização deste trabalho. 


\section{SUMÁRIO}

\section{LISTA DE FIGURAS}

\section{LISTA DE TABELAS}

\section{SUMÁRIO}

1. INTRODUÇÃO e REVISÃO DE LITERATURA ….............................. 17

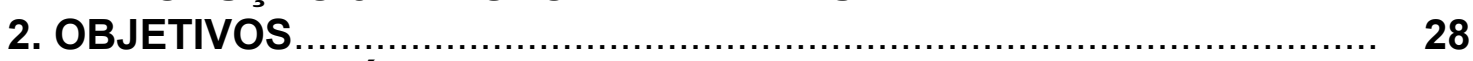

3. MATERIAL E MÉTODOS …......................................................... 30

3.1 Casuística...................................................................... 31

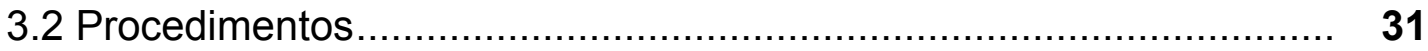

3.2.1 Rinosseptoplastia......................................................... 33

3.2.2 Avaliação das dimensões internas nasais por rinometria acústica............................................................... $\quad 36$

3.2.3 Avaliação da ressonância da fala por nasometria.................... 43

3.3 Consentimento livre e esclarecido ............................................ $\quad 46$

3.4 Análise estatística ................................................................ 46

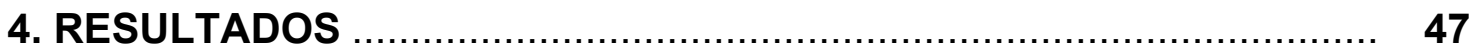

4.1 Análise das dimensões internas nasais por rinometria acústica........ $\quad 48$

4.1.1 Áreas seccionais nasais .................................................. 48

4.1.1.1 Áreas de secção transversa da cavidade nasal correspondente ao lado da fissura antes da descongestão nasal .................................................

4.1.1.2 Áreas de secção transversa da cavidade nasal correspondente ao lado não-fissurado antes da descongestão nasal .....

4.1.1.3 Áreas de secção transversa da cavidade nasal correspondente ao lado da fissura após descongestão nasal

4.1.1.4 Áreas de secção transversa da cavidade nasal correspondente ao lado não-fissurado após descongestão nasal ................................................. 56

\subsubsection{Volumes Nasais}

4.1.2.1 Volumes da cavidade nasal correspondente ao lado da fissura antes da descongestão nasal 58

4.1.2.2 Volumes da cavidade nasal correspondente ao lado não-fissurado antes da descongestão nasal .

4.1.2.3 Volumes da cavidade nasal correspondente ao lado da fissura após descongestão nasal

63

4.1.2.4 Volumes da cavidade nasal correspondente ao lado não-fissurado após descongestão nasal 
4.2.1 Nasalância no texto nasal ............................................ 67

4.2.2 Nasalância no texto oral............................................... 70

5. DISCUSSÃO ............................................................................ 71

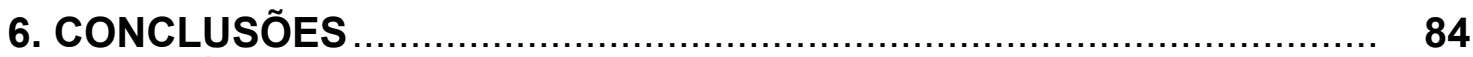

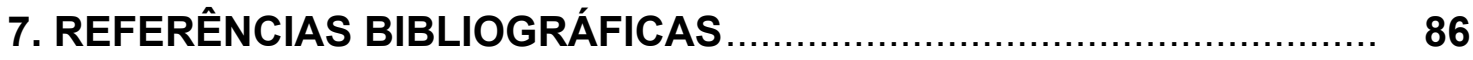
ANEXOS 


\section{LISTA DE FIGURAS}

Figura 1 - llustração das etapas cirúrgicas da rinosseptoplastia.

Figura 2 - Instrumentação para a medida das dimensões da cavidade nasal (Rinômetro Acústico Eccovision, Hood Laboratories, Pembroke, MA, USA)

Figura 3 - Curva área-distância típica aferida por rinometria acústica, ilustrando as áreas de secção transversa (AST) medidas em pontos correspondentes à área da válvula nasal (AST1), à porção anterior da concha nasal inferior (AST2) e à porção posterior da concha nasal inferior (AST3).

Figura 4 - Curva área-distância típica aferida por rinometria acústica, ilustrando os volumes medidos em segmentos correspondentes à região da válvula nasal (V1) e à região das conchas nasais (V2)

Figura 5 - Instrumentação para a medida da nasalância (Nasômetro 6200-3 IBM, Kay Elemetrics Corp., Lincoln Park, NJ, USA) ...

Figura 6 - Variações percentuais induzidas pela rinosseptoplastia nas áreas de secção transversa de três diferentes segmentos da cavidade nasal (AST1, AST2 e AST3) aferidas por rinometria acústica, antes da aplicação tópica de vasoconstrictor nasal, em indivíduos com fissura de lábio e palato unilateral reparada, observadas no primeiro (POS1) e segundo (POS2) pós-operatório, no lado fissurado

Figura 7 - Variações percentuais induzidas pela rinosseptoplastia nas áreas de secção transversa de três diferentes segmentos da cavidade nasal (AST1, AST2 e AST3) aferidas por rinometria acústica, antes da aplicação tópica de vasoconstrictor nasal, em indivíduos com fissura de lábio e palato unilateral reparada, observadas no primeiro (POS1) e segundo (POS2) pós-operatório, no lado nãofissurado

Figura 8 - Variações percentuais induzidas pela rinosseptoplastia nas áreas de secção transversa de três diferentes segmentos da cavidade nasal (AST1, AST2 e AST3) aferidas por rinometria acústica, após a aplicação tópica de vasoconstrictor nasal, em indivíduos com fissura de lábio e palato unilateral reparada, observadas no primeiro (POS1) e segundo (POS2) pós-operatório, no lado fissurado 
Figura 9 - Variações percentuais induzidas pela rinosseptoplastia nas áreas de secção transversa de três diferentes segmentos da cavidade nasal (AST1, AST2 e AST3) aferidas por rinometria acústica, após a aplicação tópica de vasoconstrictor nasal, em indivíduos com fissura de lábio e palato unilateral reparada, observadas no primeiro (POS1) e segundo (POS2) pós-operatório, no lado nãofissurado

Figura 10 - Variações percentuais induzidas pela rinosseptoplastia nos volumes de dois diferentes segmentos da cavidade nasal (V1 e V2) aferidos por rinometria acústica, antes da aplicação tópica de vasoconstrictor nasal, em indivíduos com fissura de lábio e palato unilateral reparada, observadas no primeiro (POS1) e segundo (POS2) pósoperatório, no lado fissurado

Figura 11 - Variações percentuais induzidas pela rinosseptoplastia nos volumes de dois diferentes segmentos da cavidade nasal (V1 e V2) aferidos por rinometria acústica, antes da aplicação tópica de vasoconstrictor nasal, em indivíduos com fissura de lábio e palato unilateral reparada, observadas no primeiro (POS1) e segundo (POS2) pósoperatório, no lado não-fissurado

Figura 12 - Variações percentuais induzidas pela rinosseptoplastia nos volumes de dois diferentes segmentos da cavidade nasal (V1 e V2) aferidos por rinometria acústica, após a aplicação tópica de vasoconstrictor nasal, em indivíduos com fissura de lábio e palato unilateral reparada, observadas no primeiro (POS1) e segundo (POS2) pósoperatório, no lado fissurado

Figura 13 - Variações percentuais induzidas pela rinosseptoplastia nos volumes de dois diferentes segmentos da cavidade nasal (V1 e V2) aferidos por rinometria acústica, após a aplicação tópica de vasoconstrictor nasal, em indivíduos com fissura de lábio e palato unilateral reparada, observadas no primeiro (POS1) e segundo (POS2) pósoperatório, no lado não-fissurado

Figura 14 - Variações percentuais induzidas pela rinosseptoplastia na nasalância, aferida por nasometria, em indivíduos com fissura de lábio e palato unilateral reparada, observadas no primeiro (POS1) e segundo (POS2) pós-operatório, na leitura do texto nasal e do texto oral 


\section{LISTA DE TABELAS}

Tabela 1 - Dados gerais acerca dos indivíduos com fissura de lábio e palato unilateral reparada analisados.

Tabela 2 - Valores médios ( \pm desvio padrão) e porcentagem de variação $(\% \Delta)$ das áreas de secção transversa de três diferentes segmentos da cavidade nasal (AST1, AST2 e AST3), aferidas por rinometria acústica em 21 indivíduos com fissura de lábio e palato unilateral reparada, previamente (PRE) à rinosseptoplastia e no primeiro (POS1) e segundo (POS2) pós-operatório, dos lados fissurado (LF) e não-fissurado (LNF), antes e após a aplicação tópica de vasoconstrictor nasal. As áreas seccionais são expressas em $\mathrm{cm}^{2}$.

Tabela 3 - Valores médios ( \pm desvio padrão) e porcentagem de variação $(\% \Delta)$ dos volumes de dois diferentes segmentos da cavidade nasal (V1 e V2), aferidos por rinometria acústica em 21 indivíduos com fissura de lábio e palato unilateral reparada, previamente (PRE) à rinosseptoplastia e no primeiro (POS1) e segundo (POS2) pós-operatório, dos lados fissurado (LF) e não-fissurado (LNF), antes e após a aplicação tópica de vasoconstrictor nasal. Os volumes são expressos em $\mathrm{cm}^{3}$.

Tabela 4 - Valores médios ( \pm desvio padrão) da nasalância, aferida por nasometria, em 21 indivíduos com fissura de lábio e palato unilateral reparada, previamente (PRE) à rinosseptoplastia e no primeiro (POS1) e segundo (POS2) pós-operatório, na leitura do texto nasal e texto oral. A nasalância é expressa em porcentagem (\%). 


\section{RESUMO}

Bertier CE. Efeitos da rinosseptoplastia sobre as dimensões internas nasais e ressonância da fala em indivíduos com fissura de lábio e palato unilateral reparada: Análise por rinometria acústica e nasometria. [Tese]. Bauru: Hospital de Reabilitação de Anomalias Craniofaciais, Universidade de São Paulo; 2006.

Objetivo: Analisar os efeitos da rinosseptoplatia sobre as áreas seccionais e volumes nasais e a nasalância da fala de indivíduos com fissura de lábio e palato unilateral reparada, utilizando rinometria acústica e nasometria.

Modelo: Análise prospectiva.

Local de Execução: Centro Cirúrgico e Laboratório de Fisiologia, HRAC-USP. Participantes: Indivíduos com fissura de lábio e palato unilateral reparada $(n=21$, idade $=15-46$ anos) foram avaliados antes da cirurgia (PRE) e 6-9 meses (POS1) e 12-23 meses (POS2) após.

Variáveis: $\mathrm{Na}$ rinometria acústica foram aferidas as áreas de secção transversa dos segmentos correspondentes à válvula nasal (AST1), porção anterior (AST2) e porção posterior da concha nasal inferior (AST3), e, os volumes da região da válvula (V1) e conchas (V2) nasais, de ambas os lados, antes e após a descongestão nasal com vasoconstrictor tópico. Na nasometria, avaliou-se a nasalância na leitura de um texto contendo predominantemente sons nasais, e, outro, exclusivamente sons orais.

Resultados: No lado fissurado, antes da descongestão nasal, observou-se um aumento significante $(p<0.05)$ nos valores médios de AST1 e V1 em POS1 e POS2, relativamente ao PRE. Após a descongestão, observou-se aumento também para AST2 e V2 em POS2. No lado não-fissurado, não foram observadas variações significativas. Os valores médios de nasalância em PRE, POS1 e POS2 não diferiram entre si, nos textos oral e nasal.

Conclusão: A medida das áreas seccionais e volumes mostraram que a rinosseptoplastia levou, na maioria dos casos analisados, a um aumento significativo da permeabilidade nasal, sem modificações concomitantes na ressonância da fala, estimada pela medida da nasalância.

Descritores: rinoplastia, septo nasal, cavidade nasal, rinometria acústica, nasometria, fissura palatina, fissura labial. 


\begin{abstract}
Bertier CE. Effects of rhinoseptoplasty on the internal nasal dimensions and speech resonance in individuals with repaired unilateral cleft lip and palate: assessment by acoustic rhinometry and nasometry [thesis]. Bauru: Hospital for Rehabilitation of Craniofacial Anomalies, University of São Paulo; 2006.
\end{abstract}

Objective: To analyze the effects of rhinoseptoplasty on the nasal crosssectional areas and volumes, and the speech nasalance of individuals with repaired unilateral cleft lip and palate, assessed by acoustic rhinometry and nasometry.

Design: Prospective analysis.

Setting: Surgery Service and Laboratory of Physiology at the Hospital for Rehabilitation of Craniofacial Anomalies (HRAC-USP).

Participants: Individuals with previously repaired unilateral cleft lip and palate $(n=21$, age $=15-46$ years) were evaluated before surgery (PRE) after 6-9 months (POST1) and after 12-18 months (POST2).

Variables: Acoustic rhinometry was used to measure the cross-sectional areas of segments corresponding to the nasal valve (CSA1), anterior portion (CSA2) and posterior portion (CSA3) of the lower turbinate, and the nasal volumes at the regions of the nasal valve (V1) and nasal turbinates (V2) at both sides, before and after nasal decongestion with a topical vasoconstrictor. Nasometry was employed to evaluate the speech nasalance during the reading of a text predominantly containing nasal sounds and other containing only oral sounds.

Results: At the cleft side, before nasal decongestion, there was a significant increase $(p<0.05)$ in mean CSA1 and CSA2 values at POST1 and POST2 compared to PRE. After decongestion, increased values were also observed for CSA2 and V2 at POST2. No significant changes were observed at the non-cleft side. The mean nasalance values at PRE, POST1 and POST2 were not different from each other in both oral and nasal texts.

Conclusion: The measurement of cross-sectional areas and volumes by acoustic rhinometry revealed that rhinoseptoplasty provided, in most cases analyzed, a significant increase in nasal patency, without concomitant changes in speech resonance, as estimated by nasalance assessment.

Descriptors: rhinoplasty, nasal septum, nasal cavity, acoustic rhinometry, nasometry, cleft palate, cleft lip. 


\section{INTRODUÇÃO e REVISÃO}

DE LITERATURA 
Introduçào e Revısào de Lıteratura

\section{INTRODUÇÃO e REVISÃO DE LITERATURA.}

As fissuras congênitas que envolvem o lábio e o palato, simultaneamente, são associadas a deformidades nasais características que comprometem o nariz do ponto de vista estético e funcional, e que resultam da anomalia em si, e, parcialmente, de cirurgias prévias. Sua correção é parte integrante do tratamento secundário das fissuras de lábio e palato, sendo feita por meio de procedimentos cirúrgicos que envolvem, basicamente, a correção do septo, do arcabouço ósseo e da ponta nasal, narinas e bases alares (Gubisch et al 1998).

As deformidades nasais que acompanham as fissuras labiopalatinas reduzem as dimensões internas da cavidade nasal, aumentam a resistência ao fluxo aéreo respiratório e produzem uma respiração oral de suplência (Wetmore 1992, Warren e Drake 1993), a qual pode prejudicar o desenvolvimento craniofacial (Linder-Aronson 1979) e comprometer a função das vias aéreas inferiores (Trindade 1990, Trindade et al 1992).

As alterações associadas às fissuras unilaterais diferem daquelas verificadas nas fissuras bilaterais. O nariz de indivíduos com fissura de lábio e palato unilateral, em particular, caracteriza-se por deformidades, como, na ponta: deslocamento inferior da cartilagem alar no lado fissurado e tendência à bifidez; na columela: desvio no topo para o lado fissurado e na base para o lado não-fissurado, nas bases alares: deslocamento lateral resultando em rotação mais horizontal da narina no lado fissurado; no dorso: desvio da pirâmide óssea para o lado não-fissurado, ossos nasais assimétricos e 
Introduçào e Revısào de Lıteratura

achatados no lado fissurado e cartilagens laterais superiores assimétricas e alteração da união entre as laterais superiores e inferiores no lado fissurado; no septo: desvio da lâmina perpendicular para o lado fissurado, desvio da cartilagem quadrangular na junção com a lâmina perpendicular para o lado fissurado, desvio caudal da cartilagem quadrangular para o lado não-fissurado e desvio da espinha nasal anterior para o lado não-fissurado (Trenité 1993). Essas alterações nem sempre se manifestam todas num mesmo paciente e sua gravidade varia consideravelmente entre pacientes (Warren e Drake 1993).

Ainda que exista consenso quanto aos efeitos favoráveis das chamadas "rinosseptoplastias" sobre a estética nasal, o conhecimento detalhado de suas repercussões funcionais é ainda escasso.

Fukushiro e Trindade (2005) demonstraram, por meio de rinomanometria, que, em adultos, a fissura de lábio e palato bilateral está associada a um maior comprometimento da permeabilidade nasal, seguida da fissura unilateral, e finalmente, da fissura de palato isolada. A rinomanometria é a técnica utilizada, há mais de meio século, para avaliar a permeabilidade nasal de maneira quantitativa; por meio dela mede-se a resistência nasal. O método baseia-se no princípio hidráulico de que a resistência oferecida por uma constrição pode ser estimada pela medida simultânea da diferença de pressão existente entre os dois lados da constrição e do fluxo aéreo que a atravessa. Com base na equação de $\mathrm{Ohm}$, a resistência nasal é definida como a razão entre a pressão diferencial transnasal e o fluxo aéreo nasal. Warren et al (1969) verificaram que indivíduos com fissura de lábio e/ou palato, reparada ou não, apresentavam resistência nasal significantemente menor que indivíduos nãofissurados, atribuindo esse achado às deformidades nasais e alterações de 
Introduçào e Revısào de Lıteratura

crescimento maxilar encontradas nesta população. Posteriormente, Sandham e Solow (1987) e Sandham e Murray (1993) demonstraram que a resistência é maior no lado afetado em pacientes com fissura de lábio e palato unilateral, não havendo diferenças entre as cavidades em indivíduos com fissura de palato isolada e em indivíduos sem fissura. Apesar de tratar-se de um método válido, a medida da resistência nasal apresenta certas limitações; a mais importante reside no fato de que é fluxo-dependente (Warren e Drake 1993). Em função disto, Warren (1984) introduziu uma modificação na rinomanometria convencional, de forma a estimar não a resistência, mas a menor área de secção transversa da via aérea nasal. Estudos subseqüentes vieram confirmar a hipótese de que a área seccional de adultos com fissura envolvendo lábio e palato é consideravelmente menor que a encontrada em adultos sem fissura e mostraram que mais de $60 \%$ desta população apresenta a via aérea nasal inadequada para uma respiração normal (Hairfield e Warren 1989, Warren et al 1990, Liu et al 1992, Trindade et al 1995). Na rinomanometria, a válvula nasal é usualmente a área estimada, porém, se outras constrições significantes estão presentes a área obtida é uma composição delas, o que representa, de certa forma, uma limitação. Além disso, a técnica não fornece informação sobre o local da constrição (Warren e Drake 1993).

Nos últimos anos, uma nova técnica tem sido empregada para avaliar as dimensões internas da cavidade nasal, prestando-se, portanto, para avaliar o efeito de procedimentos como a rinosseptoplastia sobre a permeabilidade nasal; trata-se da rinometria acústica, introduzida por Sondhi e Gopinath (1971). A técnica foi utilizada inicialmente para avaliar as dimensões da traquéia e da árvore brônquica de cães por Jackson et al (1977), e para a 
medida de vias aéreas faríngeas, laríngeas e traqueais de humanos por Hoffstein et al (1984), Brown et al (1986), D’Urzo et al $(1987,1988)$ e Fredberg et al (1980). Sua introdução na prática clínica, como método de avaliação da geometria nasal, se deu com o trabalho de Hilberg et al (1989).

A técnica baseia-se no princípio físico de que um som ao atravessar um tubo (no caso, a cavidade nasal) é refletido frente a mudanças de impedância causadas por variações nas dimensões internas do tubo (no caso, obstruções). Em outras palavras, a rinometria acústica compreende a análise dos sons refletidos pela cavidade nasal, emitidos por uma fonte acústica e captados por um microfone, ambos posicionados no interior do rinômetro adaptado a uma das narinas (Hilberg e Pedersen 2000, Hilberg 2002). Permite medições consecutivas de diferentes segmentos da cavidade nasal, desde as narinas até a nasofaringe e, deste modo, a identificação exata do local das diferentes constrições que contribuem para a resistência nasal, de forma rápida e não invasiva, sem a necessidade da participação ativa do paciente (Hilberg et al 1989, Roithmann e Cole 1995, Hilberg 2002). Esses recursos representam um avanço em relação à rinomanometria de Warren, uma vez que esta permite a medida apenas do segmento de maior constrição e exige maior colaboração do paciente.

Valores de referência normais foram relatados por diversos autores como Grymer et al (1989, 1991, 1997), Hilberg et al (1990), Lenders e Pirsig (1990), Lenders et al (1991), Kesavanathan et al (1995), Morgan et al (1995), Roithmann et al (1995, 1997), Millqvist e Bende (1998), Corey et al (1998), Tomkinson e Eccles (1998), Silkoff et al (1999), Kunkel et al (1999), Sung et al (2000), Larsson et al (2001) e Ognibene et al (2001), compilados por Gomes 
Introduçào e Revısào de Lıteratura

(2004) em trabalho recente do Laboratório de Fisiologia do HRAC-USP, onde o presente estudo foi desenvolvido. Esta autora analisou as áreas seccionais e os volumes de segmentos específicos da cavidade nasal de indivíduos sem evidências de obstrução nasal. Entre outras variáveis, foram determinadas as áreas de secção transversa nos segmentos correspondentes à válvula nasal (AST1), porção anterior da concha nasal inferior (AST2) e porção posterior da concha nasal inferior (AST3) e os volumes dos segmentos correspondentes à região da válvula nasal (V1) e das conchas nasais (V2), antes e após a aplicação tópica de um vasoconstrictor para promover a descongestão nasal, a fim de eliminar o efeito da mucosa sobre as medidas. Os valores médios ( $\pm \mathrm{DP})$ das áreas e volumes obtidos foram os seguintes: $A_{S T}=0,54 \pm 0,13 \mathrm{~cm}^{2}$, $\mathrm{AST}_{2}=0,98 \pm 0,31 \mathrm{~cm}^{2}, \quad \mathrm{AST}_{3}=1,42 \pm 0,44 \mathrm{~cm}^{2}, \quad \mathrm{~V}_{1}=1,68 \pm 0,32 \mathrm{~cm}^{3} \quad$ e $\mathrm{V}_{2}=3,98 \pm 1,12 \mathrm{~cm}^{3}$. Após a descongestão nasal, os valores foram significantemente maiores. A comparação dessas áreas seccionais e volumes obtidos com os relatados na literatura validaram seu uso como valores de referência, assim como o emprego da rinometria como método de avaliação objetiva da geometria nasal.

A técnica tem também sido empregada por vários autores para estimar a obstrução de vias aéreas nasais de diferentes etiologias. Nessas condições, valores subnormais foram observados por autores como Grymer et al (1989), Hilberg et al (1990), Lenders e Pirsig (1990), Lenders et al (1991), Fisher et al (1995), Roithmann et al (1995, 1997), Gilain et al (1997), Kunkel et al (1997), Reber et al (1998), Mamikoglu et al (2000, 2002), Carlini et al (2002), entre outros. 
Introduçào e Revısào de Lıteratura

Em função dos recursos que oferece, a rinometria acústica tem se mostrado particularmente importante como método de avaliação das dimensões nasais antes e após as cirurgias nasais, na medida em que identifica, com precisão, o local e o grau da obstrução, facilitando o planejamento cirúrgico e diminuindo a incidência de problemas residuais (Wahlmam et al 1998). Por estas razões tem sido considerada importante ferramenta no controle de qualidade desses procedimentos (Kunkel et al 1999).

O impacto favorável (ou mesmo desfavorável) das cirurgias realizadas em vias nasais e nasofaríngeas sobre as áreas seccionais e volumes foram relatados por autores como Grymer et al (1989), Fisher et al (1995), Antila et al (1997), Mann et al (1997), Shemen e Hamburg (1997), Kim et al (1998), Reber et al (1998), Kemker et al (1999), Anselmo-Lima e Lund (2001), Pirilä e Tikanto (2001), Voegels et al (2002) e Marques e Anselmo-Lima (2004), Can et al (2005).

Em pacientes com fissura de lábio e palato, poucos são os estudos que se valeram da rinometria acústica para aferir o impacto dessa anomalia sobre as dimensões internas da cavidade nasal (Kunkel et al 1997, Wahlmann et al 1998, Kunkel et al 1999) e apenas um artigo publicado na literatura alemã (Hümpfner-Hierl et al 2003) acompanhou os efeitos da correção cirúrgica das deformidades nasais.

Kunkel et al (1997) avaliaram pacientes com fissura de lábio e palato unilateral comparativamente a pacientes com fissura bilateral e indivíduos controles. Observaram que, nos casos com fissura unilateral, a cavidade nasal do lado fissurado apresentava um volume nasal menor que a do lado não- 
Introduçào e Revısào de Lıteratura

fissurado e que a área de secção transversa mínima nasal do lado fissurado $\left(0.31 \mathrm{~cm}^{2}\right)$ era comparativamente menor que a do lado não-fissurado $\left(0,52 \mathrm{~cm}^{2}\right)$, diferença que desapareceu após descongestão nasal por vasoconstrictor tópico. Adicionalmente, constaram que a capacidade de descongestão era maior no segmento posterior, indicando a presença de hipertrofia de mucosa do lado fissurado nos pacientes analisados. Em outro estudo similar publicado pelo mesmo grupo (Wahlmann et al 1998), encontrou-se, em pacientes com fissura unilateral, resultados sugestivos de obstrução da válvula nasal em $85 \%$ dos pacientes no lado da fissura e, em apenas $15 \%$, no lado contralateral. Verificou-se, ainda, um segundo sítio de estenose em posição mais posterior à válvula nasal. Esses resultados foram, mais tarde, confirmados pelos mesmos autores para uma amostra maior de pacientes (Kunkel et al 1999).

Afim de ilustrar as aplicações da rinometria acústica, em seu último trabalho, Kunkel et al (1999) apresentaram dois casos clínicos de pacientes com fissura submetidos à cirurgia nasal; para o primeiro caso, que apresentava obstrução nasal moderada do lado da fissura, ficou demonstrado que a correção da deformidade nasal foi acompanhada de uma melhora marcante das variáveis que apontavam a existência de estenose anterior no préoperatório. No segundo caso, com estenose cicatricial anterior grave e obstrução decorrente de desvio de septo e hipertrofia de conchas, a análise dos dados revelou uma obstrução persistente por estreitamento cicatricial recorrente da válvula nasal e pequeno efeito da cirurgia sobre as conchas nasais. 
Introduçào e Revısào de Lıteratura

Mais recentemente, Hümpfner-Hierl et al (2003) realizaram um estudo mais abrangente; avaliaram os resultados funcionais da cirurgia nasal em 37 casos de fissura de lábio e palato unilateral (além de pacientes com fissura bilateral) utilizando três métodos: a rinomanometria, rinoresistometria (uma variante) e a rinometria acústica. Os autores encontraram evidências de melhora significativa de parâmetros aerodinâmicos da função nasal nos pacientes com fissura unilateral, mas não puderam demonstrar variações do volume nasal aferido pela rinometria acústica. Achados como estes demonstram o importante papel que a rinometria acústica pode desempenhar no controle de qualidade das cirurgias nasais.

Há que se destacar, ainda, que as deformidades nasais associadas às fissuras labiopalatinas, além de comprometerem a respiração nasal, podem interferir na qualidade da fala (Warren et al 1992), na medida em que a cavidade nasal age como caixa de ressonância modulando a energia sonora gerada em diferentes porções do trato vocal (Trindade e Trindade Junior 1996).

A ressonância é um fenômeno acústico que pode ser definido como "a resposta vibratória de um corpo ou de uma cavidade preenchida com ar a uma freqüência de vibração que Ihe é imposta". Como na literatura não existe nenhum termo que expresse os aspectos perceptivos da fala sob condições variáveis de ressonância, este termo tem sido empregado indistintamente para descrever os atributos físico e perceptivo da fala (Peterson-Falzone 2001).

É sabido que o comprometimento anatômico das estruturas nasais nas fissuras de lábio e palato pode resultar em hiponasalidade, um distúrbio que se caracteriza pelo desvio das ondas sonoras e emissão do ar expiratório para a 
Introduçào e Revısào de Lıteratura

cavidade oral, resultando em pouca ou nenhuma ressonância nasal durante a produção de sons nasais. Por outro lado, pacientes com fissura de palato, mesmo após a cirurgia corretora primária, como decorrência de uma disfunção do mecanismo velofaríngeo, podem apresentar hipernasalidade, que corresponde a uma quantidade excessiva e indesejável de ressonância nasal acompanhando sons normalmente não nasalisados (Trindade e Trindade Junior 1996).

Um dos métodos que avalia a ressonância nasal da fala é a nasometria, por meio da qual mede-se a nasalância, uma grandeza física que corresponde à quantidade relativa de energia acústica emitida pela cavidade nasal na fala. A nasalância é o correlato acústico da nasalidade que, por sua vez, corresponde à percepção subjetiva que um ouvinte tem especificamente do componente nasal da fala (Fletcher 1976, Fletcher et al 1989). As bases da medida instrumental da ressonância foram estabelecidas por Fletcher, em 1970, ao desenvolver um equipamento denominado Tonar para medir a nasalância. Em 1986, o Nasometer (nasômetro) comercializado pela Kay Elemetrics Corporation passou a ser utilizado em lugar do Tonar, como equipamento padrão da nasometria.

Em pacientes com fissura palatina, a nasalância tem sido medida durante a leitura de dois tipos de textos: um contendo exclusivamente sons orais e outro contendo predominantemente sons nasais. O primeiro é usado para identificar a hipernasalidade resultante da disfunção velofaríngea (Dalston et al 1991a) e o segundo auxilia na identificação da hiponasalidade decorrente de obstrução nasal (Dalston et al 1991b) ou mesmo da "hipercorreção" resultante das faringoplastias de retalho (Zuiani 1998, Yamashita 2003). 
Introduçào e Revısào de Lıteratura

Valores normais de nasalância em falantes do português foram determinados no laboratório de Fisiologia do HRAC-USP por Trindade et al (1997).

A nasometria é uma técnica de fácil execução e não invasiva, que envolve equipamento de custo relativamente reduzido, e, que, como corretamente apontado por Kummer (2001), é útil na avaliação da ressonância porque "suplementa o que se ouve na avaliação perceptiva e o que se vê nos métodos de avaliação diretos", referindo-se neste caso a exames como a nasoendoscopia. $\mathrm{Na}$ medida em que fornece informações objetivas, a nasometria pode ser usada para comparar dados pré e pós-tratamento e quantificar o sucesso cirúrgico como, por exemplo, feito para a cirurgia ortognática em pacientes com fissura labiopalatina por Trindade et al (2003).

Assim sendo, na medida em que as rinosseptoplastias levam a alterações anatômicas que tem o efeito potencial alterar a ressonância da fala, eventualmente eliminando uma hiponasalidade decorrente da obstrução nasal tipicamente associada às fissuras, ou, eventualmente uma hipernasalidade mascarada pela obstrução nasal, é de se supor que a nasometria pode, como a rinometria acústica, ser utilizada no controle de qualidade das cirurgias nasais. Contudo, até o presente momento, não existem relatos na literatura quanto às repercussões das rinosseptoplastias sobre a ressonância da fala em portadores de fissura de lábio e palato, avaliadas por nasometria. 
2. OBJETIVOS 


\section{OBJETIVOS.}

O presente estudo teve por objetivo avaliar os efeitos da rinosseptoplastia sobre as dimensões internas nasais e a ressonância da fala em indivíduos com fissura de lábio e palato unilateral reparada, utilizando, respectivamente, as seguintes abordagens:

1. determinação das áreas de secção transversa e dos volumes de segmentos específicos da cavidade nasal, por rinometria acústica;

2. determinação da nasalância na leitura de textos padronizados, por nasometria. 
3. MATERIAL E MÉtODOS 


\section{MATERIAL E MÉTODOS.}

\subsection{Casuística.}

Foram avaliados 21 indivíduos portadores de fissura de lábio e palato unilateral reparada, não sindrômicos, com idade entre 15 e 46 anos, sendo 13 do sexo masculino e 8 do sexo feminino, em atendimento regular no Hospital de Reabilitação de Anomalias Craniofaciais-USP, Bauru-SP. Na tabela 1 são mostrados os dados individuais referentes ao sexo, idade e lado da fissura da amostra de indivíduos analisada.

Foram incluídos no estudo pacientes com indicação para rinosseptoplastia primária por apresentarem as deformidades nasais tipicamente decorrentes da fissura, as quais são detalhadas no anexo 3A. Não foram incluídos pacientes submetidos a cirurgias nasais prévias, com sintomas respiratórios ou alérgicos evidentes que resultassem em congestão nasal ao exame e com fístulas residuais no palato.

\subsection{Procedimentos.}

Os pacientes foram submetidos à rinosseptoplastia segundo técnica utilizada de rotina no HRAC-USP pelo pesquisador principal (Carlos Eduardo Bertier). Todos foram submetidos à rinometria acústica e nasometria, realizada por profissional com experiência nos exames, (Ana Claudia Martins Sampaio), 
Tabela 1 - Dados gerais acerca dos indivíduos com fissura de lábio e palato unilateral reparada analisados.

\begin{tabular}{|c|c|c|c|c|c|}
\hline PACIENTES & SEXO & IDADE & $\begin{array}{l}\text { LADO DA } \\
\text { FISSURA }\end{array}$ & $\begin{array}{r}\text { TEMPO D } \\
(r\end{array}$ & $\begin{array}{l}\text { ALIAÇÃ } \\
\text { ) }\end{array}$ \\
\hline & & & & POS1 & POS2 \\
\hline 1 & $M$ & 31 & $E$ & $8 m$ & $16 \mathrm{~m}$ \\
\hline 2 & $F$ & 16 & $\mathrm{D}$ & $6 m$ & - \\
\hline 3 & $M$ & 16 & $E$ & $6 m$ & $12 \mathrm{~m}$ \\
\hline 4 & $M$ & 16 & $E$ & $7 \mathrm{~m}$ & $16 \mathrm{~m}$ \\
\hline 5 & $M$ & 24 & $\mathrm{D}$ & $7 \mathrm{~m}$ & $14 \mathrm{~m}$ \\
\hline 6 & M & 16 & $E$ & $8 m$ & $12 \mathrm{~m}$ \\
\hline 7 & $F$ & 22 & $D$ & $7 \mathrm{~m}$ & $15 \mathrm{~m}$ \\
\hline 8 & $M$ & 22 & $D$ & $7 \mathrm{~m}$ & $12 \mathrm{~m}$ \\
\hline 9 & $M$ & 17 & $D$ & $6 m$ & $19 \mathrm{~m}$ \\
\hline 10 & $M$ & 18 & $\mathrm{D}$ & $6 m$ & $14 \mathrm{~m}$ \\
\hline 11 & $F$ & 17 & $E$ & $9 m$ & $14 \mathrm{~m}$ \\
\hline 12 & $F$ & 17 & $E$ & $8 m$ & $15 \mathrm{~m}$ \\
\hline 13 & $M$ & 15 & $D$ & $8 m$ & - \\
\hline 14 & $F$ & 46 & $E$ & $8 m$ & $16 m$ \\
\hline 15 & M & 32 & $E$ & $9 m$ & $20 m$ \\
\hline 16 & $M$ & 30 & $E$ & $9 m$ & $23 \mathrm{~m}$ \\
\hline 17 & $F$ & 25 & $E$ & $8 m$ & $15 \mathrm{~m}$ \\
\hline 18 & $M$ & 24 & $E$ & $9 m$ & $22 \mathrm{~m}$ \\
\hline 19 & $F$ & 24 & $E$ & $9 m$ & $17 \mathrm{~m}$ \\
\hline 20 & $M$ & 25 & $E$ & $7 \mathrm{~m}$ & - \\
\hline 21 & $F$ & 15 & $E$ & $8 m$ & $14 \mathrm{~m}$ \\
\hline
\end{tabular}

POS1 - primeiro pós-operatório (relativamente ao pré-operatório) POS2 - segundo pós-operatório (relativamente ao pré-operatório) 
em três momentos do tratamento: pré-operatório (PRE): 1 ou 2 dias antes da rinosseptoplastia; primeiro pós-operatório (POS1): 6 a 9 meses após a cirurgia e segundo pós-operatório (POS2): 12 a 23 meses após a cirurgia. A tabela 1 mostra os tempos de avaliação pós-operatória individuais da amostra de indivíduos analisada.

\subsubsection{Rinosseptoplastia.}

Como já mencionado, a indicação da rinosseptoplastia se baseou em observações feitas ao exame clínico do nariz externo e interno, o qual foi realizado de maneira padronizada, utilizando formulário especialmente elaborado para o presente estudo, apresentado no anexo 2. Os procedimentos cirúrgicos individuais foram anotados em outra ficha elaborada para este fim, mostrada no mesmo anexo, e, estão detalhados no anexo 3B.

A figura 1 ilustra as principais etapas da cirurgia realizada em um caso de fissura de lábio e palato unilateral reparada (figuras $1 A$ a 1D). A rinoplastia realizada é do tipo aberta, permitindo a exposição das cartilagens laterais inferiores. A cirurgia é iniciada com uma marcação prévia em forma de "V", feita com tinta verde brilhante na porção superior da columela (figura 1E). Faz-se a tricotomia das vibrissas de ambas as narinas e infiltração anestésica de xilocaína com adrenalina numa diluição de 1:200.000 UI, no dorso, asas, ponta, base da columela e septo nasal. 


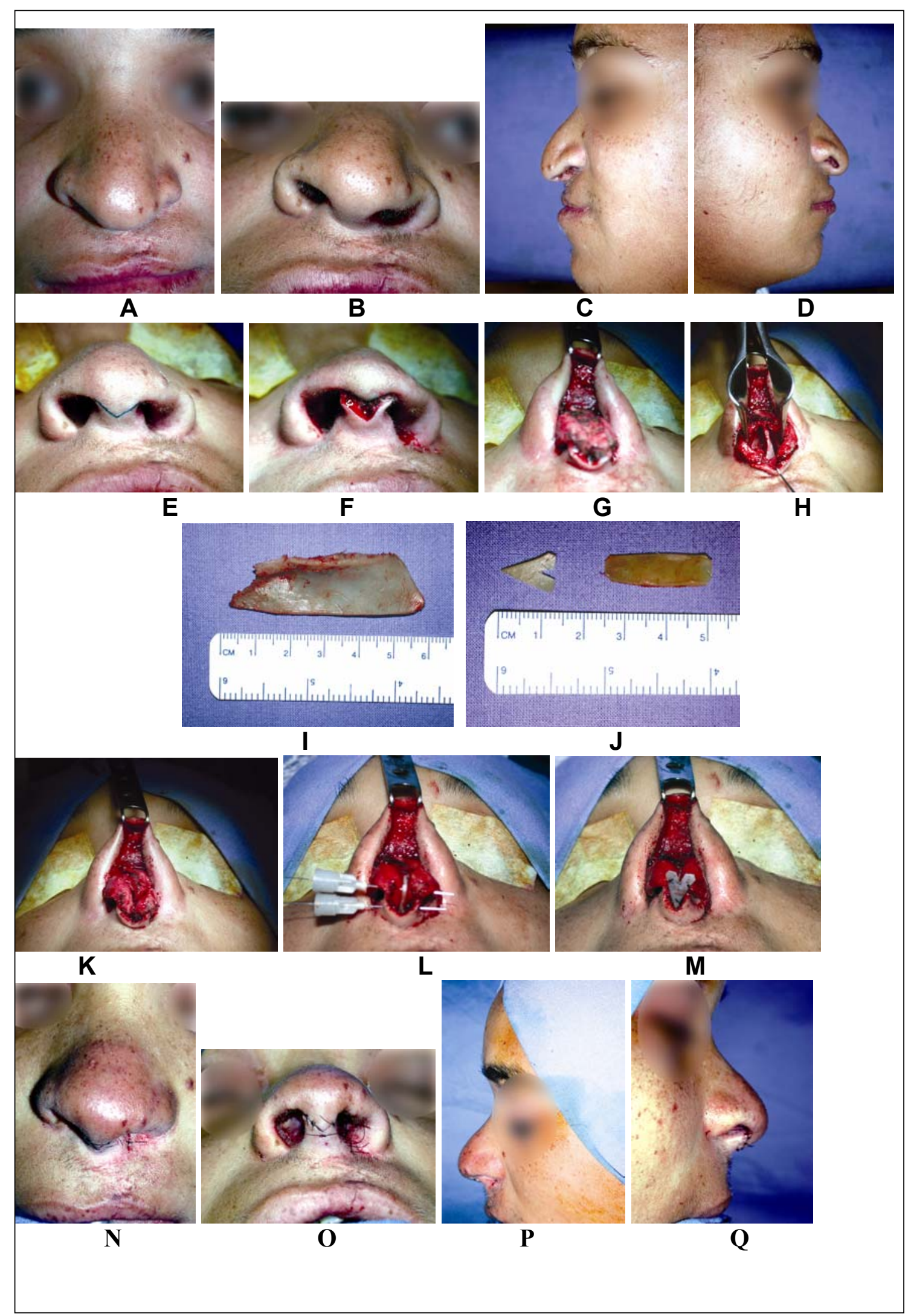

Figura 1 - Ilustração das etapas cirúrgicas da rinosseptoplastia. 
A incisão inicia-se na área previamente marcada e é prolongada de ambos os lados pela borda anterior da cartilagem lateral inferior até a base alar (figura 1F). Em seguida, é realizada uma dissecção cuidadosa do retalho cutâneo columelar com tesouras curvas, liberando todo o retalho do domus e das cartilagens laterais inferiores e superiores até os ossos nasais (figura 1G). Após hemostasia rigorosa, é realizada uma dissecção na base alar da cartilagem lateral inferior junto com a mucosa vestibular do lado da fissura, a qual é prolongada até a borda posterior da cartilagem lateral inferior seguindo em direção à válvula nasal; na seqüência, realiza-se a retirada do $1 / 3$ posterior das laterais inferiores para melhor simetria. Remove-se todo tecido dermogorduroso sobrejacente ao domus, separando os ligamentos inter-crurais mediais para visualização da cartilagem quadrangular. Uma incisão é feita na borda de ambos os lados da cartilagem quadrangular, seguida pela criação de túneis subpericondrais e subperiostais, de modo a expor melhor a cartilagem (figura 1H). Realiza-se, então, a separação da cartilagem quadrangular da prémaxila e vômer (na maior parte dos casos, a cartilagem quadrangular está deslocada da pré-maxila em direção ao lado não-fissurado).

O passo seguinte é uma condrotomia vertical para separar a lâmina perpendicular da cartilagem quadrangular, seguida por ressecção limitada da cartilagem para viabilizar o reposicionamento na linha média. Enxertos de cartilagem autógena são, então, obtidos da cartilagem quadrangular (figura $1 \mathrm{H})$, tomando-se o cuidado de não alterar o suporte septal do dorso e da ponta nasal. A cartilagem restante é reposicionada entre as lâminas de mucoperincôndrio para previnir uma possível perfuração septal. Confeccionase, com parte da cartilagem quadrangular, um enxerto de forma retangular de 
aproximadamente $2,5 \mathrm{~cm} \times 0,5 \mathrm{~cm}$ e outro em forma de um triângulo isóscele de aproximadamente $1 \mathrm{~cm}$ (figuras $1 \mathrm{l}$ e $1 \mathrm{~J}$ ). É feita, na seqüência, uma bolsa retrocolumelar por dissecção entre as cruras mediais, na qual é colocada o enxerto cartilaginoso retangular, que é transfixado com agulhas e suturado nas cruras mediais (figura $1 \mathrm{~K}$ ).

A cartilagem lateral inferior do lado fissurado (crura lateral) é, então, reposicionada mais medialmente e superiormente, e, fixada com sutura na lateral superior do mesmo lado para fornecer um domus simétrico mais proeminente (figura 1L). Em seguida, é realizada a fixação do enxerto triangular na região anterior à crura medial e ao domus com o vértice para baixo, para projeção da ponta nasal (figura $1 \mathrm{M}$ ). Finalmente, reposiciona-se o retalho cutâneo columelar sobre o esqueleto nasal, suturando-o em toda a extensão incisada. As figuras $1 \mathrm{~N}$ a $1 \mathrm{Q}$ mostram o resultado cirúrgico no pós-operatório imediato.

\subsubsection{Avaliação das dimensões internas nasais por rinometria acústica.}

\section{Equipamento}

A avaliação rinométrica foi realizada utilizando-se o sistema Eccovision Acoustic Rhinometer (HOOD Laboratories). O equipamento consiste de uma fonte sonora (alto-falante) montado na porção distal de um tubo de $24 \mathrm{~cm}$ que tem na sua porção proximal um microfone de registro. A configuração do sistema é mostrada na figura 2. 


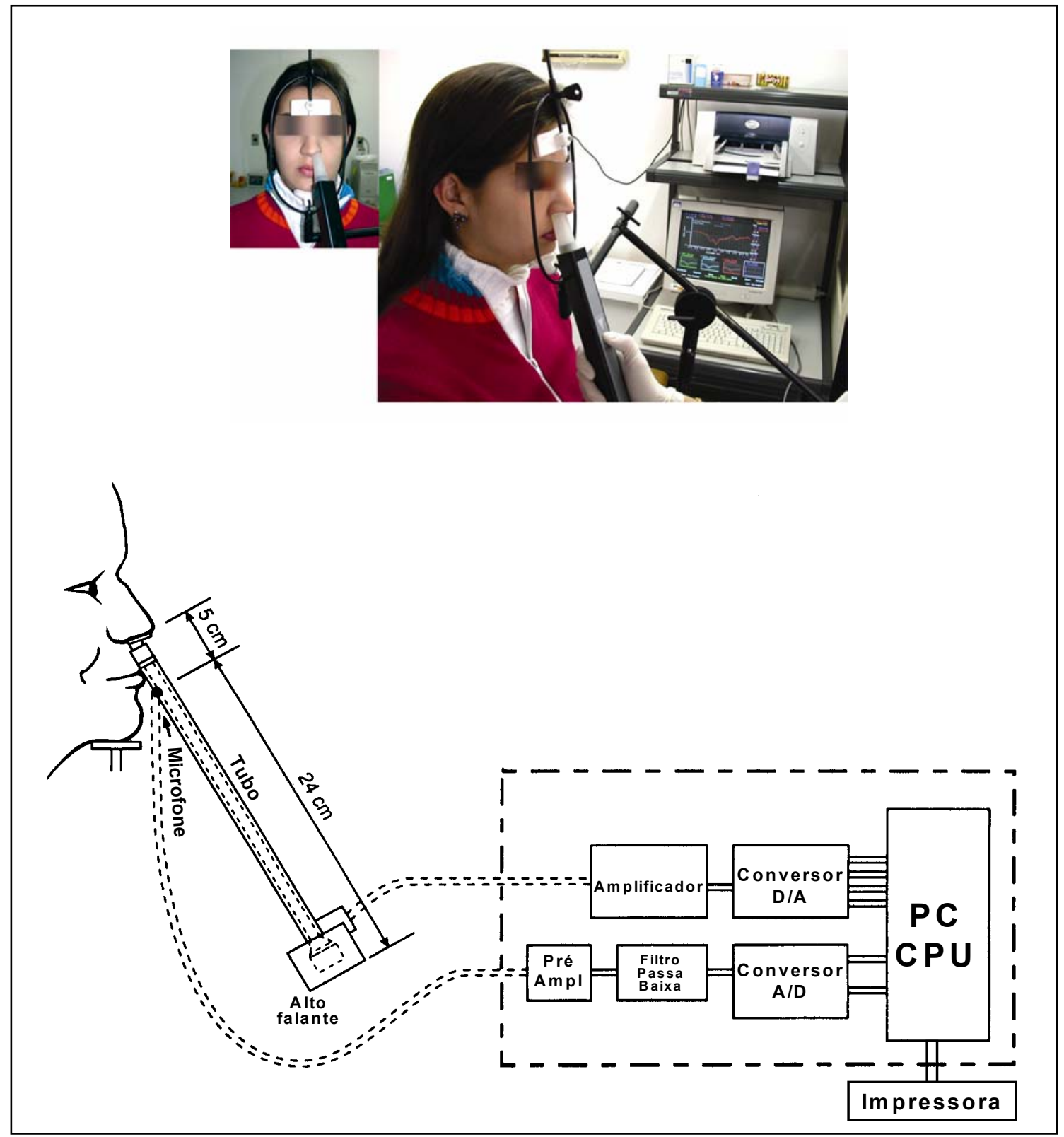

Figura 2 - Instrumentação para a medida das dimensões da cavidade nasal (Rinômetro Acústico Eccovision, Hood Laboratories, Prembroke, MA, USA). 


\section{Procedimento}

A técnica se baseia na medida de ondas sonoras refletidas (ecos) que emergem da cavidade nasal em resposta a uma onda sonora incidente.

O exame é realizado da seguinte forma: o tubo do rinômetro é encostado em uma das narinas; uma onda sonora gerada pelo alto-falante se propaga pelo tubo, passa pelo microfone e entra na cavidade nasal. Variações da área de secção transversa, ou seja, qualquer constricção que diminua a luz da cavidade, causa a reflexão da onda sonora de volta para o tubo do rinômetro. Os sinais de pressão sensibilizam o microfone, são amplificados e digitalizados. Um microcomputador com software específico é utilizado para a obtenção e análise dos dados.

A distância da constrição é calculada com base na velocidade da onda e o tempo de chegada do eco. A área de secção transversa nasal é calculada a partir da intensidade do eco. Os dados são convertidos em função áreadistância que é analisada em um gráfico (rinograma), representando-se a área $\left(\mathrm{cm}^{2}\right)$ em escala semilogarítmica no eixo y e a distância $(\mathrm{cm})$ no eixo $x$. Um rinograma típico é mostrado na figura 3 . O sistema faz medições em rápida sucessão (aproximadamente a cada 0,5 segundos) e permite medidas de toda a cavidade nasal, dos lados direito e esquerdo independentemente.

No presente estudo, três medições foram feitas em cada cavidade nasal. Os valores considerados para análise representam a média dessas três medidas, as quais foram feitas antes e 10 minutos após instilação de 5 gotas de um vasoconstrictor nasal (cloridrato de xilometazolina a 1\%) em cada narina, após higiene nasal, estando a cabeça do indivíduo reclinada para trás. 


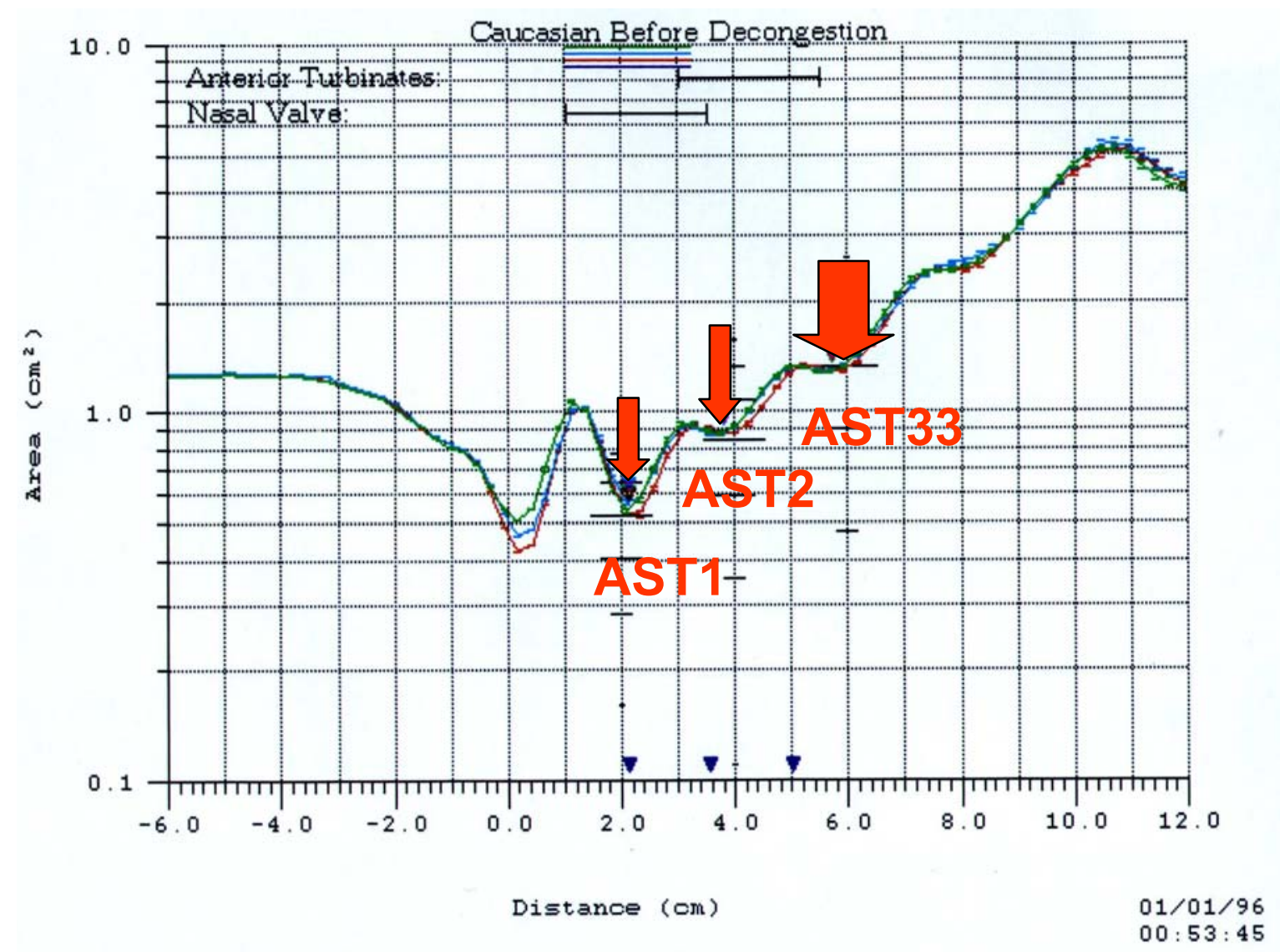

Figura 3 - Curva área-distância típica aferida por rinometria acústica, ilustrando as áreas de secção transversa (AST) medidas em pontos correspondentes à área da válvula nasal (AST1), à porção anterior da concha nasal inferior (AST2) e à porção posterior da concha nasal inferior (AST3). 
A descongestão nasal tem por objetivo eliminar o efeito funcional da mucosa nasal e aferir exclusivamente o efeito estrutural da cirurgia. Curvas com irregularidades foram descartadas. A calibração do equipamento foi realizada a cada início de período do dia.

Cuidados foram tomados para minimizar possíveis causas de erro nas medições (Gomes 2004), como aquelas resultantes de variações da temperatura ambiente e de ruídos externos. Essas variáveis não foram controladas; porém, as medidas foram realizadas sempre na mesma sala, em ambiente com temperatura relativamente estável e nível de ruído não superior a $60 \mathrm{~dB}$, após um período de adaptação do paciente às condições ambientais de cerca de 30 minutos.

Para uniformizar a posição do tubo do rinômetro num mesmo exame e em exames sucessivos, e, para evitar perda sonora, o tubo foi sempre posicionado em paralelo ao dorso do nariz e o vedamento entre o adaptador nasal e a narina foi assegurado pelo uso de gel neutro para eletrocardiograma. Assim também, tomou-se o devido cuidado para não provocar a deformação da narina e, por conseqüência, da válvula nasal. Óculos foram, também, retirados para não haver pressões externas sobre o nariz.

Cuidados adicionais foram tomados no sentido de manter a posição da cabeça estável durante o exame. Com este propósito, utilizou-se a armação desenvolvida para o estudo de Gomes (2004) para apoio do mento e da testa, de modo que todas as medidas fossem realizadas com a cabeça estabilizada e paralela ao solo, como visualizado no destaque da figura 2.

Para evitar que a respiração e a deglutição pudessem interferir nas medidas e na qualidade dos rinogramas, o exame foi sempre realizado durante 
a suspensão voluntária da respiração nasal ao final de uma expiração, sendo o paciente orientado a permanecer com a boca fechada, sem deglutir ou movimentar a língua no momento da aquisição dos dados.

\section{Variáveis aferidas}

A partir do gráfico área-distância (figura 3) foram calculadas as áreas de secção transversas nasais (AST) na $1^{\text {a }}$ deflexão da curva: correspondente à área da válvula nasal (AST1), na $2^{\mathrm{a}}$ deflexão (AST2): correspondente à porção anterior da concha nasal inferior e na $3^{a}$ deflexão (AST3): correspondente à porção posterior da concha nasal inferior, em $\mathrm{cm}^{2}$.

A partir da integração da curva área-distância, foram, também, determinados os volumes V1: segmento situado entre 10 e $32 \mathrm{~mm}$ em relação à narina, correspondente à região da válvula nasal, e, V2: segmento situado entre 33 e $64 \mathrm{~mm}$, correspondente à região das conchas nasais, em $\mathrm{cm}^{3}$ (figura 4).

As variações induzidas nas áreas seccionais e volumes pela rinosseptoplastia (aumento ou diminuição) foram consideradas significativas quando superiores aos coeficientes de variação observados em estudo anterior no Laboratório de Fisiologia do HRAC-USP, de 7\%, 9\% e 8\% para AST1, AST2 e AST3, respectivamente, e, 6\% e $8 \%$ para V1 e V2, respectivamente (Gomes et al 2003, Garbino et al 2003). 


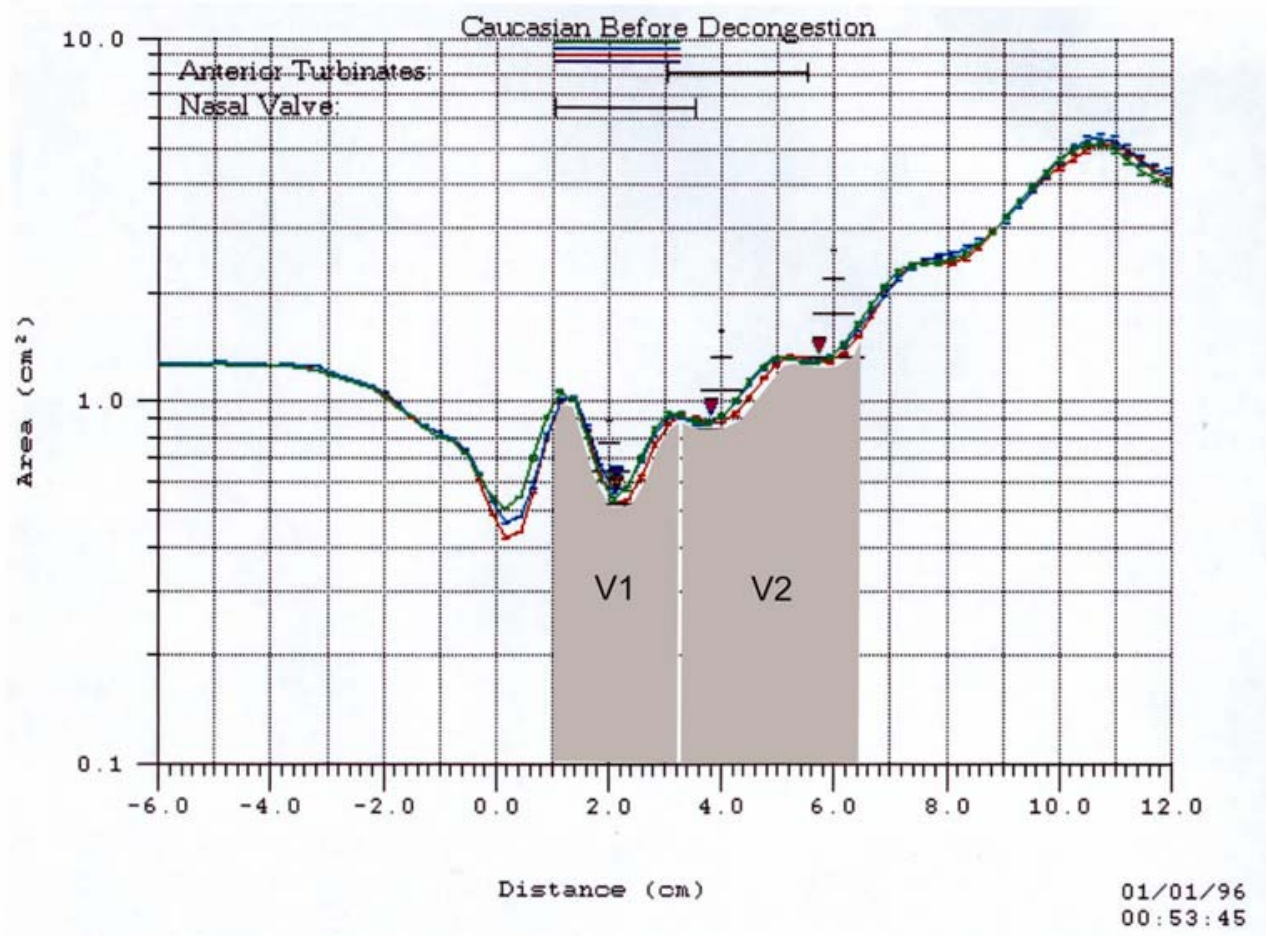

Figura 4 - Curva área-distância típica aferida por rinometria acústica, ilustrando os volumes medidos em segmentos correspondentes à região da válvula nasal (V1) e à região das conchas nasais (V2). 


\subsubsection{Avaliação da ressonância da fala por nasometria.}

\section{Equipamento}

A determinação da nasalância foi realizada com um nasômetro modelo 6200-3 IBM (Kay Elemetrics Corp., software versão 30-02-3.22), cuja configuração é apresentada na figura 5.

\section{Procedimento}

A nasometria permite avaliar a nasalância, que corresponde ao correlato físico da nasalidade. O método faz uso de um sistema composto por dois microfones posicionados um de cada lado de uma placa de separação sonora, apoiada sobre o lábio superior. O conjunto é mantido em posição por um capacete, adaptado conforme instruções do fabricante. O microfone superior capta os sinais acústicos do componente nasal da fala e o inferior, os sinais acústicos do componente oral, durante a leitura de textos padronizados apresentados na tela de um microcomputador conectado ao sistema. Os sinais são filtrados e digitalizados por módulos eletrônicos e, então, analisados por meio de um software específico.

A nasalância é calculada pela razão numérica entre a energia acústica nasal e a energia acústica total (soma da energia acústica nasal e oral), multiplicada por 100 , ou seja, \% nasalância $=$ nasal $/$ oral + nasal $\times 100.0$ valor da nasalância corresponde, portanto, à quantidade relativa de energia acústica nasal na fala, sendo calculada, pelo software, na faixa de freqüências de 300 a 


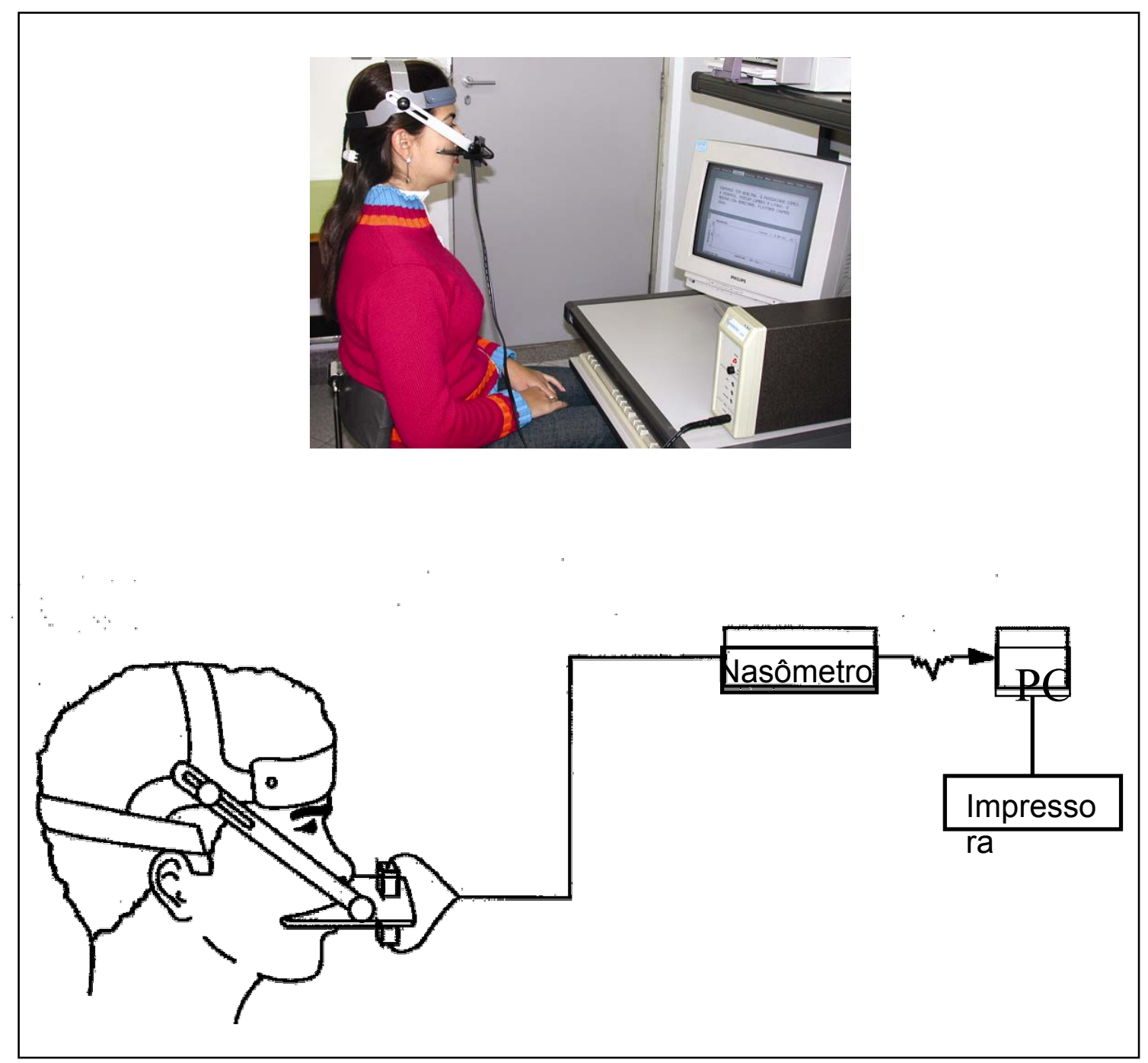

Figura 5 - Instrumentação para a medida da nasalância (Nasômetro 6200-3 IBM, Kay Elemetrics Corp., Lincoln Park, NJ. USA). 
$600 \mathrm{~Hz}$. Teoricamente, pode variar entre $0 \%$ (ausência de som pelo nariz) e $100 \%$ (todo som emergente pelo nariz). A calibração do sistema é realizada antes de cada exame, utilizando fonte geradora de som do próprio equipamento, segundo instruções fornecidas pelo fabricante.

O exame nasométrico foi realizado durante a leitura de dois conjuntos de frases em português (Trindade et al 1997): um conjunto formado por 5 frases contendo sons predominantemente nasais (texto nasal), utilizado para identificar hiponasalidade, e outro formado por 5 frases destituídas de sons nasais (texto oral), para identificação da hipernasalidade. Foram considerados para análise, os valores da nasalância média da primeira emissão tecnicamente aceitável de cada texto, ou seja, produzida sem erros até o limite de fluxo aéreo nasal e oral definido pelo software (Kay Elemetrics Corp. Manual 1994).

Variações individuais entre as medidas pré e pós-operatórias, obtidas no texto nasal e oral, foram consideradas significativas do ponto de vista clínico, quando superiores a 8 pontos percentuais. Este critério foi definido em estudo prévio conduzido no Laboratório de Fisiologia do HRAC-USP (comunicação pessoal), no qual se constatou que $95 \%$ das medidas seriadas de nasalância não variaram em mais de 8 pontos percentuais em indivíduos normais testados e retestados no mesmo dia e em intervalo de 1, 6 e 12 meses. 


\subsection{Consentimento livre e esclarecido.}

O projeto recebeu aprovação do Comitê de Ética em Pesquisa do HRAC-USP ( $n^{\circ} 322 / 02$ - UEP) e todos os participantes foram avaliados após consentimento livre e esclarecido, conforme mostrado no anexo1.

\subsection{Análise estatística.}

A significância das diferenças entre amostras relacionadas (valores PRE vs POS1 vs POS2 e LADO FISSURADO vs. LADO NÃO-FISSURADO) foi avaliada pelo teste "t" de Student para amostras pareadas. Quando os dados não atenderam à distribuição normal, aplicou-se o teste não paramétrico de Wilcoxon. Foram aceitos como significantes os valores de $p<0,05$. 
4. RESULTADOS 


\section{RESULTADOS.}

As tabelas 2 a 4 mostram os valores médios das áreas seccionais nasais, dos volumes nasais e da nasalância observados nos 21 indivíduos com fissura de lábio e palato unilateral reparada, avaliados antes da rinosseptoplastia (PRE), e, 6 a 9 meses (POS1) e 12 a 23 meses após o procedimento cirúrgico (POS2). Os resultados individuais são apresentados nos anexos 4A a 4I.

4.1 Análise das dimensões internas nasais por rinometria acústica.

\subsection{1 Áreas seccionais nasais.}

4.1.1.1 Áreas de secção transversa da cavidade nasal correspondente ao lado da fissura antes da descongestão nasal.

A tabela 2 mostra que, antes da cirurgia, antes da aplicação tópica de vasoconstrictor, os valores médios de AST1, AST2 e AST3 determinados do lado da fissura, em $\mathrm{cm}^{2}$, foram os seguintes: $0,35 \pm 0,17,0,71 \pm 0,39$ e 1,19 $\pm 0,85$, respectivamente. No primeiro pós-operatório, os valores aumentaram para, respectivamente, $0,46 \pm 0,20,0,89 \pm 0,38$ e $1,26 \pm 0,48$, sendo que a diferença foi estatisticamente significante apenas para AST1 $(p=0,007)$. No segundo pós- 
Tabela 2 - Valores médios ( \pm desvio padrão) e porcentagem de variação $(\% \Delta)$ das áreas de secção transversa de três diferentes segmentos da cavidade nasal (AST1, AST2 e AST3), aferidas por rinometria acústica em 21 indivíduos com fissura de lábio e palato unilateral reparada, previamente (PRE) à rinosseptoplastia e no primeiro (POS1) e segundo (POS2) pós-operatório, dos lados fissurado (LF) e não-fissurado (LNF), antes e após a aplicação tópica de vasoconstrictor nasal. As áreas seccionais são expressas em $\mathrm{cm}^{2}$.

\begin{tabular}{|c|c|c|c|c|c|c|c|c|c|c|}
\hline \multirow{2}{*}{$\begin{array}{l}\text { CAVIDADE } \\
\text { NASAL }\end{array}$} & & \multicolumn{3}{|c|}{ AST1 } & \multicolumn{3}{|c|}{ AST2 } & \multicolumn{3}{|c|}{ AST3 } \\
\hline & & PRE & POS1 & POS2 & PRE & $\begin{array}{c}\text { POS } \\
1\end{array}$ & POS2 & PRE & $\begin{array}{c}\text { POS } \\
1\end{array}$ & POS2 \\
\hline \multicolumn{11}{|c|}{$\begin{array}{c}\text { sem } \\
\text { vasoconstric } \\
\text { tor }\end{array}$} \\
\hline & $\mathrm{n}$ & 21 & 21 & 18 & 21 & 21 & 18 & 21 & 21 & 18 \\
\hline & $\bar{x}$ & 0,35 & $0,46^{*}$ & $0,48^{*}$ & 0,71 & 0,89 & 0,88 & 1,19 & 1,26 & 1,23 \\
\hline \multirow[t]{3}{*}{ LF } & $\pm \mathrm{DP}$ & 0,17 & 0,20 & 0,18 & 0,39 & 0,38 & 0,28 & 0,85 & 0,48 & 0,40 \\
\hline & $\% \Delta$ & & $+24 \%$ & $+27 \%$ & & $+20 \%$ & $+19 \%$ & & $+6 \%$ & $+3 \%$ \\
\hline & $\bar{x}$ & $0,49^{\#}$ & 0,43 & 0,48 & 0,94 & 1,04 & 0,91 & 1,28 & 1,35 & 1,34 \\
\hline \multirow[t]{2}{*}{ LNF } & $\pm \mathrm{DP}$ & 0,17 & 0,17 & 0,19 & 0,44 & 0,65 & 0,51 & 0,53 & 0,70 & 0,83 \\
\hline & $\% \Delta$ & & $-12 \%$ & $-2 \%$ & & $+10 \%$ & $-3 \%$ & & $+5 \%$ & $+4 \%$ \\
\hline \multicolumn{11}{|l|}{$\begin{array}{c}\text { com } \\
\text { vasoconstrictor }\end{array}$} \\
\hline & $n$ & 21 & 20 & 18 & 21 & 20 & 18 & 21 & 20 & 18 \\
\hline & $\bar{x}$ & 0,38 & $0,49^{*}$ & $0.55^{*}$ & 1,11 & 1,19 & $1,35^{*}$ & 1,59 & 1,82 & 1,89 \\
\hline \multirow[t]{3}{*}{ LF } & $\pm \mathrm{DP}$ & 0,19 & 0,24 & 0,24 & 0,43 & 0,46 & 0,33 & 0,96 & 0,81 & 0,42 \\
\hline & $\% \Delta$ & & $+22 \%$ & $+31 \%$ & & $+7 \%$ & $+18 \%$ & & $+13 \%$ & $+16 \%$ \\
\hline & $\bar{x}$ & $0,61^{\#}$ & 0,55 & 0,60 & $1,45^{\#}$ & 1,52 & 1,60 & 1,91 & 1,90 & 2,13 \\
\hline \multirow[t]{2}{*}{ LNF } & $\pm \mathrm{DP}$ & 0,14 & 0,16 & 0,18 & 0,45 & 0,50 & 0,43 & 0,57 & 0,59 & 0,76 \\
\hline & $\% \Delta$ & & $-11 \%$ & $-2 \%$ & & $+5 \%$ & $+9 \%$ & & $-1 \%$ & $+10 \%$ \\
\hline
\end{tabular}


Resultados

operatório, os valores permaneceram aumentados, relativamente ao pré-

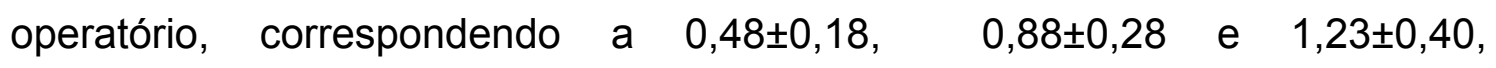
respectivamente; também neste caso, as diferenças foram significantes apenas para AST1 $(p=0,015)$. As diferenças entre o primeiro e o segundo pósoperatório não foram estatisticamente significantes.

As maiores variações percentuais entre os valores médios pré e pósoperatórios foram observadas para AST1 (+24\% em POS1 e +27\% em POS2) e AST2 (+20\% em POS1 e $+19 \%$ em POS2). As variações observadas para AST3 foram comparativamente menores ( $+6 \%$ em POS1 e $+3 \%$ em POS 2$)$.

A figura 6 mostra a porcentagem de pacientes que apresentaram aumento ou redução, ou, ainda, que não sofreram alteração das três áreas seccionais analisadas, relativamente ao pré-operatório, do lado da fissura antes da aplicação de vasoconstrictor nasal. Observou-se que, nesta situação, o número de pacientes que apresentaram aumento de AST após a cirurgia foi nitidamente maior.

\subsubsection{2 Áreas de secção transversa da cavidade nasal correspondente ao lado não-fissurado antes da descongestão nasal.}

A tabela 2 mostra, também, que, antes da cirurgia, sem o uso de vasoconstrictor, os valores médios de AST1, AST2 e AST3 determinados do lado não-fissurado, em $\mathrm{cm}^{2}$, foram os seguintes: $0,49 \pm 0,17,0,94 \pm 0,44$ e $1,28 \pm 0,53$, respectivamente. No primeiro e segundo pós-operatório, os valores 


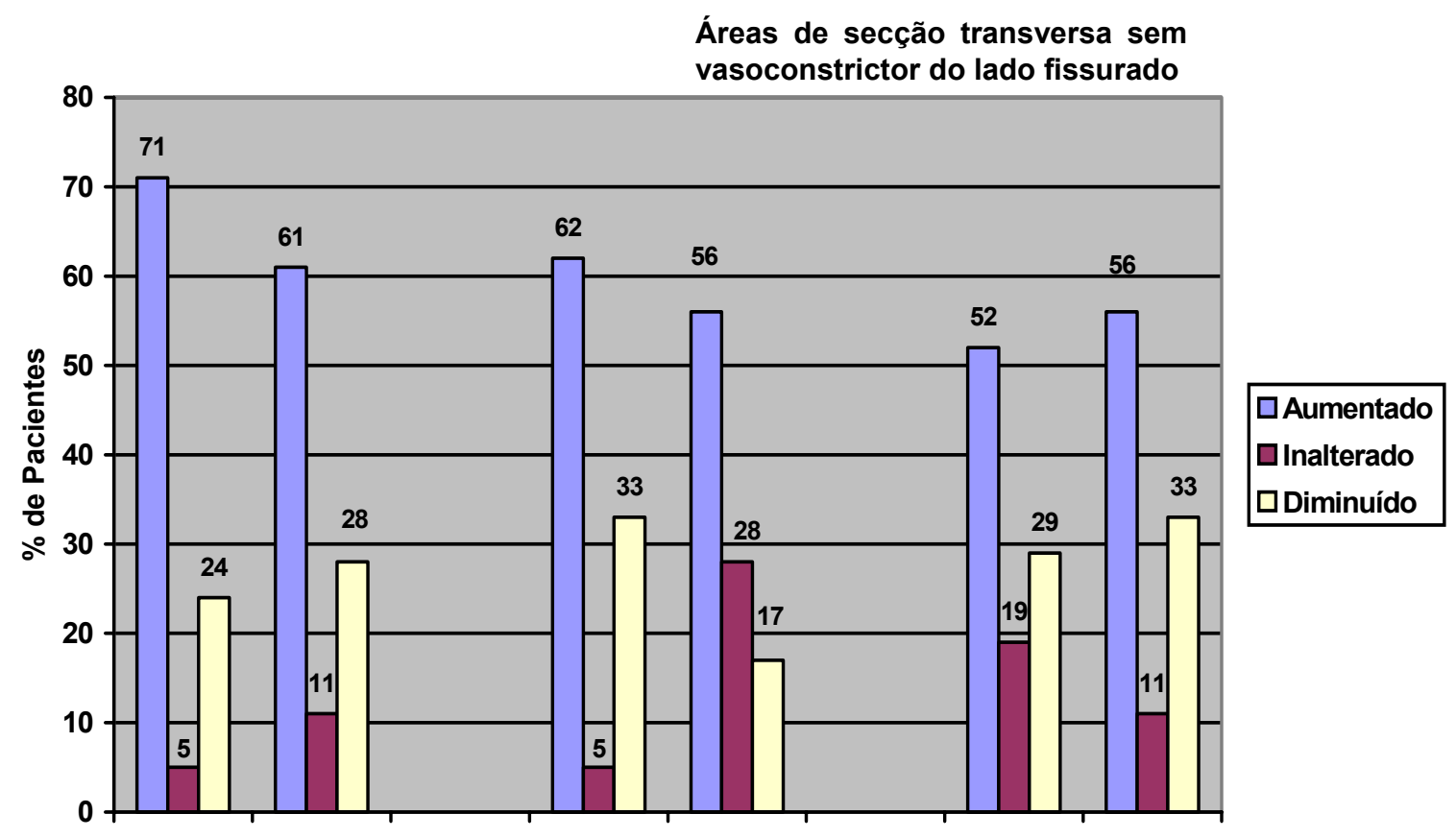

Figura 6 - Variações percentuais induzidas pela rinosseptoplastia nas áreas de secção transversa de três diferentes segmentos da cavidade nasal (AST1, AST2 e AST3) aferidas por rinometria acústica, antes da aplicação tópica de vasoconstrictor nasal, em indivíduos com fissura de lábio e palato unilateral reparada, observadas no primeiro (POS1) e segundo (POS2) pós-operatório, no lado fissurado. 
Resultados

observados não diferiram estatisticamente dos valores do pré-operatório (respectivamente, $0,43 \pm 0,17,1,04 \pm 0,65,1,35 \pm 0,70$, e, $0,48 \pm 0,19,0,91 \pm 0,51 \mathrm{e}$ $1,34 \pm 0,83)$. As diferenças entre o primeiro e o segundo pós-operatório também não foram estatisticamente significantes.

As variações percentuais entre os valores médios pré e pós-operatórios foram comparativamente menores que as observadas no lado fissurado para AST1 (-12\% em POS1 e -2\% em POS2) e AST2 (+10\% em POS1 e -3\% em POS2). As variações observadas para AST3 foram equivalentes $(+5 \% \mathrm{em}$ POS1 e $+4 \%$ em POS2).

A figura 7 mostra a porcentagem de pacientes que apresentaram aumento ou redução, ou, ainda, que não sofreram alteração das três áreas seccionais analisadas, relativamente ao pré-operatório, do lado não-fissurado, antes do uso de vasoconstrictor nasal. Observou-se, nesta situação, uma tendência do número de pacientes que apresentaram diminuição da AST após a cirurgia ser ligeiramente maior que aqueles que apresentaram aumento (exceto para AST1 em POS2 e AST2 em POS1, em que as proporções de aumento e redução foram iguais).

Na tabela 2 observou-se, ainda, que, antes do vasoconstrictor o valor médio de AST1 do lado fissurado no pré-operatório foi significantemente menor que o do lado não-fissurado $(p=0,020)$. Após a cirurgia, os valores dos dois lados não mais diferiram entre si. As diferenças para AST2 e AST3 não foram estatisticamente significantes, tanto no pré como no pós-operatório. 


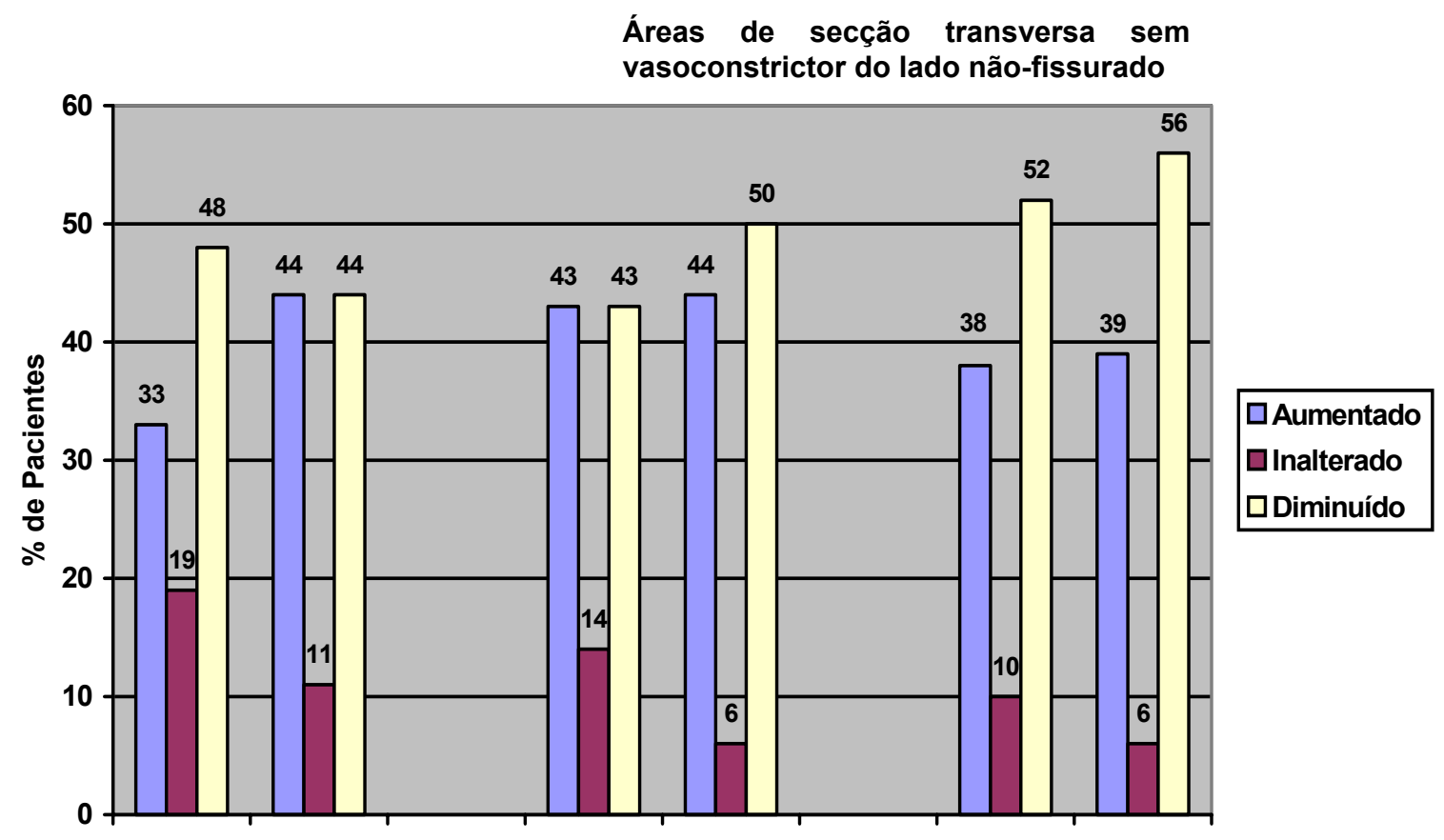

Figura 7 - Variações percentuais induzidas pela rinosseptoplastia nas áreas de secção transversa de três diferentes segmentos da cavidade nasal (AST1, AST2 e AST3) aferidas por rinometria acústica, antes da aplicação tópica de vasoconstrictor nasal, em indivíduos com fissura de lábio e palato unilateral reparada, observadas no primeiro (POS1) e segundo (POS2) pós-operatório, no lado não-fissurado. 


\subsubsection{3 Áreas de secção transversa da cavidade nasal correspondente ao lado da fissura após descongestão nasal.}

A tabela 2 mostra que, antes da cirurgia, com o uso de vasoconstrictor, os valores médios de AST1, AST2 e AST3 determinados do lado da fissura, em $\mathrm{cm}^{2}$, foram iguais a $0,38 \pm 0,19,1,11 \pm 0,43$ e $1,59 \pm 0,96$, respectivamente. No primeiro pós-operatório, os valores aumentaram para, respectivamente, $0,49 \pm 0,24,1,19 \pm 0,46$ e $1,82 \pm 0,81$, sendo que a diferença foi estatisticamente significante apenas para AST1 $(p=0,021)$. No segundo pós-operatório, os valores permaneceram aumentados, relativamente ao pré-operatório, correspondendo a $0,55 \pm 0,24,1,35 \pm 0,33$ e 1,89 $\pm 0,42$, respectivamente; neste caso, as diferenças foram significantes para AST1 e AST2 $(p=0,002)$. As diferenças entre o primeiro e o segundo pós-operatório não foram estatisticamente significantes.

As maiores variações percentuais entre os valores médios pré e pósoperatórios foram observadas para AST1 (+22\% em POS1 e +31\% em POS2) e AST2 em POS2 (+18\%) e AST3 em POS2 (+16\%). As variações observadas para AST2 em POS1 (+7\%) e para AST3 em POS1 (+13\%), foram comparativamente menores.

A figura 8 mostra a porcentagem de pacientes que apresentaram aumento ou redução, ou, ainda, que não sofreram alteração das três áreas seccionais analisadas, relativamente ao pré-operatório, do lado da fissura após o uso de vasoconstrictor nasal. Observou-se que, nesta situação, o número de pacientes que apresentaram aumento de AST após a cirurgia foi nitidamente maior. 


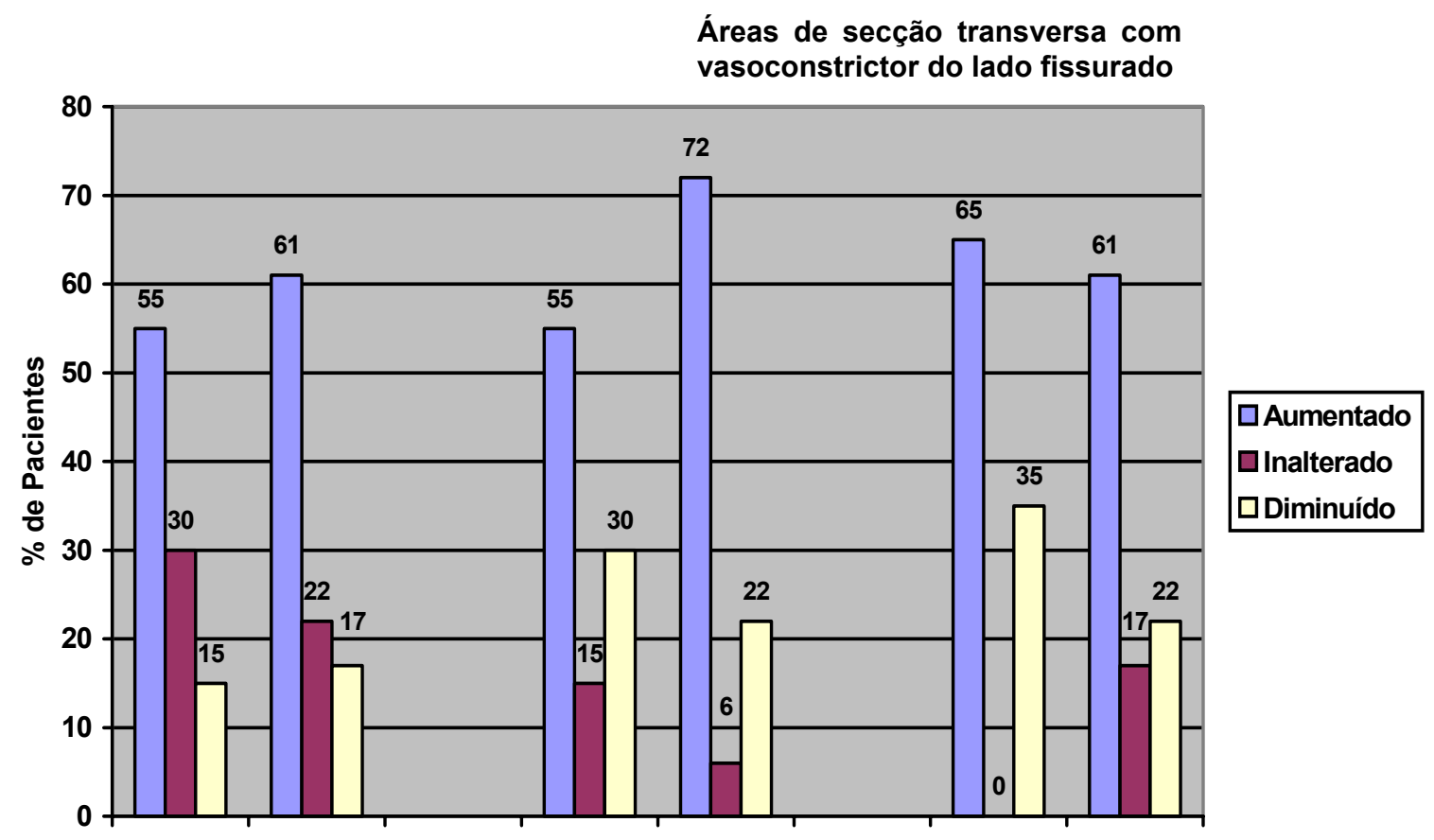

Figura 8 - Variações percentuais induzidas pela rinosseptoplastia nas áreas de secção transversa de três diferentes segmentos da cavidade nasal (AST1, AST2 e AST3) aferidas por rinometria acústica, após a aplicação tópica de vasoconstrictor nasal, em indivíduos com fissura de lábio e palato unilateral reparada, observadas no primeiro (POS1) e segundo (POS2) pós-operatório, no lado fissurado. 


\subsubsection{4 Áreas de secção transversa da cavidade nasal correspondente ao lado não-fissurado após descongestão nasal.}

A tabela 2 mostra, também, que, antes da cirurgia, com o uso de vasoconstrictor, os valores médios de AST1, AST2 e AST3 determinados do lado não-fissurado, em $\mathrm{cm}^{2}$, foram iguais a $0,61 \pm 0,14,1,45 \pm 0,45$ e 1,91 $\pm 0,57$, respectivamente. No primeiro e segundo pós-operatório, os valores observados não diferiram estatisticamente dos valores do pré-operatório (respectivamente, $0,55 \pm 0,16,1,52 \pm 0,50,1,90 \pm 0,59$, e, $0,60 \pm 0,18,1,60 \pm 0,43$ e $2,13 \pm 0,76)$. As diferenças entre o primeiro e o segundo pós-operatório também não foram estatisticamente significantes.

As variações percentuais entre os valores médios pré e pós-operatórios foram comparativamente menores que as observadas no lado fissurado para AST1 (-11\% em POS1 e $-2 \%$ em POS2), AST2 (+5\% em POS1 e $+9 \%$ em POS2) e AST3 (-1\% em POS1 e +10\% em POS2).

A figura 9 mostra a porcentagem de pacientes que apresentaram aumento ou redução, ou, ainda, que não sofreram alteração das três áreas seccionais analisadas, relativamente ao pré-operatório, do lado não-fissurado após o uso de vasoconstrictor nasal. Observou-se, nesta situação, uma tendência do número de pacientes que apresentaram diminuição da AST após a cirurgia ser maior que aqueles que apresentaram aumento (exceto para AST2 em POS1, em que as proporções de aumento e redução foram iguais, e em POS2, onde observou-se maior número de pacientes com aumento). 


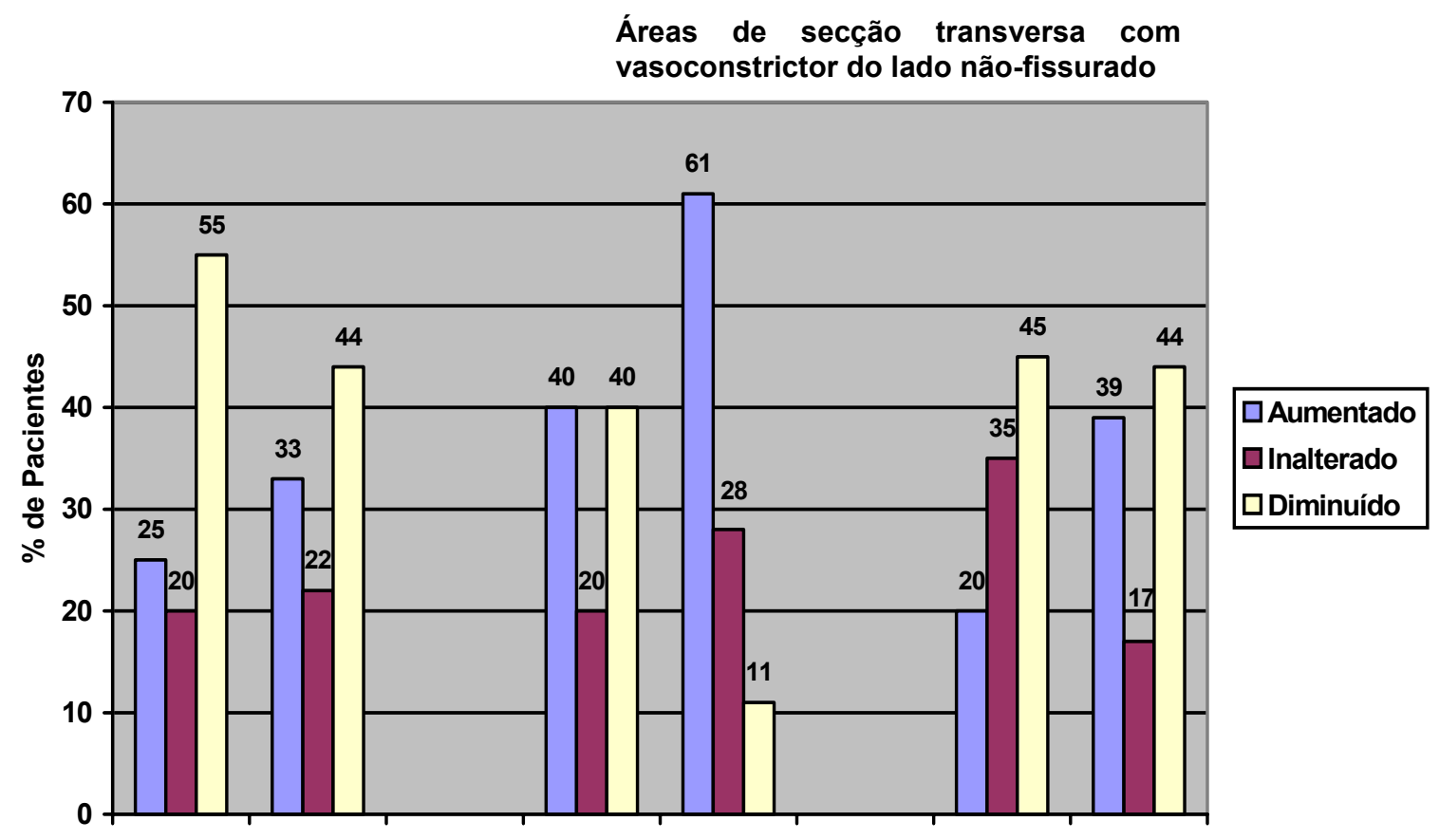

Figura 9 - Variações percentuais induzidas pela rinosseptoplastia nas áreas de secção transversa de três diferentes segmentos da cavidade nasal (AST1, AST2 e AST3) aferidas por rinometria acústica, após a aplicação tópica de vasoconstrictor nasal, em indivíduos com fissura de lábio e palato unilateral reparada, observadas no primeiro (POS1) e segundo (POS2) pós-operatório, no lado não-fissurado. 
Resultados

Observou-se, ainda, que, após a vasoconstricção nasal, os valores médios de AST1 e AST2 do lado fissurado, obtidos antes da cirurgia, foram significantemente menores que os do lado não-fissurado $(p=0,001)$. Após a cirurgia, os valores dos dois lados não mais diferiram entre si. As diferenças para AST3 não foram estatisticamente significantes, tanto no pré como no pósoperatório.

\subsubsection{Volumes Nasais.}

\subsubsection{Volumes da cavidade nasal correspondente ao lado da fissura antes da descongestão nasal.}

A tabela 3 mostra que, antes da cirurgia, sem o uso de vasoconstrictor nasal, os valores médios de V1 e V2 determinados do lado da fissura, em $\mathrm{cm}^{3}$, foram os seguintes: $1,11 \pm 0,36$ e $2,95 \pm 1,60$, respectivamente. No primeiro pósoperatório, os valores aumentaram para, respectivamente, 1,44 10,48 e $3,67 \pm 1,58$, sendo que a diferença foi estatisticamente significante apenas para V1 $(p=0,003)$. No segundo pós-operatório, os valores permaneceram aumentados, relativamente ao pré-operatório, correspondendo a 1,46 $\pm 0,38$ e $3,74 \pm 1,26$, respectivamente; também neste caso, as diferenças foram significantes apenas para $\mathrm{V} 1(p=0,003)$. As diferenças entre o primeiro e o segundo pós-operatório não foram estatisticamente significantes.

As variações percentuais entre os valores médios pré e pós-operatórios foram similares para V1 (+23\% em POS1 e $+24 \%$ em POS 2$)$ e V2 (+20\% em POS1 e $+21 \%$ em POS2). 
Tabela 3 - Valores médios ( \pm desvio padrão) e porcentagem de variação ( $\% \Delta)$ dos volumes de dois diferentes segmentos da cavidade nasal (V1 e V2), aferidos por rinometria acústica em 21 indivíduos com fissura de lábio e palato unilateral reparada, previamente (PRE) à rinosseptoplastia e no primeiro (POS1) e segundo (POS2) pós-operatório, dos lados fissurado (LF) e nãofissurado (LNF), antes e após a aplicação tópica de vasoconstrictor nasal. Os volumes são expressos em $\mathrm{cm}^{3}$.

\begin{tabular}{|c|c|c|c|c|c|c|c|}
\hline \multirow{2}{*}{$\begin{array}{l}\text { CAVIDADE } \\
\text { NASAL }\end{array}$} & & \multicolumn{3}{|c|}{ V1 } & \multicolumn{3}{|c|}{ V2 } \\
\hline & & PRE & POS1I & POS2 & PRE & POS1 & POS2 \\
\hline \multicolumn{8}{|l|}{$\begin{array}{c}\text { sem } \\
\text { vasoconstrictor }\end{array}$} \\
\hline & $n$ & 21 & 21 & 18 & 21 & 21 & 18 \\
\hline & $\bar{x}$ & 1,11 & $1,44^{*}$ & $1.46^{*}$ & 2,95 & 3,67 & 3.74 \\
\hline \multirow[t]{3}{*}{ LF } & $\pm \mathrm{DP}$ & 0,36 & 0,48 & 0.38 & 1,60 & 1,58 & 1.26 \\
\hline & $\% \Delta$ & & $+23 \%$ & $+24 \%$ & & $+20 \%$ & $+21 \%$ \\
\hline & $\bar{x}$ & $1,57^{\#}$ & 1,43 & 1,46 & 3,80 & 4,00 & 3,53 \\
\hline \multirow[t]{2}{*}{ LNF } & $\pm \mathrm{DP}$ & 0,46 & 0,46 & 0,46 & 1,63 & 2,08 & 1,81 \\
\hline & $\% \Delta$ & & $-9 \%$ & $-7 \%$ & & $+5 \%$ & $-7 \%$ \\
\hline \multicolumn{8}{|l|}{$\begin{array}{c}\text { com } \\
\text { vasoconstrictor }\end{array}$} \\
\hline & $n$ & 21 & 20 & 18 & 21 & 20 & 18 \\
\hline & $\bar{x}$ & 1,24 & $1,59^{*}$ & $1,76^{*}$ & 4,28 & 5,01 & $5,67^{*}$ \\
\hline \multirow[t]{3}{*}{ LF } & $\pm \mathrm{DP}$ & 0,46 & 0,56 & 0,53 & 1,67 & 1,63 & 1,43 \\
\hline & $\% \Delta$ & & $+22 \%$ & $+30 \%$ & & $+15 \%$ & $+25 \%$ \\
\hline & $\bar{x}$ & $1,87^{\#}$ & 1,84 & 1,93 & $5,71^{\#}$ & 5,89 & 6,10 \\
\hline \multirow[t]{2}{*}{ LNF } & $\pm \mathrm{DP}$ & 0,31 & 0,37 & 0,39 & 1,61 & 1,47 & 1,37 \\
\hline & $\% \Delta$ & & $-2 \%$ & $+3 \%$ & & $+3 \%$ & $+6 \%$ \\
\hline
\end{tabular}

${ }^{*} p<0,05$ diferença estatisticamente significante (PRE versus POS)

$\# p<0,05$ diferença estatisticamente significante (LF versus LNF) 
Resultados

A figura 10 mostra a porcentagem de pacientes que apresentaram aumento ou redução, ou, ainda, que não sofreram alteração dos dois volumes analisados, relativamente ao pré-operatório, do lado da fissura antes da aplicação do vasoconstrictor nasal. Observou-se que, nesta situação, o número de pacientes que apresentaram aumento de $\mathrm{V}$ após a cirurgia foi nitidamente maior.

\subsubsection{Volumes da cavidade nasal correspondente ao lado não-fissurado antes da descongestão nasal.}

A tabela 3 mostra, também, que, antes da cirurgia, sem o uso de vasoconstrictor, os valores médios de V1 e V2 determinados do lado nãofissurado, em $\mathrm{cm}^{3}$, foram iguais a $1,57 \pm 0,46$ e $3,80 \pm 1,63$, respectivamente. No primeiro e segundo pós-operatório, os valores observados não diferiram estatisticamente dos valores do pré-operatório (respectivamente, 1,43 $\pm 0,46$, $4,00 \pm 2,08$, e, $1,46 \pm 0,46$ e $3,53 \pm 1,81$ ), As diferenças entre o primeiro e o segundo pós-operatório também não foram estatisticamente significantes.

As variações percentuais entre os valores médios pré e pós-operatórios foram comparativamente menores que as observadas no lado fissurado para V1 (-9\% em POS1 e -7\% em POS2) e V2 (+5\% em POS1 e -7\% em POS2).

A figura 11 mostra a porcentagem de pacientes que apresentaram aumento ou redução, ou, ainda, que não sofreram alteração dos dois volumes analisados, relativamente ao pré-operatório, do lado não-fissurado antes do uso de vasoconstrictor nasal. Observou-se, nesta situação, uma tendência do 


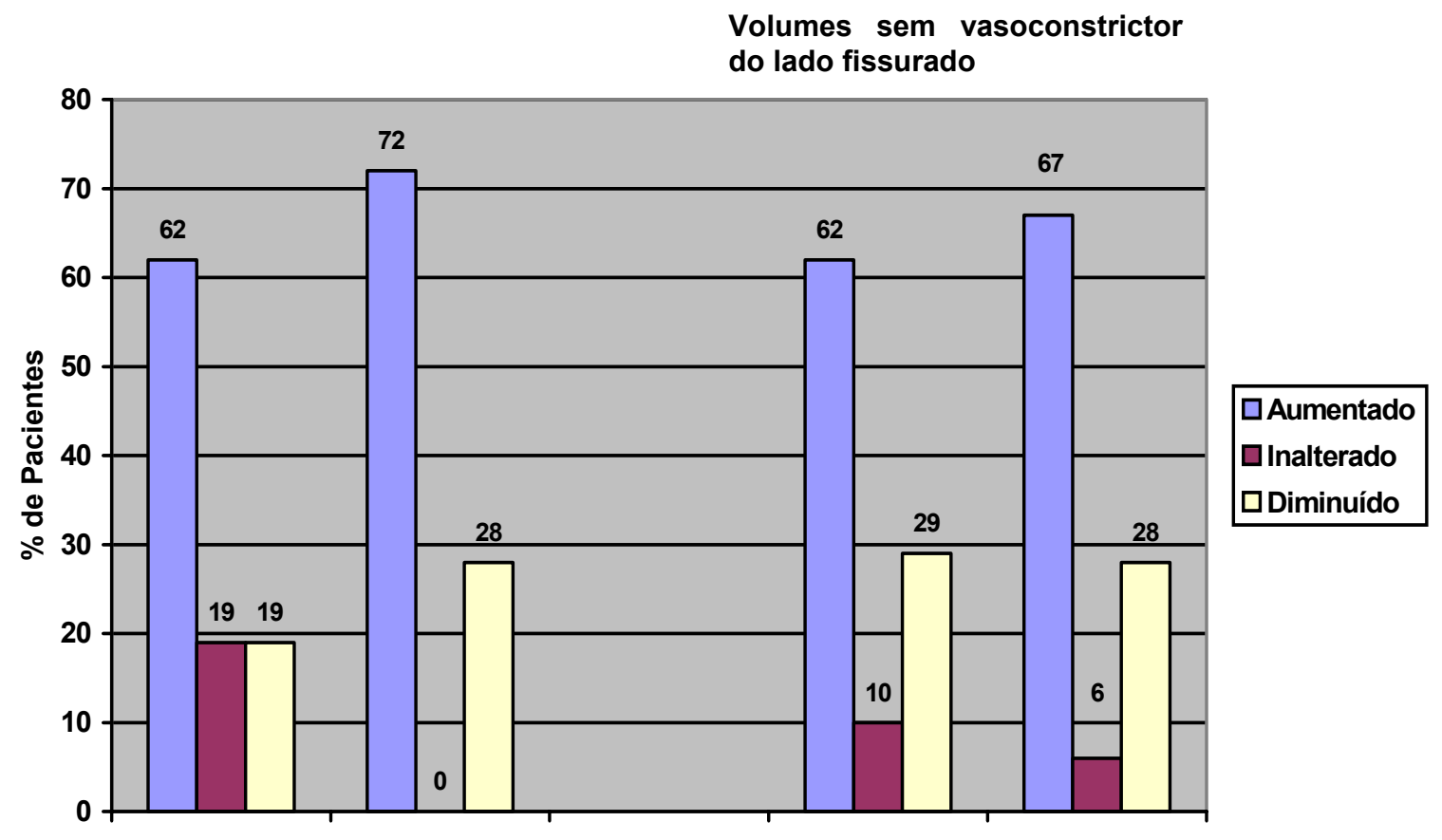

Figura 10 - Variações percentuais induzidas pela rinosseptoplastia nos volumes de dois diferentes segmentos da cavidade nasal (V1 e V2) aferidos por rinometria acústica, antes da aplicação tópica de vasoconstrictor nasal, em indivíduos com fissura de lábio e palato unilateral reparada, observadas no primeiro (POS1) e segundo (POS2) pós-operatório, no lado fissurado. 


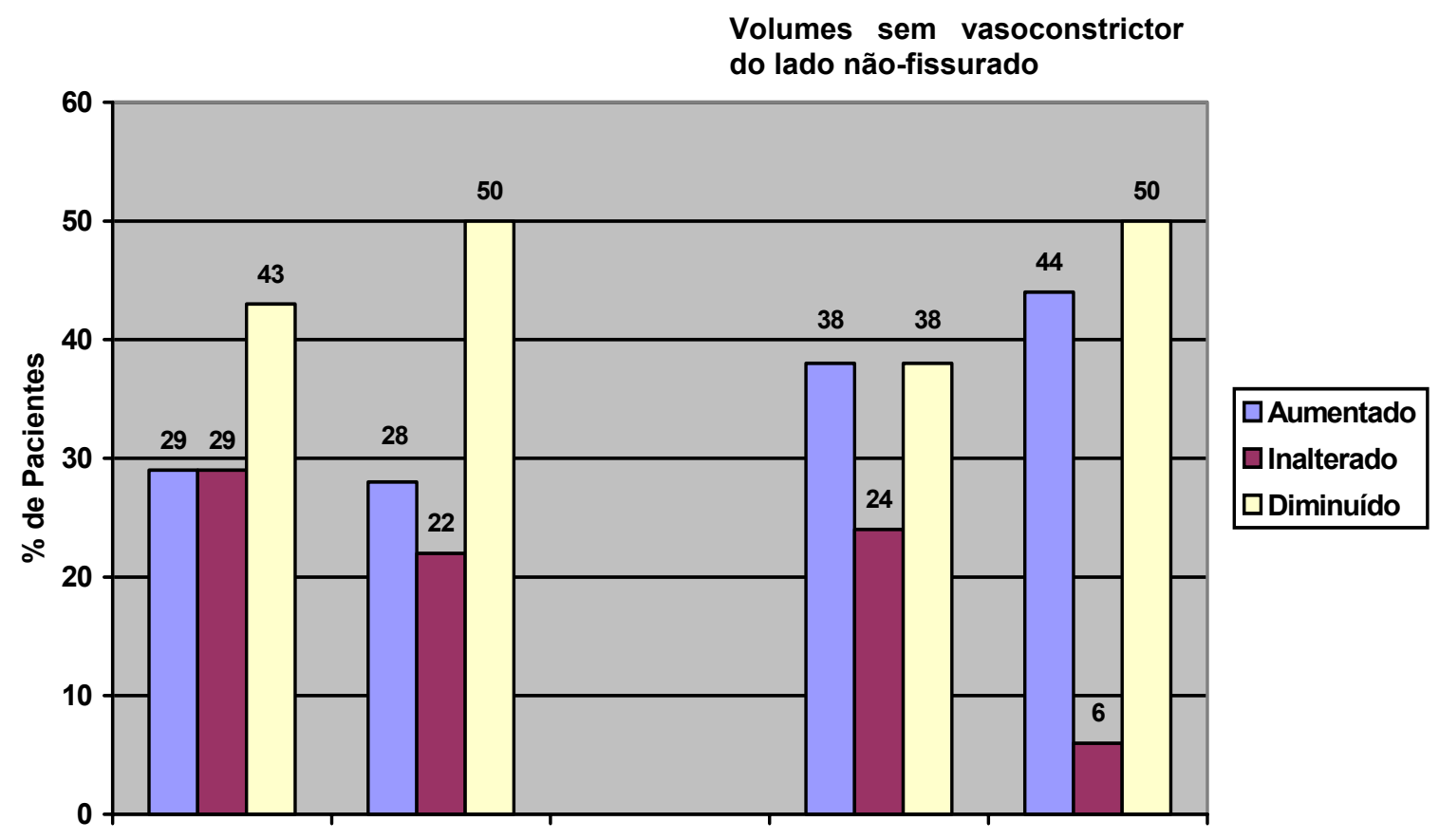

Figura 11 - Variações percentuais induzidas pela rinosseptoplastia nos volumes de dois diferentes segmentos da cavidade nasal (V1 e V2) aferidos por rinometria acústica, antes da aplicação tópica de vasoconstrictor nasal, em indivíduos com fissura de lábio e palato unilateral reparada, observadas no primeiro (POS1) e segundo (POS2) pós-operatório, no lado não-fissurado. 
número de pacientes que apresentaram diminuição do $\mathrm{V}$ após a cirurgia ser maior que aqueles que apresentaram aumento (exceto para V2 em POS1, em que as proporções de aumento e redução foram iguais).

Na tabela 3, observa-se, ainda, que, antes do vasoconstrictor nasal, o valor médio de V1 do lado fissurado obtido antes da cirurgia foi significantemente menor que $o$ do lado não-fissurado $(p=0,003)$. Após a cirurgia, os valores de V1 dos dois lados não mais diferiram entre si. As diferenças para V2 não foram estatisticamente significantes, tanto no pré como no pós-operatório.

\subsubsection{Volumes da cavidade nasal correspondente ao lado da fissura após descongestão nasal.}

A tabela 3 mostra que, antes da cirurgia, com o uso de vasoconstrictor, os valores médios de V1 e V2 determinados do lado da fissura, em $\mathrm{cm}^{3}$, foram iguais a $1,24 \pm 0,46$ e 4,28 $\pm 1,67$, respectivamente. No primeiro pós-operatório, os valores aumentaram para, respectivamente, $1,59 \pm 0,56$ e $5,01 \pm 1,63$, sendo que a diferença foi estatisticamente significante apenas para V1 $(p=0,006)$. No segundo pós-operatório, os valores permaneceram aumentados, relativamente

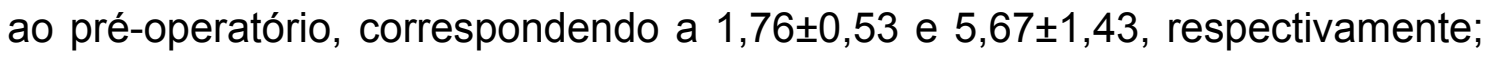
neste caso, as diferenças foram significantes para V1 e V2 $(p=0,001)$. As diferenças entre o primeiro e o segundo pós-operatório não foram estatisticamente significantes.

As variações percentuais entre os valores médios pré e pós-operatórios foram 
Resultados

similares para V1 (+22\% em POS1 e $+30 \%$ em POS 2$)$ e V2 (+15\% em POS1 e $+25 \%$ em POS2).

A figura 12 mostra a porcentagem de pacientes que apresentaram aumento ou redução, ou, ainda, que não sofreram alteração dos dois volumes analisados, relativamente ao pré-operatório, do lado da fissura após da descongestão nasal. Observou-se que, nesta situação, o número de pacientes que apresentaram aumento de $\mathrm{V}$ após a cirurgia foi nitidamente maior.

\subsubsection{Volumes da cavidade nasal correspondente ao lado não-fissurado após descongestão nasal.}

A tabela 3 mostra, também, que, antes da cirurgia, com o uso de vasoconstrictor nasal, os valores médios de V1 e V2 determinados do lado nãofissurado, em $\mathrm{cm}^{3}$, foram iguais a $1,87 \pm 0,31$ e $5,71 \pm 1,61$, respectivamente. No primeiro e segundo pós-operatório, os valores observados não diferiram

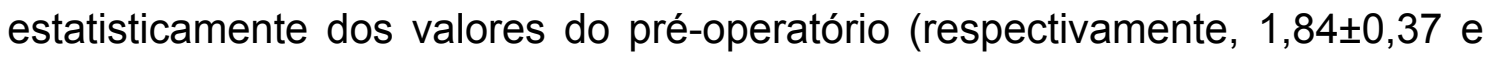
$5,89 \pm 1,47$, e, $1,93 \pm 0,39$ e $6,10 \pm 1,37)$. As diferenças entre o primeiro e o segundo pós-operatório também não foram estatisticamente significantes.

As variações percentuais entre os valores médios pré e pós-operatórios foram comparativamente menores que as observadas no lado fissurado para V1 (-2\% em POS1 e +3\% em POS 2$)$ e V2 (+3\% em POS1 e +6\% em POS 2$)$

A figura 13 mostra a porcentagem de pacientes que apresentaram aumento ou redução, ou, ainda, que não sofreram alteração dos dois volumes analisados, relativamente ao pré-operatório, do lado não-fissurado após o uso de vasoconstrictor nasal. Em POS1, observou-se, uma tendência do número de 


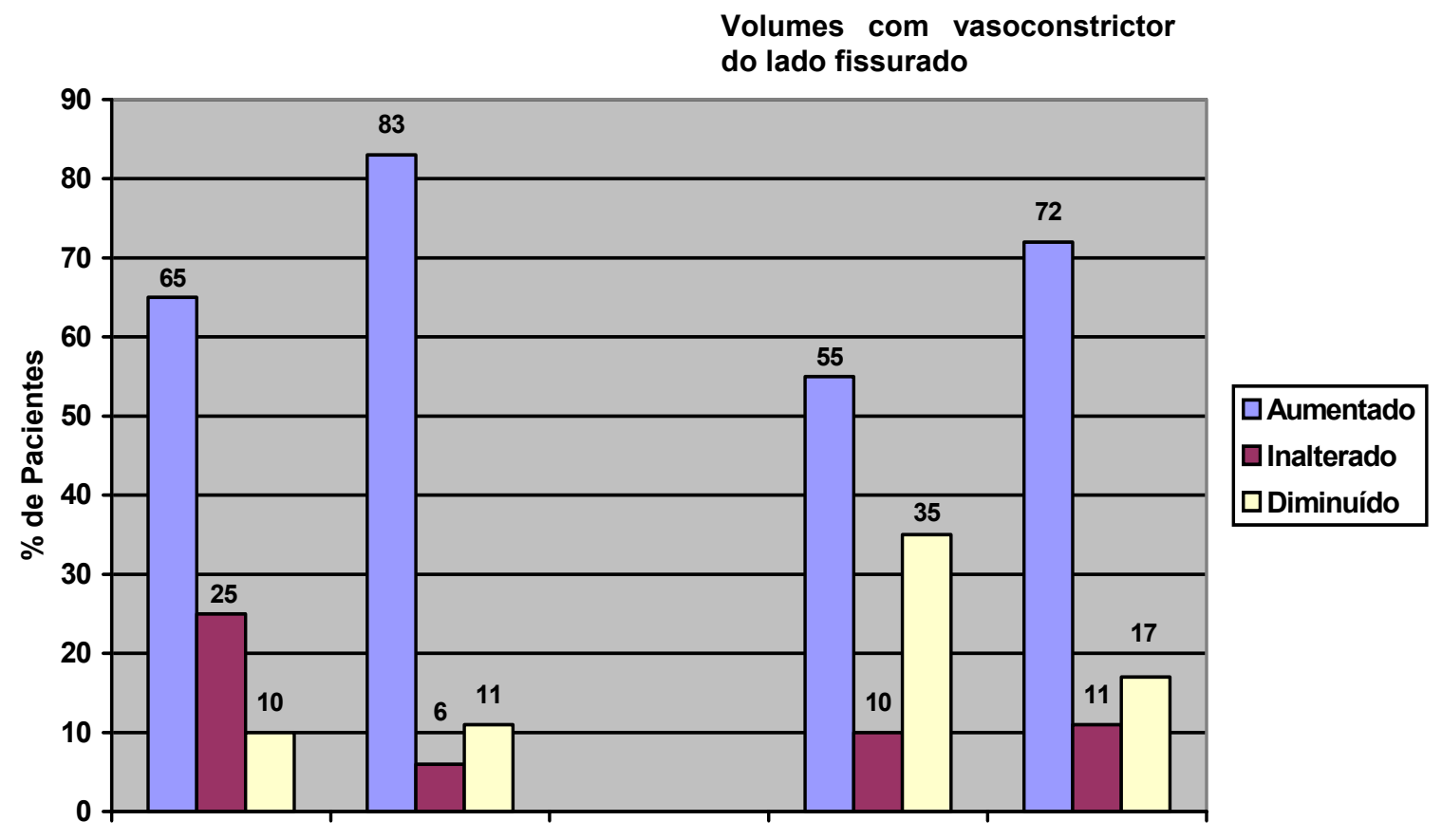

Figura 12 - Variações percentuais induzidas pela rinosseptoplastia nos volumes de dois diferentes segmentos da cavidade nasal (V1 e V2) aferidos por rinometria acústica, após a aplicação tópica de vasoconstrictor nasal, em indivíduos com fissura de lábio e palato unilateral reparada, observadas no primeiro (POS1) e segundo (POS2) pós-operatório, no lado fissurado. 


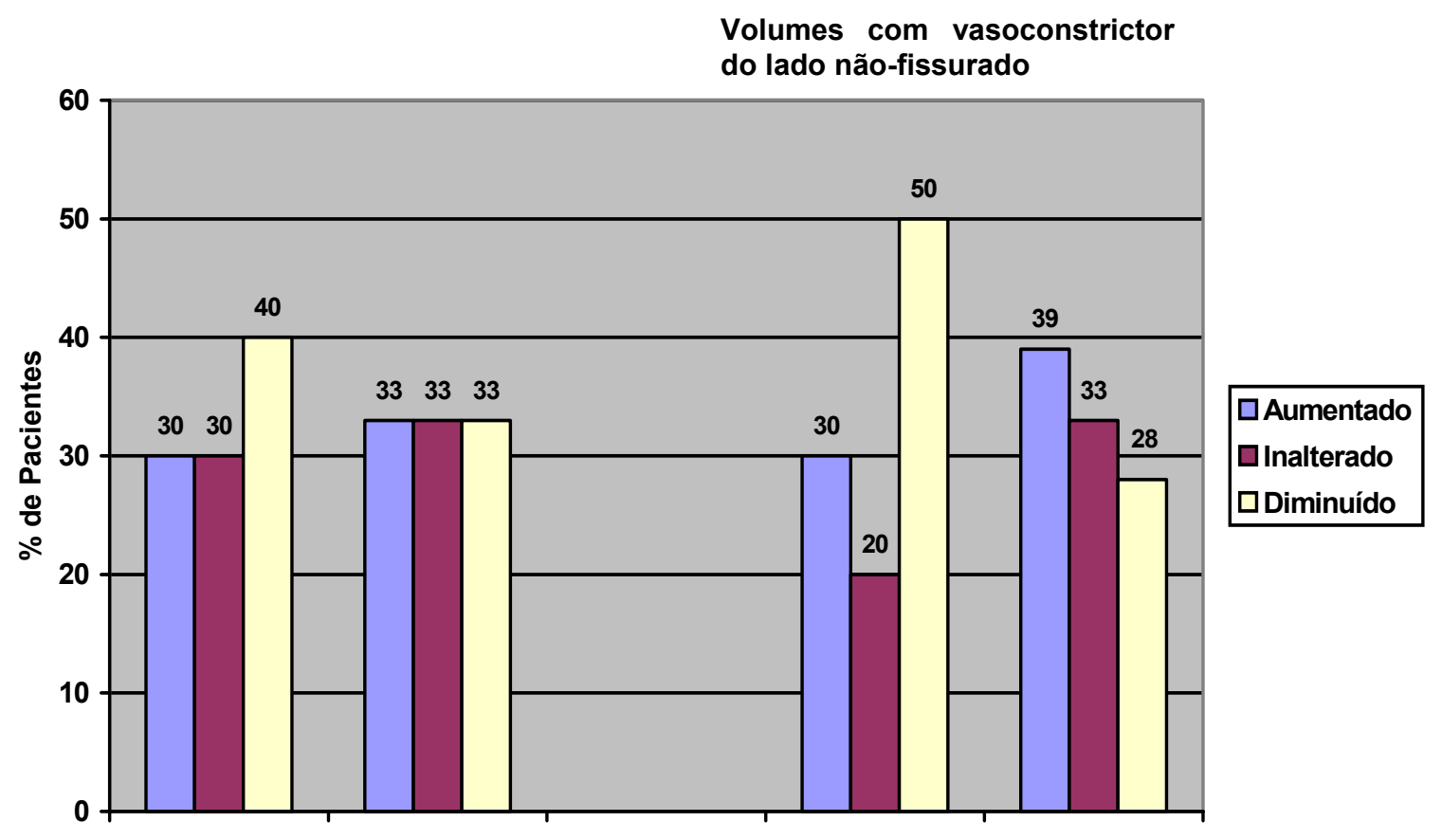

Figura 13 - Variações percentuais induzidas pela rinosseptoplastia nos volumes de dois diferentes segmentos da cavidade nasal (V1 e V2) aferidos por rinometria acústica, após a aplicação tópica de vasoconstrictor nasal, em indivíduos com fissura de lábio e palato unilateral reparada, observadas no primeiro (POS1) e segundo (POS2) pós-operatório, no lado não-fissurado. 
Resultados

pacientes que apresentaram diminuição de V1 e V2 ser maior que aqueles que apresentaram aumento. Em POS2, as proporções de aumento e redução foram iguais para V1. Já, para V2, o número de pacientes com aumento foi maior.

Na tabela 3 observa-se, ainda, que, após a vasoconstricção nasal, os valores médios de V1 e V2 do lado fissurado, obtidos antes da cirurgia foram significantemente menores que os do lado não-fissurado $(p=0,001)$. Após a cirurgia, os valores dos dois lados não mais diferiram entre si.

\subsection{Análise da ressonância da fala por nasometria.}

\subsubsection{Nasalância no texto nasal.}

A tabela 4 mostra que, antes da cirurgia, o valor médio de nasalância obtido na leitura do texto nasal foi de $50 \pm 9 \%$. No primeiro e segundo pósoperatório, os valores observados foram, respectivamente, de $53 \pm 10 \%$ e $49 \pm 10 \%$. As diferenças observadas entre os valores pré e pós-operatórios não foram estatisticamente significantes.

A figura 14 mostra a porcentagem de pacientes que apresentaram aumento ou redução, ou, ainda, que não sofreram alteração da nasalância, relativamente ao pré-operatório. Observou-se que em POS1 e POS2 o número de pacientes que não sofreram alterações da nasalância foi muito superior ao dos pacientes que apresentaram aumento ou redução. 
Tabela 4 - Valores médios ( \pm desvio padrão) da nasalância, aferida por nasometria, em 21 indivíduos com fissura de lábio e palato unilateral reparada, previamente (PRE) à rinosseptoplastia e no primeiro (POS1) e segundo (POS2) pós-operatório, na leitura do texto nasal e texto oral. A nasalância é expressa em porcentagem (\%).

\begin{tabular}{|c|c|c|c|c|c|c|}
\hline & \multicolumn{3}{|c|}{ Texto Nasal } & \multicolumn{3}{|c|}{ Texto Oral } \\
\hline & PRE & POS1 & POS2 & PRE & POS1 & POS2 \\
\hline $\mathrm{n}$ & 21 & 21 & 19 & 21 & 21 & 19 \\
\hline $\bar{x}$ & 50 & 53 & 49 & 27 & 29 & 25 \\
\hline$\pm \mathrm{DP}$ & 9 & 10 & 10 & 13 & 16 & 15 \\
\hline
\end{tabular}

diferenças estatisticamente não significante PRE versus POS1 versus POS2 


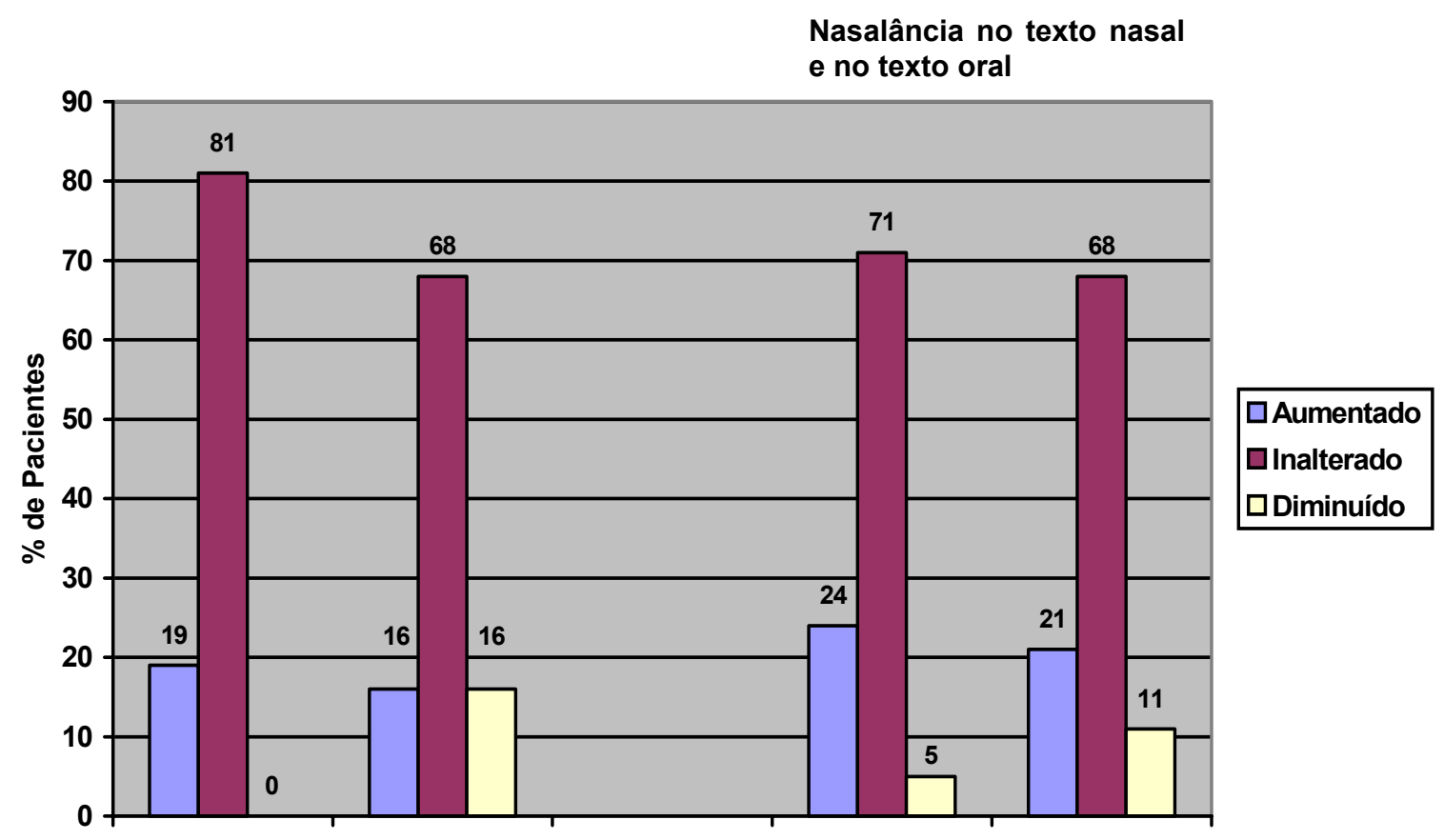

Figura 14 - Variações percentuais induzidas pela rinosseptoplastia na nasalância, aferida por nasometria, em indivíduos com fissura de lábio e palato unilateral reparada, observadas no primeiro (POS1) e segundo (POS2) pósoperatório, na leitura do texto nasal e do texto oral. 


\subsubsection{Nasalância no texto oral.}

A tabela 4 mostra, ainda, que, antes da cirurgia, o valor médio de nasalância obtido na leitura do texto oral foi de $27 \pm 13 \%$. No primeiro e segundo pós-operatório, os valores observados foram, respectivamente, de $29 \pm 16 \%$ e $25 \pm 15 \%$. As diferenças observadas entre os valores pré e pós-operatórios não foram estatisticamente significantes.

A figura 14 mostra a porcentagem de pacientes que apresentaram aumento ou redução, ou, ainda, que não sofreram alteração da nasalância, relativamente ao pré-operatório. Observou-se que em POS1 e POS2 o número de pacientes que não sofreram alterações da nasalância foi muito superior ao dos pacientes que apresentaram aumento ou redução. 
5. DISCUSSÃO 


\section{DISCUSSÃO.}

No presente estudo foram investigados os resultados funcionais da rinosseptoplastia utilizada no Hospital de Reabilitação de Anomalias Craniofaciais-USP para a correção das deformidades usualmente associadas às fissuras de lábio e palato unilaterais. Para tanto, lançou-se mão de metodologia objetiva de avaliação: a rinometria acústica e a nasometria. A primeira foi utilizada para aferir as mudanças causadas pela cirurgia na permeabilidade nasal ao fluxo aéreo respiratório, estimada pela medida das dimensões internas da cavidade nasal, mais precisamente, das áreas seccionais e volumes nasais em segmentos específicos. A segunda foi utilizada para aferir as eventuais repercussões da cirurgia sobre a ressonância da fala, aqui estimada pela medida da nasalância, o correlato acústico da nasalidade.

Este tipo de abordagem reveste-se de fundamental importância, primeiro porque atende orientações da Organização Mundial da Saúde sobre a necessidade dos serviços que prestam assistência aos portadores de fissura labiopalatina estabelecerem rotinas de avaliação dos resultados de seus procedimentos (World Health Organization 2002). Segundo, porque ainda que muito tenha sido descrito sobre os efeitos estéticos das rinosseptoplastias em fissurados de lábio e palato, apenas um estudo da literatura alemã HümpfnerHierl et al (2003) dedicou-se à análise sistematizada de suas repercussões funcionais utilizando métodos instrumentais, entre eles a rinometria acústica. Nenhum outro se preocupou em avaliar a qualidade da fala como no presente estudo.

Nesse contexto, a rinometria acústica demonstrou que, na maioria dos casos analisados, a rinosseptoplastia resultou em melhora significativa da 
Dıscussào

permeabilidade nasal. Adicionalmente, verificou-se que as alterações estruturais não resultaram em modificações significativas na ressonância nasal da fala, estimada pela nasometria. Esses achados merecem discussão pormenorizada, primeiramente com a análise dos resultados obtidos antes da cirurgia e, depois, dos resultados obtidos após a realização da cirurgia.

Em estudo anterior do Laboratório de Fisiologia do HRAC-USP, as dimensões das vias aéreas nasais de indivíduos adultos com diferentes tipos de fissura reparada foram avaliadas pela rinomanometria, uma técnica que permite a aferição da área de secção transversa mínima da cavidade nasal pela medida de pressões e fluxos gerados durante a respiração nasal (Fukushiro e Trindade 2005). Constatou-se que a fissura de lábio e palato unilateral estava associada a uma diminuição da permeabilidade nasal em parcela significativa dos casos analisados. De um lado, o comprometimento se mostrou de menor gravidade que aquele associado à fissura de lábio e palato bilateral, e, de outro, o resultado diferiu do verificado em pacientes com fissura isolada de palato, que, apresentaram-se dentro da normalidade.

O nariz do portador de fissura de lábio e palato unilateral apresenta deformidades típicas que justificam as alterações de permeabilidade observadas por Fukushiro e Trindade (2005) e que explicam a necessidade freqüente da realização da cirurgia corretora. Os pacientes avaliados no presente estudo reuniam as principais dessas deformidades: ponta nasal com tendência à bifidez; assoalho nasal e base alar rebaixados do lado da fissura; narina e válvula nasal reduzidas do lado da fissura; dorso, pirâmide nasal e septo nasal anterior desviados para o lado não-fissurado; septo nasal posterior 
Dıscussào

desviado para o lado fissurado; conchas nasais média e inferior hipertróficas do lado não-fissurado.

Confirmando os achados clínicos, as dimensões internas nasais dos pacientes analisados comparativamente menores que as de indivíduos normais avaliados no Laboratório de Fisiologia do HRAC-USP por Gomes (2004). Naquele estudo, no qual foi empregada a mesma metodologia da presente investigação, observou-se que em 60 cavidades de 30 voluntários adultos sem queixas de obstrução nasal, com idade entre 18 e 30 anos, as áreas de secção transversa nos segmentos correspondentes à válvula nasal (AST1), porção anterior da concha nasal inferior (AST2) e porção posterior da concha nasal inferior (AST3) foram, respectivamente, iguais a $0,54 \pm 0,13,0,98 \pm 0,31$ e $1,42 \pm 0,44 \mathrm{~cm}^{2}$, em média. Verificou-se que esses valores foram muito próximos aos de Corey et al (1998), que são utilizados como referência pelo fabricante do Eccovision Acoustic Rhinometer $\left(0,52 \pm 0,12 \mathrm{~cm}^{2}, 0,83 \pm 0,24 \mathrm{~cm}^{2} \mathrm{e}\right.$ $1,31 \pm 0,42 \mathrm{~cm}^{2}$, respectivamente). O mesmo se observou com relação aos valores obtidos após o uso de descongestionante nasal. A AST1 média observada por Gomes (2004), que é a medida-padrão de todos os trabalhos da área, também não diferiu em mais de $10 \%$ das obtidas por outros autores como Tomkinson e Eccles (1998), Larsson et al (2001) e Ognibene et al (2001), que se situaram entre 0.57 e $0,59 \mathrm{~cm}^{2}$, validando, portanto, o método utilizado.

No presente estudo, os valores médios de AST1, AST2 e AST3, $\left(0,35 \pm 0,17,0,71 \pm 0,39\right.$ e $\left.1,19 \pm 0,85 \mathrm{~cm}^{2}\right)$, determinados antes da cirurgia, do lado da fissura e sem o uso de vasoconstrictor, foram nitidamente menores que os valores de referência, confirmando o efeito deletério da fissura sobre as áreas seccionais de diferentes segmentos da cavidade nasal ipsilateral. Vale 
destacar que, proporcionalmente, a área seccional da válvula nasal foi a mais afetada, com uma diferença da ordem de $35 \%$, em relação ao valor normal obtido por Gomes (2004), o que, do ponto de vista fisiológico, representa importante prejuízo à sensação de patência (boa permeabilidade) nasal, uma vez que a válvula representa o ponto de maior constricção da vias respiratórias, e, portanto, o principal mecanismo a controlar a função nasal (Hilberg et al 1989, Warren e Drake 1993, Pirilä e Tikano 2001).

Quanto aos volumes dos segmentos correspondentes à região da válvula nasal (V1) e das conchas nasais (V2), no estudo de Gomes (2004)

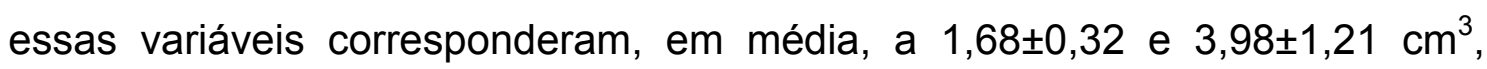
respectivamente. Neste caso, a comparação com outros estudos não foi possível, pois os autores que realizaram esse tipo de medida em normais (Grymer et al 1989, 1991, Kesavanathan et al 1995, Morgan et al 1995, Roithmannet al 1995, 1997, Tomkinson e Eccles 1998, Corey et al 1998, Kunkel et al 1999, Silkoff et al 1999, Sung et al 2000) o fizeram em segmentos diversos dos propostos por Antila et al (1997), nos quais nos baseamos, ou então, reportaram medidas bilaterais, como Kunkel et al (1999), impedindo a comparação. Antila et al (1997), em particular, não analisaram indivíduos normais, mas, sim, pacientes com evidências de obstrução nasofaríngea, queixa de ronco e apnéia no sono, de modo que a comparação, também neste caso, ficou prejudicada.

De qualquer forma, comparando os dados de Gomes (2004) com os do presente estudo, em que os volumes médios, determinados antes da cirurgia do lado da fissura e sem o uso de vasoconstrictor, corresponderam a 1,11 $\pm 0,36$ e 2,95 $\pm 1,60 \mathrm{~cm}^{3}$, confirma-se, mais uma vez, o impacto da fissura sobre a 
patência nasal, agora sobre as dimensões volumétricas da cavidade nasal, que também se mostraram mais reduzidas na região da válvula nasal, em $34 \%$, comparativamente aos volumes obtidos nos indivíduos analisados por Gomes (2004).

As mesmas observações, relativamente à comparação de áreas e volumes entre fissurados e normais, são válidas para os dados obtidos no presente estudo após a aplicação tópica de um vasoconstrictor nasal. Vale lembrar que este é um recurso que elimina o efeito da congestão da mucosa nasal sobre as medidas (Hilberg 2000), o que se comprovou, pela obtenção de áreas e volumes médios comparativamente maiores após o uso do vasocontrictor, em todas as situações analisadas. Disso se conclui que as diferenças encontradas entre normais (do estudo de Gomes, 2004) e fissurados (do presente estudo), na avaliação feita do lado da fissura, são efetivamente resultantes de anormalidades estruturais presente nos indivíduos com fissura.

No que se refere ao lado não-fissurado, os valores médios de AST1, AST2 e AST3 $\left(0,49 \pm 0,17,0,94 \pm 0,44\right.$ e $1,28 \pm 0,53 \mathrm{~cm}^{2}$, respectivamente) e os de V1 e V2 $\left(1,57 \pm 0,46\right.$ e $3,80 \pm 1,63 \mathrm{~cm}^{3}$, respectivamente), foram maiores que os verificados do lado fissurado (para AST2 e AST3 a diferença não foi estatisticamente significante); por outro lado, foram ainda inferiores aos observados por Gomes (2004) em normais, o que demonstra que a fissura unilateral afeta ambas as cavidades, e que, confirmando impressões clínicas e observações anteriores feitas com a rinomanometria por Fukushiro e Trindade (2005), a mais comprometida é a aquela correspondente ao lado da fissura. 
Discussão

Isto posto, passemos a análise dos efeitos provocados pela rinosseptoplatia sobre as dimensões internas nasais. Vale, antes, reenfatizar que todas as intervenções foram feitas sempre pelo mesmo cirurgião e seguiram um protocolo equivalente nos 21 pacientes analisados, ou seja, em todos o procedimento foi primário, o acesso foi externo, intercartilaginoso, sendo feito na altura do terço superior da columela, as cartilagens laterais inferiores de ambos os lados ou apenas do lado da fissura foram seccionadas no terço posterior, o desvio septal antero-posterior foi corrigido, a válvula nasal foi aumentada, a projeção da ponta nasal foi aumentada utilizando enxertos septais cartilaginosos retrocolumelar e anterior. Nenhum paciente foi submetido a turbinectomia ou turbinoplastia.

Na primeira avaliação pós-operatória do lado da fissura, observou-se que, na maioria dos pacientes analisados, a cirurgia resultou em aumento das áreas seccionais dos três segmentos analisados, efeito ainda observado na segunda avaliação pós-operatória. Contudo, a comparação estatística dos valores médios mostrou que apenas o aumento da área seccional do segmento correspondente à válvula nasal (AST1), da ordem de $24 \%$, foi estatisticamente significante. Considerando que a válvula nasal é o principal determinante da sensação subjetiva de patência nasal normal (Pirilä e Tikano 2001) esse resultado, por si só, representa um importante ganho funcional, e, é um indicador do sucesso das cirurgias realizadas. Os mesmos resultados foram observados após a descongestão nasal, com um aumento também significante para AST2 (em POS2), comprovando que as alterações observadas se deveram, de fato, às mudanças estruturais causadas pela cirurgia.

Há que se destacar, entretanto, que uma parcela dos pacientes não 
sofreram alterações das áreas seccionais e outros, ainda, sofreram redução das áreas do lado da fissura. Resultados negativos foram também observados em alguns casos de indivíduos não-fissurados analisados por rinometria acústica por autores como Reber et al (1998). Particularidades anatômicas do nariz desses pacientes, complicações no pós-operatório, como, por exemplo, estenose causada por sinéquia, colabamento ou retração cicatricial, ou mesmo, diferenças na abordagem cirúrgica, podem explicar esses achados. Estudo subseqüente a ser realizado no Laboratório de Fisiologia do HRAC-USP pretende investigar mais pormenorizadamente estas variações individuais. Há que se considerar a possibilidade de que esses pacientes, em particular, talvez tivessem se beneficiado de uma turbinectomia ou turbinoplastia, procedimentos não adotados nos pacientes incluídos na amostra, o que, também, em função desses achados, deve ser objeto de estudo posterior.

Os resultados do lado não-fissurado não foram os mesmos. Neste caso, a cirurgia não levou a alterações significantes das áreas seccionais médias de nenhum dos segmentos analisados e em nenhuma das duas avaliações pósoperatórias realizadas. Individualmente, efeitos variáveis foram observados, antes e após a descongestão nasal, notando-se um ligeiro predomínio de casos com redução das dimensões nasais em uma ou em ambas as avaliações pós-cirúrgicas, o que segundo Grymer et al (1989) pode ser explicado pelo impacto da septoplatia não acompanhada de turbinectomia do lado contralateral ao desvio, como foi o caso do presente estudo.

Quanto às variações médias e individuais dos volumes nasais causadas pela rinosseptoplasia, do lado da fissura, os resultados foram essencialmente os mesmos que aqueles observados para as áreas seccionais. 
Nas duas avaliações pós-operatórias, sem ou com o uso de vasoconstrictor, os valores médios de V1 e V2 se mostraram aumentados, respectivamente, em 24 e $21 \%$, relativamente ao pré-operatório; entretanto, significância estatística só foi demonstrada para V1 (e V2 na avaliação feita em POS2 após descongestão). Esses achados confirmam, de maneira mais abrangente, o efeito favorável da cirurgia, particularmente sobre as dimensões da região da válvula nasal. Do lado não-fissurado, uma vez mais, as variações não foram significativas.

Ressalte-se, ainda, que, se antes da cirurgia, os valores médios das áreas seccionais e dos volumes diferiam significativamente entre os lados fissurado e não-fissurado, estas diferenças deixaram de existir após a cirurgia, falando a favor da normalização das dimensões da via aérea nasal do lado fissurado, pelo menos na maioria dos pacientes analisados. De fato, os valores de AST1, AST2 e AST3 $\left(0,48 \pm 0,18,0,88 \pm 0,28\right.$ e 1,23 $\left.\pm 0,40 \mathrm{~cm}^{2}\right)$ e de V1 e V2 $\left(1,46 \pm 0,38\right.$ e $\left.3,74 \pm 1,26 \mathrm{~cm}^{3}\right)$ do segundo pós-operatório, do lado fissurado, se aproximaram (mas não se igualaram) aos dos obtidos por Gomes (2004) em indivíduos normais, que, conforme já mostrado anteriormente, foram iguais a $0,54 \pm 0,13, \quad 0,98 \pm 0,31, \quad 1,42 \pm 0,44 \mathrm{~cm}^{2}, \quad$ e, $1,68 \pm 0,32$ e $3,98 \pm 1,21 \mathrm{~cm}^{3}$, respectivamente.

Diferentes estudos demonstraram, por meio da rinometria acústica, os efeitos favoráveis das cirurgias nasais, mais precisamente, das septoplastias e turbinectomias, sobre a permeabilidade nasal em crianças e adultos com obstrução nasal não decorrente de fissura (Grymer et al 1989, Mann et al 1997, Shemen e Hamburg 1997, Reber et al 1998, Kemker et al 1999, Pirilä e Tikanto 2001, Voegels et al 2002, Can et al 2005). Porém, 
apenas Hümpfner-Hierl et al (2003) analisaram, como no presente estudo, pacientes com fissura. Esses autores avaliaram 37 casos de fissura unilateral e 23 casos de fissura bilateral, com idade entre 7 e 50 anos, utilizando, entre outros métodos, a rinometria acústica para avaliar os resultados da cirurgia. Os autores encontraram evidências de melhora significativa da função nasal em pacientes com fissura unilateral, como no presente estudo, mas não em pacientes com fissura bilateral, que, ao contrário, apresentaram evidências, ainda que não significantes, de deterioração da função. Na rinomanometria, demonstraram um aumento significativo do diâmetro da cavidade nasal após a cirurgia, sem uso de vasocontrictor (de $5,1 \mathrm{~mm}$ para $5,9 \mathrm{~mm}$ ). Na rinometria acústica, utilizando um equipamento diverso do empregado no presente estudo (Rhinoklack RK1000), não verificaram variações significantes dos volumes analisados nos segmentos $0-2 \mathrm{~cm}, 0-4 \mathrm{~cm}$ e $0-6 \mathrm{~cm}$. É possível que a opção de analisar, no presente estudo, o volume do segmento situado entre 1 e 3,2 cm a partir das narinas (região da válvula nasal), conforme sugerido por Antila et al (1997), tenha sido mais eficaz em detectar as variações volumétricas induzidas pela rinosseptoplastia.

Finalmente, é preciso analisar se as mudanças nas dimensões internas nasais se fizeram acompanhar de mudanças na ressonância da fala. É sabido que a produção de uma fala com ressonância oro-nasal equilibrada depende de uma permeabilidade adequada das primeiras porções das vias aéreas: a cavidade nasal e a faringe (Dalston e Vig 1984, Andreassen et al 1991, Laine et al 1989, Parker et al 1990, Dang et al 1994; Trindade et al 2003, PegoraroKrook et al 2006). Como já mencionado, a nasometria foi aqui utilizada para 
estimar, de forma objetiva, a ressonância nasal da fala. Para tanto mediu-se a nasalância, uma grandeza física que corresponde à quantidade relativa de energia acústica emitida pela cavidade nasal na fala e representa o correlato acústico da nasalidade, que corresponde à percepção subjetiva que um ouvinte tem do componente nasal da fala (Fletcher 1976; Fletcher et al. 1989).

O método parte do pressuposto que uma nasalância aumentada na produção de amostras de fala contendo exclusivamente sons orais (o texto oral presentemente empregado) é sugestiva de hipernasalidade, um dos sinais da disfunção velofaríngea que acompanha as fissuras que envolvem o palato. Como recurso adicional, a nasometria pode também ser usada para estimar o comprometimento da permeabilidade nasal, como aquele decorrente da obstrução nasal, quando a nasalância é determinada durante a produção de amostras de fala contendo predominantemente sons nasais (o texto nasal aqui empregado); neste caso, uma nasalância reduzida é entendida como hiponasalidade (Trindade e Trindade Jr 1996 e Genaro et al 2005).

Em estudo conduzido no Laboratório de Fisiologia do HRAC-USP (Zuiani 1996), determinou-se como limite inferior de normalidade o valor de nasalância de $43 \%$ para a produção do texto nasal, e, como limite superior de normalidade o valor de $27 \%$, para a produção do texto oral. Isto significa que valores inferiores a $43 \%$ no texto nasal devem considerados como sugestivos de hiponasalidade e valores superiores a $27 \%$ no texto oral, como sugestivos de hipernasalidade. Esses níveis de corte foram definidos a partir de uma análise da eficiência da nasometria em detectar desvios de nasalidade, em 194 pacientes com fissura atendidos no Laboratório de Fisiologia do HRAC-USP. 
Os escores de $43 \%$ para o texto nasal e $27 \%$ para o texto oral foram os que maximizaram a sensibilidade e a especificidade da nasometria em identificar, respectivamente, a presença e a ausência dos referidos sinais.

$\mathrm{Na}$ presente investigação, observou-se que, antes da rinoseptoplastia, o valor médio de nasalância obtido na leitura do texto nasal foi de $50 \pm 9 \%$ e na leitura do texto oral foi de $27 \pm 13 \%$. Com base nos valores de corte acima mencionados, é de se supor, portanto, que poucos pacientes apresentavam desvios de nasalidade previamente à cirurgia. De fato, dos 21 pacientes incluídos no presente estudo, apenas 5 apresentavam valores sugestivos de hiponasalidade $(<43 \%)$ antes da cirurgia, o que em função das deformidades nasais que apresentavam é um número relativamente pequeno. Há que se questionar, portanto, a acurácia da nasometria em sinalizar a presença de obstrução nasal, o que já foi motivo de discussão por Dalston et al (1991a, b). Por outro lado, 10 pacientes apresentavam valores maiores que $27 \%$ no texto oral, sugerindo presença de hipernasalidade, o que é um resultado esperado para pacientes com fissura de palato, que, com certa freqüência, apresentam disfunção velofaríngea após a cirurgia corretora primária. Ainda assim, o valor médio encontrado foi menor que o verificado por Zuiani et al (1998) em pacientes portadores de diferentes tipos de fissura e indicação para faringoplastia, que apresentaram uma nasalância média de $42 \pm 8 \%$.

Isto posto, resta analisar os efeitos da rinosseptoplastia sobre as medidas de nasalância. Individualmente, observou-se que, na maior parcela dos casos analisados, os valores de nasalância nos dois textos estudados não sofreram alterações significativas, além daquelas inerentes ao método. Isto se 
refletiu nas médias, que não sofreram alterações estatisticamente significantes nas duas avaliações feitas após a cirurgia e nos dois textos. Dos 5 casos com valores de nasalância sugestivos de hiponasalidade no pré-operatório, um terminou o estudo com nasalância normal. Dos 11 casos com valores de nasalância sugestivos de ausência de hipernasalidade no pré-operatório, dois terminaram o estudo com nasalância sugestiva de hipernasalidade. Ambos os efeitos, um favorável e outro desfavorável à qualidade da fala, são, possivelmente, decorrentes do aumento das dimensões internas nasais promovidas pela cirurgia. É de se supor, portanto, que ainda que a rinosseptoplastia, em pacientes com fissura de lábio e palato unilateral, modifique as dimensões internas de parcela considerável de pacientes, esse efeito não é de magnitude suficiente para alterar as características de ressonância da cavidade nasal. 
6. CONCLUSÕES 


\section{CONCLUSÕES.}

Os resultados observados com a rinometria acústica e a nasometria em indivíduos com fissura de lábio e palato unilateral reparada submetidos à rinosseptoplastia para a correção de deformidades nasais sugerem que, na maioria dos casos analisados:

1. a cirurgia levou a um aumento persistente da permeabilidade nasal, traduzida por um aumento estatisticamente significante da área de secção transversa e do volume do segmento correspondente à válvula nasal do lado da fissura;

2. as variações das dimensões internas nasais não foram acompanhadas por mudanças na ressonância da fala, o que se constatou pela ausência de variações estatisticamente significantes da nasalância.

Esses achados constituem bons indicadores do sucesso das cirurgias realizadas em termos funcionais, e, reforçam a importância do uso de métodos objetivos, particularmente a rinometria acústica, para acompanhar a qualidade de procedimentos cirúrgicos que envolvam a correção das deformidades nasais tipicamente associadas às fissuras labiopalatinas. 


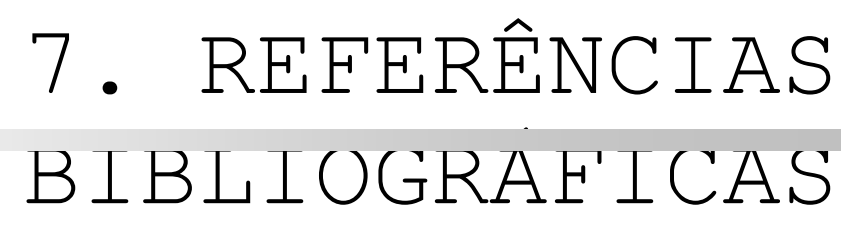




\section{REFERÊNCIAS BIBLIOGRÁFICAS.}

Andreassen ML, Leeper HA, MacRae DL. Changes in vocal resonance and nasalization following adenoidectomy in normal children: preliminary findings. J Otolaryngol 1991; 20:237-42.

Anselmo-Lima WT, Lund VJ. The effects of endoscopic sinus surgery on the nasal cycle as assessed by acoustic rhinometry. Am J Rhinol 2001; 15:165-8.

Antila J, Sipilä J, Tshushima Y, Polo O, Laurikainen E, Suonpää J. The effect of laser-uvulopalatopharyngoplasty on the nasal and nasopharyngeal volume measured with acoustic rhinometry. Acta Otolaryngol Suppl 1997; 529:202-5.

Brown IG, Zamel N, Hoffstein V. Pharyngeal cross-sectional area in normal men and women. J Appl Physiol 1986; 61:890-5.

Can IH, Ceylan K, Bayiz U, Olmez A, Samim E. Acoustic rhinometry in the objective evaluation of childhood septoplasties. Int J Pediatr Otorhinolaryngol. 2005 Apr; 69:445-8.

Carlini D, Ouriques DM, Weckx LLM, Fujita RR. Modified Method of Acoustic Rhinometry. Acta Otolaryngol 2002; 122:298-301.

Corey JP, Gungor A, Nelson R, Liu X, Fredberg J. Normative standards for nasal cross-sectional areas by race as measured by acoustic rhinometry. Otolaryngol Head Neck Surg 1998; 119:389-93.

D'Urzo AD, Lawson VG, Vassal KP, Rebuck AS, Slutsky AS, Hoffstein V. Airway area by acoustic response measurements and computerized tomography. Am Rev Respir Dis 1987; 135:392-5.

D'Urzo AD, Rubinstein I, Lawson VG Vassal KP, Rebuck AS, Slutsky AS, et al. Comparison of glottic areas measured by acoustic reflection vs. computerized tomography. J Appl Physiol 1988; 64:367-70.

Dang J, Honda K, Suzuki H. Morphological and acoustical analysis of the nasal and the paranasal cavities. J Acoust Soc Am 1994; 96:2088-100.

Dalston RM. Acoustic assessment of the nasal airway. Cleft Palate Craniofac J 1992; 29:520-6. 
Dalston RM, Vig PS. Effects of orthognathic surgery on speech: a prospective study. Am J Orthod 1984; 86:291-8.

Dalston RM, Warren DW, Dalston ET. A preliminary investigation concerning the use of nasometry in identifying patients with hyponasality and/or nasal airway impairment. J Speech Hear Res 1991a; 34:11-8.

Dalston RM, Warren DW, Dalston ET.The identification of nasal obstruction through clinical judgments of hyponasality and nasometric assessment of speech acoustics. Am J Orthod Dentofacial Orthop 1991b;100:59-65.

Drettner B. The nasal airway and hearing in patients with cleft palate. Acta Otolaryngol 1960;57:131-42.

Fisher EW, Palmer CR, Daly NJ, Lund VJ. Acoustic rhinometry in the preoperative assessment of adenoidectomy candidates. Acta Otolaryngol 1995; 115:815-22.

Fletcher SG, Adams LE, McCutcheon MJ. Cleft palate speech assessment through oral-nasal acoustic measures. In: Bzoch KR, editor. Communicative disorders related to cleft lip and palate. $3^{\text {rd }}$ ed. Boston: Little-Brown; 1989. p.246-57.

Fletcher SG. "Nasalance" vs. eistner judgements of nasality. Cleft Palate $J$ 1976; 13:31-44

Fletcher SG. Theory and instrumentation for quantitative measurement of nasality. Cleft Palate J 1970; 7:601-9.

Fredberg JJ, Wohl ME, Glass GM, Dorkin HL. Airway area by acoustic reflections measured at the mouth. J Appl Physiol 1980; 48:749-58.

Fukushiro AP, Trindade IEK. Nasal airway dimensions of adults with cleft lip and palate: differences among cleft types. Cleft Palate Craniofac J 2005; 42:396-402.

Garbino JF, Gomes AOC, Sampaio ACM, Lauris JRP, Trindade IEK. A rinometria acústica como método de aferição da geometria nasal: reprodutibilidade das medidas de volume. In Anais do $5^{\circ}$ Encontro Científico de Pós-Graduação do HRAC-USP; 2003, 21-23 nov, Bauru, Brasil: Hospital de Reabilitação de Anomalias Craniofaciais, Universidade de São Paulo. p.29.

Gilain L, Coste A, Ricolf F, Dahan E, Marliac D, Peynegre R et al. Nasal cavity geometry measured by acoustic rhinometry and computed tomography. Arch Otolaryngol Head Neck Surg 1997; 123:401-5. 
Gomes AOC. Dimensões nasais e nasofaríngeas de indivíduos sem evidências de obstrução nasal avaliadas por rinometria acústica no repouso e na fala [dissertação]. Bauru: Hospital de Reabilitação de Anomalias Craniofaciais, Universidade de São Paulo; 2004.

Gomes AOC, Garbino JF, Sampaio ACM, Lauris JRP, Trindade IEK. Reprodutibilidade de medidas de área de secção transversa nasal aferidas por rinometria acústica. In Anais do $5^{\circ}$ Encontro Científico de Pós-Graduação do HRAC-USP; 2003, 21-23 nov, Bauru, Brasil: Hospital de Reabilitação de Anomalias Craniofaciais, Universidade de São Paulo. p.28.

Grymer LF, Hilberg O, Elbrond O, Pedersen OF. Acoustic rhinometry: evaluation of the nasal cavity with septal deviations, before and after septoplasty. Laryngoscope 1989; 99:1180-7.

Grymer L, Hilberg O, Pedersen O, Rasmussen TR. Acoustic rhinometry: values from adults with subjective normal nasal patency. Rhinology 1991; 29:35-47.

Gubisch W, Constantinescu MA, Grüner M. The relevance of extracorporeal septoplasty in cleft nose correction. J Craniomaxillofac Surg 1998; 26:294-300.

Hairfield WM, Warren DW. Dimensions of the cleft nasal airway in adults: a comparison with subjects without cleft. Cleft Palate J 1989; 26:9-13.

Hilberg O. Objective measurement of nasal airway dimensions using acoustic rhinometry: methodological and clinical aspects. Allergy 2002; 57:5-39.

Hilberg O, Grymer LF, Pedersen O, ElbrØnd O. Turbinate hypertrophy: evaluation of the nasal cavity by acoustic rhinometry. Arch Otolaryngol Head Neck Surg 1990; 116:283-9.

Hilberg O, Jackson AC, Swift DL, Pedersen OF. Acoustic rhinometry: evaluation of nasal cavity geometry by acoustic reflection. J Appl Physiol 1989; 66:295303.

Hilberg O, Pedersen OF. Acoustic rhinometry: recommendations for technical specifications and standard operating procedures. Rhinol Suppl 2000; 16:3-17.

Hoffstein V, Zamel N, Phillipson EA. Lung volume dependence of pharyngeal cross-sectional area in patients with obstructive sleep apnea Am Rev Respir Dis 1984; 130:175-8.

Humpfner-Hierl $\mathrm{H}$, Hierl T, Hemprich A. Functional and aesthetic outcome of nasal surgery in cleft lip palate patients. Mud Kiefer Gesichtschir 2003; 7:254260. 
Jackson AC, Butler JP, Millet EJ, Hoppin Junior FG, Dawson SV. Airway geometry by analysis of acoustic pulse response measurements. J Appl Physiol 1977; 43:523-36

Kesavanathan J, Swift DL, Bascom R. Nasal pressure-volume relationship determined with acoustic rhinometry. J Appl Physiol 1995; 79:547-53.

Kim YK, Kang JH, Yoon KS. Acoustic rhinometric evaluation of nasal cavity and nasopharynx after adenoidectomy and tonsillectomy. Int $J$ Pediatr Otorhinolaryngol 1998; 44:215-220.

Kay Elemetrics Corporation. Instruction manual: Nasometer model 6200-3 IBM. Pine Brooks: Lincoln Park; 1994.

Kemker B, Liu X, Gungor A, Moinuddin R, Corey J. Effect of nasal surgery on the nasal cavity as determined by acoustic rhinometry. Otolaryngol Head Neck Surg 1999; 121:567-71.

Kummer AW. Nasometry. In: Kummer AW, editor. Cleft palate and craniofacial anomalies. ed. San Diego: Singular; 2001. p.311-30.

Kunkel M, Hochban W. Acoustic rhinometry: a new diagnostic procedureexperimental and clinical experience. Int J Oral Maxillofac Surg 1994; 23:40912.

Kunkel M, Wahlmann U, Wagner W. Nasal airway in cleft-palate patients: acoustic rhinometric data. J Cranio-Max Fac Surg 1997; 25:270-4.

Kunkel M, Wahlmann U, Wagner W. Acoustic airway profiles in unilateral cleft palate patients. Cleft Palate Craniofac J 1999; 36:434-40.

Lai VWS, Corey JP. The objective assessment of nasal patency. Ear Nose Throat J 1993; 72:395-400.

Laine T, Warren DW, Dalston RM, Morr KE. Effects of velar resistance on speech aerodynamics. Eur J Orthod 1989; 11:52-8.

Larsson C, Millqvist E, Bende M. Relationship between subjective nasal stuffiness and nasal patency measured by acoustic rhinometry. Am J Rhinol $2001 ; 15: 403-5$.

Lenders H, Pirsig W. Diagnostic value of acoustic rhinometry: patients with allergic and vasomotor rhinitis compared with normal controls. Rhinology 1990; 28:5-16. 
Lenders H, Schaefer J, Pirsig W. Turbinate hypertrophy in habitual snorers and patients with obstrutive sleep apnea: findings of acoustic rhinometry. Laryngoscope 1991; 101:614-8.

Linder-Aronson S. Naso-respiratory function and craniofacial growth. In: McNamara Junior JA, editor. Naso-respiratory function and craniofacial growth. Ann Arbor: Center for Human Growth and Development; 1979. p.121-47.

Liu H, Warren DW, Drake AF, Davies JU. Is nasal airway size a marker for susceptibility toward clefting. Cleft Palate Craniofac J 1992; 29:336-9.

Mamikoglu B, Houser S, Akbar I, NG B, Corey JP. Acoustic rhinometry and computed tomography scans for the diagnosis of nasal septal deviation, with clinical correlation. Otolaryngol Head Neck Surg 2000; 123:61-8.

Mamikoglu B, Houser SM, Corey JP. An interpretation method for objective assessment of nasal congestion with acoustic rhinometry. Laryngoscope 2002; 112:926-9.

Mann WJ, Riechelmann H, Hinni ML. Acoustic rhinometry-predictive value in septal and turbinate surgery. Adv Otorhinolaryngol 1997; 51:61-7.

Marques VC, Anselmo-Lima WT. Pre and postoperative evaluation by acoustic rhinometry of children submitted to adenoidectomy or adenotonsillectomy. Int $J$ Pediatr Otorhinolaryngol 2004; 68:311-6.

Millqvist $\mathrm{E}$, Bende $\mathrm{M}$. Reference values for acoustic rhinometry in subjects without nasal symptoms. Am J Rhinol 1998; 12:341-3.

Morgan NJ, MacGregor FB, Birchall MA, Lund VJ, Sittampalam Y. Racial differences in nasal fossa dimensions determined by acoustic rhinometry. Rhinology 1995; 33:224-8

Ognibene NE, Merrick MA, Ingersoll CD. Intra and intercession reliability of acoustic rhinometry in measuring nasal cross-sectional area. Ear Nose Throat $J$ 2001; 80:536-40.

Parker AJ, Clarke PM, Dawes PJ, Maw AR. A comparison of active anterior rhinomanometry and nasometry in the objective assessment of nasal obstruction. Rhinology 1990; 28:47-53.

Parvez L, Erasala G, Noronha A. Novel techniques, standartization tools to enhance reliability of acoustic rhinometry measurements. Rhinol Suppl 2000; 16:18-28. 
Pegoraro-Krook MI, Dutka-Souza JC, Williams WN, Teles Magalhaes LC, Rossetto PC, Riski JE. Effect of nasal decongestion on nasalance measures. Cleft Palate Craniofac J 2006; 43:289-94.

Peterson-Falzone SJ, Hardin-Jones MA, Karnell MP. Implications of inadequade velopharyngeal function for articulation, resonance, and voice. In: Peterson-Falzone SJ, Hardin-Jones MA, Karnell MP, editor. Cleft Palate Speech. $3^{\mathrm{a}}$ ed. St Louis, Missouri: Mosby, 2001. p. 273-88.

Pirilä T, Tikanto J. Unilateral and bilateral effects of nasal septum surgery demonstrated with acoustic rhinometry, rhinomanometry, and subjective assessment. Am J Rhinol 2001; 15:127-33.

Reber M, Rahm F, Monnier Ph. The role of acoustic rhinometry in the pre- and potoperative evaluation of surgery for nasal obstruction. Rhinology 1998; 36:184-7.

Riechelmann $\mathrm{H}$, Rheinheimer $\mathrm{MC}$, Wolfensberger $\mathrm{M}$. Acoustic rhinometry in pre-school children. Clin Otolaryngol Allied Sci 1993; 18:272-7.

Roithmann R, Chapnik J, Zamel N, Barreto SM, Cole P. Acoustic rhinometric assessment of the nasal valve. Am J Rhinol 1997; 11:379-85.

Roithmann R, Cole P, Chapnik J, Shpirer I, Hoffstein V, Zamel N. Acoustic rhinometry in the evaluation of nasal obstruction. Laryngoscope 1995; 105:27581.

Roithmann R, Cole P. Objective assessment of nasal patency: why, when, how? Rev Bras Otorrinolaringol 1995; 61:104-9.

Shemen L, Hamburg R. Preoperative and postoperative nasal septal surgery assessment with acoustic rhinometry. Otolaryngol Head Neck Surg 1997; 117:338-42.

Silkoff PE, Chakravorty S, Chapnik J, Cole P, Zamel N. Reproducibility of acoustic rhinometry and rhinomanometry in normal subjects. Am J Rhinol 1999; 13:131-5.

Snedecor GW, Cochran WG. Statistical methods. $7^{\text {th }}$ ed. lowa: lowa State University Press; 1980.

Sondhi MM, Gopinath B. Determination of vocal tract shape from impulse response at the lips. J Acoust Soc Am 1971; 49:1867-73.

Sung Y, Lee M, Kim I, Lim D, Rha K, Park C. Nasal cycle in patients with septal deviation: evaluation by acoustic rhinometry. Am J Rhinol 2000; 14:171-4. 
Tomkinson A, Eccles R. Acoustic rhinometry: an explanation of some common artefacts associated with nasal decongestion. Clin Otolaryngol 1998; 23:20-6.

Trindade IEK. Estudo da função pulmonar de indivíduos com fissura palatina congênita [tese]. Ribeirão Preto: Faculdade de Medicina de Ribeirão Preto, Universidade de São Paulo; 1990.

Trindade IEK, Genaro KF, Dalston RM. Nasalance scores of normal Brazilian Portuguese speakers. Braz J Dysmorphol Speech Dis 1997; 1:23-34

Trindade IEK, Manço JC, Trindade Junior AS. Pulmonary function of individuals with congenital cleft palate. Cleft Palate Craniofac J 1992; 29:429-34.

Trindade IEK, Sampaio ACM, Trindade Junior AS, Drake AF, Warren DW. A medida da área de secção transversa nasal como estimativa da função nasorespiratória. In: Livro de Resumos da X Reunião Anual da Federação de Sociedades de Biologia Experimental; 1995 23-26 ago; Serra Negra, Brasil. São Paulo: FESBE; 1995. p.159.

Trindade IEK, Trindade Junior AS. Avaliação funcional da inadequação velofaríngea. In: Carreirão S, Lessa S, Zanini AS, editores. Tratamento das fissuras labiopalatinas. $2^{a}$.ed. Rio de Janeiro: Revinter; 1996. p.223-35.

Trindade IEK, Yamashita RP, Suguimoto RM, Mazzottini R, Trindade Junior AS. Effects of orthognathic surgery on speech and breathing of subjects with cleft lip and palate: acoustic and aerodynamic assessment. Cleft Palate Craniofac J. 2003;40:54-64.

Vig PS, Spalding PM, Lints RR. Sensitivity and specificity of diagnostic tests for impaired nasal respiration. Am J Orthod Dentofac Orthop 1991; 99:354-60.

Voegels RL, Goto EY, Lessa MM, Romano FR, Neves MC, Tavares R, et al. Avaliação pré e pós-operatória por rinometria acústica de pacientes submetidos à cirurgia de septo nasal e conchas inferiores. Arq Otorrinolaryngol 2002; 6:169-72.

Wahlmam U, Kunkel M, Wagner W. Preoperative assessment of airway patency in the planning of corrective cleft nose surgery. Mund Kiefer Gesichtschir 1998; 2:153-7.

Warren DW. A quantitative technique for assessing nasal airway impairment. Amer J Orthod 1984; 86:306-14.

Warren DW, Drake A, Davis JU. Nasal airway in breathing and speech. Cleft Palate Craniofac J 1992; 29:511-9. 
Warren DW, Drake AF. Cleft nose: form and function. Clin Plast Surg 1993; 20:769-79.

Warren DW, Duany LF, Fisher ND. Nasal pathway resistance in normal and cleft palate subjects. Cleft Palate J 1969; 6:134-40.

Warren DW, Hairfield WM. The nasal airway in cleft palate. In: Bardach J, Morris HL, editors. Multidisciplinary management of cleft lip and palate. Philadelphia: WB Saunders; 1990. p.688-92.

Wetmore RF. Importance of maintaining normal nasal function in the cleft palate patient. Cleft Palate Craniofac J 1992; 29:498-506.

World Health Organization. Global strategies to reduce the health-care burden of craniofacial anomalies. Report of WHO Meetings on International Collaborative Research on Craniofacial Anomalies: WHO Human Genetics Programme; 2002; 9-10 Apr; Toronto, Canada; 2002. p.140-148

Yamashita RP, Dimensões nasofaríngeas e queixas respiratórias em indivíduos com insuficiência velofaríngea submetidos à cirurgia de retalho faríngeo [Tese]. Bauru: Hospital de Reabilitação de Anomalias Craniofaciais - HRAC-USP; 2003.

Zuiani TBB. Efeitos do tratamento cirúrgico da inadequação velofaríngea sobre a ressonância da fala: análise perceptiva e nasométrica [dissertação]. São Paulo: Pontifícia Universidade Católica de São Paulo; 1996.

Zuiani TBB, Trindade IEK, Yamashita RP, Trindade Junior. AS. The pharyngeal flap surgery in patients with velofaringeal insufficiency: perceptual and nasometric speech assessment. Braz J Dysmorfol Speech Dis 1998; 2:31-42. 
ANEXOS 


\section{Anexo 1}

Carta de informação ao sujeito da pesquisa 
Termo de consentimento livre e esclarecido 
Anexo 1A - Carta de informação ao sujeito da pesquisa

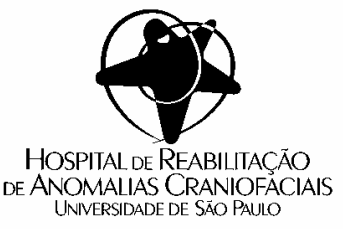

\section{CARTA DE INFORMAÇÃO AO SUJEITO DA PESQUISA}

\section{PROJETO: Efeitos da rinosseptoplastia sobre as dimensões internas nasais e ressonância da fala em indivíduos com fissura de lábio e palato unilateral reparada: Análise por rinometria acústica e nasometria}

Sr(a). Paciente ou Responsável:

Nossa pesquisa tem por objetivo avaliar os efeitos das cirurgias nasais (rinosseptoplastia), sobre as dimensões da cavidade nasal por meio da rinometria acústica e a qualidade da fala por meio da nasometria em indivíduos com fissura de lábio e palato unilateral reparada.

Para isso, pedimos que o $\mathrm{Sr}(\mathrm{a})$. se disponha a comparecer no LABORATÓRIO DE FISIOLOGIA do HRAC/USP (CENTRINHO) antes e após a cirurgia para ser entrevistado por um profissional quanto a problemas respiratórios e ser submetido ao exame, chamado rinometria acústica que permite determinar áreas e volumes de três diferentes partes da cavidade nasal. O paciente fica sentado, a cabeça é apoiada em um suporte e o rinômetro (um tubo) é encostado na narina, o que permite que sejam feitas as medições no computador. $O$ exame não causa dor ou desconforto.

Outro exame a ser realizado no LABORATÓRIO DE FISIOLOGIA do HRAC/USP (CENTRINHO) é a nasometria, um teste simples que não provoca dor ou desconforto. $O$ paciente lê algumas frases na tela do computador, com o aparelho encostado no lábio superior. As medidas são feitas por um computador enquanto o paciente encontra-se sentado, falando naturalmente.

$\mathrm{Na}$ divulgação dos dados da pesquisa a sua identidade será mantida em sigilo. Qualquer dúvida poderá ser por nós esclarecida pessoalmente ou pelo telefone (14)3235-8137. Caso queira apresentar reclamações em relação a sua participação na pesquisa, poderá entrar em contato com o Comitê de Ética em Pesquisa em Seres Humanos do HRAC/USP, no endereço Rua Silvio Marchione 3-20 ou pelo telefone (14)3235-8421. 
Anexo 1B - Termo de consentimento livre e esclarecido

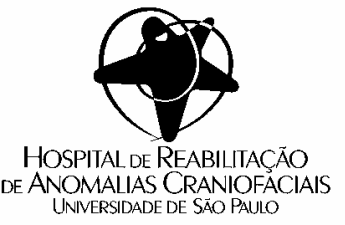

TERMO DE CONSENTIMENTO LIVRE E ESCLARECIDO

$\mathrm{Eu}$,

portador de RG $\mathrm{n}^{\circ}$ residente à Rua (Av.)

$\mathrm{n}^{\circ}$ na cidade de

Estado Matriculado (a) no Hospital de

Reabilitação de Anomalias Craniofaciais, da Universidade de São Paulo, sob o n concordo em participar na pesquisa de Título: "Efeitos da rinosseptoplastia sobre as dimensões internas nasais e ressonância da fala em indivíduos com fissura de lábio e palato unilateral reparada: Análise por rinometria acústica e nasometria", realizada por Carlos Eduardo Bertier (CRM 70928), sob orientação da Profa. Dra. Inge Elly Kiemle Trindade (CRBM 1-2081).

O objetivo da referida pesquisa é avaliar os efeitos funcionais da rinosseptoplastia, por meio de exames instrumentais que permitem avaliar a respiração nasal e a qualidade da fala.

Estou ciente que o estudo não implica em modificações na técnica cirúrgica habitualmente usada no HRAC-USP e saliento que fui orientado (a) a respeito das avaliações que serão realizadas, bem como quanto aos benefícios decorrentes destas avaliações.

Estou ciente também de que minha participação é voluntária e de que dela posso desistir a qualquer momento, sem explicar os motivos e sem comprometer meu tratamento neste Hospital.

Bauru, 1

Assinatura do Paciente

Pesquisador Responsável: Carlos Eduardo Bertier

Rua Sebastião Pregnolato, 6-70

Apto 42, Bloco E Bauru-SP

CEP: 17047-145

Telefone: (14) 97715544 


\section{Anexo 2}

Ficha de avaliação clínica pré e transoperatória 
Anexo 2 - Ficha de avaliação clínica pré e transoperatória

\section{AVALIAÇÃO CLÍNICA PRÉ E TRANSOPERATÓRIA}

IDENTIFICAÇÃO

NOME:

Sexo $\square \mathrm{F} \square \mathrm{M} D N$ :

Fissura

Avaliador:

ACHADOS

Cartilagem Alar Inferior

$\square$ completa $\square \mathrm{D}$

$\square \mathrm{E} \square$ convexa $\square$ côncava

$\square$ seccionada $\square \mathrm{D} \quad \square$ anterior

E $\square$ anterior
RG:

Idade:

RGs:

anos

\section{Cartilagem Alar Superior}

$$
\square \text { anterior } \square \text { posterior } \square \text { convexa } \square \text { côncava }
$$

Data:

$\square$ completa

$\square$ seccionada

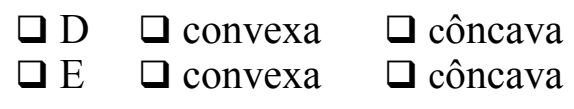

$\square \mathrm{D} \square$ convexa

$\square \mathrm{E} \square$ convexa côncava

$\square$ côncava

Dorso Nasal

$\square$ desviado $\mathrm{E}$

Pirâmide Nasal
$\square$ estreito $\square$ desviado D
$\square$ outros: especificar
$\square$ largo
giba ósseo-cartilaginosa

$\square$ desviada $\mathrm{E}$

Ponta Nasal

$\square$ des
Nasal
$\square$ fina

$\square$ globosa

$\square$ bífida

Septo Nasal Anterior

$\square$ desviado D $\square$ desviado E $\square$ removido cartilagem $\square$ removido osso

Septo Nasal Posterior

$\square$ desviado D $\square$ desviado E $\square$ removido cartilagem $\square$ removido osso

Conchas nasais
$\square$ regular
$\square$ superior
$\square$ hipertrofica
$\square$ médio
$\square$ atrofica
$\square$ inferior
$\square \mathrm{D} \quad \mathrm{E}$

Válvula Nasal

$\square$ regular

$\square$ aumentada

$\square$ reduzida

$\square \mathrm{D} \quad \mathrm{E}$

Narina Direita

$\square$ diâmetro aumentado

$\square$ diâmetro reduzido $\square$ atrésica

Narina Esquerda

$\square$ diâmetro aumentado

Assoalho Nasal

Nivelamento com o lado não-fissurado $\square$ alto $\square$ nivelado $\square$ baixo

Base Alar

Nivelamento com o lado não-fissurado $\square$ alto $\square$ nivelado $\square$ baixo

Columela
$\square$ longa
$\square$ regular
$\square$ curta
$\square$ muito curta

OBSERVAÇÕES: 


\section{PROCEDIMENTOS}

Tipo

$\square$ primário $\square$ secundário

outros: especificar

Acesso

$\square$ externo $1 / 3$ superior da columela $\square$ externo $1 / 3$ médio da columela

$\square$ externo $1 / 3$ inferior da columela

$\square$ transcartilaginoso $\square$ intercartilaginoso

$\square$ outros:

especificar

Cartilagem Alar Inferior

$\square$ secção anterior D

$\square$ secção posterior $D$

$\square$ secção anterior E

口 $1 / 3$

a $2 / 3$

enxerto alar inferior D

$\square$ secção posterior E

$\square 1 / 3$

口 $2 / 3$

$\square$ enxerto alar superior D

$\square$ enxerto alar inferior $E$

$\square$ septo

$\square$ enxerto alar superior $E$

$\square$ auricular D

$\square$ auricular E

Cartilagem Alar Superior

$\square$ secção D $\square$ secção E $\square$ enxerto alar D

enxerto alar E

septo $\square$ auricular D $\square$ auricular E

Septo Nasal

correção do desvio anterior

$\square$ correção do desvio posterior

$\square$ esporão (etmóide) D

- esporão (etmóide) E

Conchas nasais

$\square$ superior D

$\square$ superior E $\quad \square$ turbinectomia

turbinoplastia

$\square$ médio D

$\square$ médio E

$\square$ inferior D

$\square$ inferior E

Válvula Nasal

$\square$ aumento

$\square$ redução

$\square \mathrm{D} \square \mathrm{E}$

Ponta Nasal

aumento da projeção

$\square$ enxerto septal retrocolumelar (estaca)

enxerto septal

anterior

Dorso Nasal

$\square$ redução da projeção

Altura

$\square$ aumento

Dredução

Base

$\square$ larga

Destreita

$\square$ enxerto D

$\square$ enxerto $\mathrm{E}$

$\square$ ósseo

cartilaginoso

\section{Osso Nasal}

$\square$ osteotomia medial $\square$ osteotomia lateral $\square$ completa

$\square$ outros: especificar

Enxerto Autógeno

$\square$ cartilagem septal $\square$ cartilagem auricular $\quad \square$ cartilagem costal

$\square$ outros: especificar

\section{OBSERVAÇÕES:}




\section{Anexo 3}

Achados clínicos e procedimentos cirúrgicos 
Anexo 3B - Rinosseptoplastia: procedimentos cirúrgicos realizados nos indivíduos com fissura de lábio e palato unilateral reparada analisados.

\begin{tabular}{|c|c|c|c|c|c|c|c|c|c|c|c|c|}
\hline PAC & LF & TIPO & ACESSO & CAI & CAS & SN & $\mathrm{CON}$ & VN & PON & DN & ON & $\mathrm{EA}$ \\
\hline 1 & $E$ & primário & $\begin{array}{l}\text { interc, externo } \\
1 / 3 \text { sup col }\end{array}$ & $\begin{array}{c}\sec 1 / 3 \text { pos } \\
D e E\end{array}$ & - & $\begin{array}{c}\text { corr } \\
\text { desv } A / P\end{array}$ & - & $A, E$ & A, ESR, ESA & - & - & $\begin{array}{l}\text { cartilagem } \\
\text { septal }\end{array}$ \\
\hline 2 & $\mathrm{D}$ & primário & $\begin{array}{l}\text { interc, externo } \\
1 / 3 \text { sup col }\end{array}$ & $\begin{array}{c}\sec 1 / 3 \text { pos } \\
D \text { e E }\end{array}$ & - & $\begin{array}{c}\text { corr } \\
\text { desv A/P }\end{array}$ & - & $A, D$ & A, ESR, ESA & - & - & $\begin{array}{l}\text { cartilagem } \\
\text { septal }\end{array}$ \\
\hline 3 & $E$ & primário & $\begin{array}{l}\text { interc, externo } \\
1 / 3 \text { sup col }\end{array}$ & $\begin{array}{c}\sec 1 / 3 \text { pos } \\
D \text { e E }\end{array}$ & - & $\begin{array}{c}\text { corr } \\
\text { desv A/P }\end{array}$ & - & $A, E$ & A, ESR, ESA & - & - & $\begin{array}{l}\text { cartilagem } \\
\text { septal }\end{array}$ \\
\hline 4 & $E$ & primário & $\begin{array}{l}\text { interc, externo } \\
1 / 3 \text { sup col }\end{array}$ & $\begin{array}{c}\sec 1 / 3 \text { pos } \\
D \text { e E }\end{array}$ & - & $\begin{array}{c}\text { corr } \\
\text { desv A/P }\end{array}$ & - & $A, E$ & A, ESR, ESA & - & - & $\begin{array}{c}\text { cartilagem } \\
\text { septal }\end{array}$ \\
\hline 5 & $\mathrm{D}$ & primário & $\begin{array}{l}\text { interc, externo } \\
1 / 3 \text { sup col }\end{array}$ & $\begin{array}{c}\sec 1 / 3 \text { pos } \\
D \text { e E }\end{array}$ & - & $\begin{array}{c}\text { corr } \\
\operatorname{desv} A / P\end{array}$ & - & $A, D$ & A, ESR, ESA & - & - & $\begin{array}{l}\text { cartilagem } \\
\text { septal }\end{array}$ \\
\hline 6 & $E$ & primário & $\begin{array}{l}\text { interc, externo } \\
1 / 3 \text { sup col }\end{array}$ & $\begin{array}{c}\sec 1 / 3 \text { pos } \\
D \text { e E }\end{array}$ & - & $\begin{array}{c}\text { corr } \\
\text { desv A/P }\end{array}$ & - & $A, E$ & A, ESR, ESA & - & $\begin{array}{c}\text { Osteotomia } \\
\text { Me L }\end{array}$ & $\begin{array}{l}\text { cartilagem } \\
\text { septal }\end{array}$ \\
\hline 7 & $\mathrm{D}$ & primário & $\begin{array}{l}\text { interc, externo } \\
1 / 3 \text { sup col }\end{array}$ & $\begin{array}{c}\sec 1 / 3 \text { pos } \\
D \text { e E }\end{array}$ & - & $\begin{array}{c}\text { corr } \\
\text { desv A/P }\end{array}$ & - & $A, D$ & A, ESR, ESA & - & - & $\begin{array}{l}\text { cartilagem } \\
\text { septal }\end{array}$ \\
\hline 8 & $\mathrm{D}$ & primário & $\begin{array}{l}\text { interc, externo } \\
1 / 3 \text { sup col }\end{array}$ & $\begin{array}{c}\sec 1 / 3 \text { pos } \\
D \text { e E }\end{array}$ & - & $\begin{array}{c}\text { corr } \\
\operatorname{desv} A / P\end{array}$ & - & $A, D$ & A, ESR, ESA & - & - & $\begin{array}{l}\text { cartilagem } \\
\text { septal }\end{array}$ \\
\hline 9 & $\mathrm{D}$ & primário & $\begin{array}{l}\text { interc, externo } \\
1 / 3 \text { sup col }\end{array}$ & $\begin{array}{c}\sec 1 / 3 \text { pos } \\
D \text { e E }\end{array}$ & - & $\begin{array}{c}\text { corr } \\
\text { desv A/P }\end{array}$ & - & $A, D$ & A, ESR, ESA & - & - & $\begin{array}{l}\text { cartilagem } \\
\text { septal }\end{array}$ \\
\hline 10 & $D$ & primário & $\begin{array}{l}\text { interc, externo } \\
1 / 3 \text { sup col }\end{array}$ & $\begin{array}{c}\sec 1 / 3 \text { pos } \\
D e E\end{array}$ & - & $\begin{array}{c}\text { corr } \\
\operatorname{desv} A / P\end{array}$ & - & $A, D$ & A, ESR, ESA & - & - & $\begin{array}{c}\text { cartilagem } \\
\text { septal }\end{array}$ \\
\hline 11 & $E$ & primário & $\begin{array}{l}\text { interc, externo } \\
1 / 3 \text { médio col }\end{array}$ & $\begin{array}{c}\sec 1 / 3 \text { pos } \\
D e E\end{array}$ & - & $\begin{array}{c}\text { corr } \\
\operatorname{desv} A / P\end{array}$ & - & $A, E$ & A, ESR, ESA & - & - & $\begin{array}{l}\text { cartilagem } \\
\text { septal }\end{array}$ \\
\hline 12 & $E$ & primário & $\begin{array}{l}\text { interc, externo } \\
1 / 3 \text { sup col }\end{array}$ & $\begin{array}{c}\sec 1 / 3 \text { pos } \\
D \text { e E }\end{array}$ & - & $\begin{array}{c}\text { corr } \\
\text { desv A/P }\end{array}$ & - & $A, E$ & A, ESR, ESA & - & - & $\begin{array}{l}\text { cartilagem } \\
\text { septal }\end{array}$ \\
\hline 13 & $\mathrm{D}$ & primário & $\begin{array}{l}\text { interc, externo } \\
1 / 3 \text { sup col }\end{array}$ & $\begin{array}{c}\sec 1 / 3 \text { pos } \\
D \text { e E }\end{array}$ & - & $\begin{array}{c}\text { corr } \\
\text { desv A/P }\end{array}$ & - & $A, D$ & A, ESR, ESA & - & - & $\begin{array}{l}\text { cartilagem } \\
\text { septal }\end{array}$ \\
\hline 14 & $E$ & primário & $\begin{array}{l}\text { interc, externo } \\
1 / 3 \text { sup col }\end{array}$ & $\begin{array}{c}\sec 1 / 3 \text { pos } \\
D e E\end{array}$ & - & $\begin{array}{c}\text { corr } \\
\operatorname{desv} A / P\end{array}$ & - & $A, E$ & A, ESR, ESA & - & - & $\begin{array}{l}\text { cartilagem } \\
\text { septal }\end{array}$ \\
\hline 15 & $E$ & primário & $\begin{array}{l}\text { interc, externo } \\
1 / 3 \text { sup col }\end{array}$ & $\begin{array}{c}\text { sec } 1 / 3 \text { pos } \\
D \text { e E }\end{array}$ & - & $\begin{array}{c}\text { corr } \\
\operatorname{desv} A / P\end{array}$ & - & $A, E$ & A, ESR, ESA & - & - & $\begin{array}{l}\text { cartilagem } \\
\text { septal }\end{array}$ \\
\hline 16 & $E$ & primário & $\begin{array}{l}\text { interc, externo } \\
1 / 3 \text { sup col }\end{array}$ & $\begin{array}{c}\sec 1 / 3 \text { pos } \\
D \text { e E }\end{array}$ & - & $\begin{array}{c}\text { corr } \\
\text { desv A/P }\end{array}$ & - & $A, E$ & A, ESR, ESA & - & - & $\begin{array}{l}\text { cartilagem } \\
\text { septal }\end{array}$ \\
\hline 17 & $E$ & primário & $\begin{array}{l}\text { interc, externo } \\
1 / 3 \text { sup col }\end{array}$ & $\begin{array}{c}\sec 1 / 3 \text { pos } \\
D \text { e E }\end{array}$ & - & $\begin{array}{c}\text { corr } \\
\text { desv A/P }\end{array}$ & - & $A, E$ & A, ESR, ESA & - & - & $\begin{array}{l}\text { cartilagem } \\
\text { septal }\end{array}$ \\
\hline 18 & $E$ & primário & $\begin{array}{l}\text { interc, externo } \\
1 / 3 \text { sup col }\end{array}$ & $\begin{array}{c}\text { sec } 1 / 3 \text { pos } \\
D \text { e E }\end{array}$ & - & $\begin{array}{c}\text { corr } \\
\operatorname{desv} A / P\end{array}$ & - & $A, E$ & A, ESR, ESA & - & - & $\begin{array}{l}\text { cartilagem } \\
\text { septal }\end{array}$ \\
\hline 19 & $E$ & primário & $\begin{array}{l}\text { interc, externo } \\
1 / 3 \text { sup col }\end{array}$ & $\begin{array}{c}\sec 1 / 3 \text { pos } \\
D \text { e E }\end{array}$ & - & $\begin{array}{c}\text { corr } \\
\operatorname{desv} A / P\end{array}$ & - & $A, E$ & A, ESR, ESA & - & - & $\begin{array}{l}\text { cartilagem } \\
\text { septal }\end{array}$ \\
\hline 20 & $E$ & primário & $\begin{array}{l}\text { interc, externo } \\
1 / 3 \text { sup col }\end{array}$ & $\begin{array}{c}\sec 1 / 3 \text { pos } \\
D \text { e E }\end{array}$ & - & $\begin{array}{c}\text { corr } \\
\operatorname{desv} A / P\end{array}$ & - & $A, E$ & A, ESR, ESA & - & - & $\begin{array}{c}\text { cartilagem } \\
\text { septal }\end{array}$ \\
\hline 21 & $E$ & primário & $\begin{array}{l}\text { interc, externo } \\
1 / 3 \text { sup col }\end{array}$ & $\begin{array}{c}\sec 1 / 3 \text { pos } \\
D e E\end{array}$ & - & $\begin{array}{c}\text { corr } \\
\text { desv A/P }\end{array}$ & - & $A, E$ & A, ESR, ESA & - & - & $\begin{array}{c}\text { cartilagem } \\
\text { septal }\end{array}$ \\
\hline
\end{tabular}

PAC - paciente, LF - lado da fissura, CAI - cartilagem alar inferior, CAS - cartilagem alar superior, SN - septo nasal, CON - conchas, VN - válvula nasal, PON - ponta nasal, DN - dorso nasal, ON - osso nasal, EA - enxerto autógeno.

E - Esquerda, D - direita, interc - intercartilaginoso, sup - superior, col - columela, sec pos - secção posterior, corr desv A/P - correção desvio anterior e posterior, A - aumento, ESR - enxerto septal retrocolumelar, ESA - enxerto septal anterior, M - medial, L - lateral. 


\title{
Anexo 4
}

\author{
Resultados \\ individuais
}


Anexo 4A - Valores individuais e médios ( \pm desvio padrão) das áreas de secção transversa de três diferentes segmentos da cavidade nasal (AST1, AST2 e AST3), aferidas por rinometria acústica, em 21 indivíduos com fissura de lábio e palato unilateral reparada, previamente (PRE) à rinosseptoplastia e no primeiro (POS1) e segundo (POS2) pós-operatório, do lado fissurado, antes da aplicação tópica de vasoconstrictor nasal. As áreas seccionais são expressas em $\mathrm{cm}^{2}$.

\begin{tabular}{|c|c|c|c|c|c|c|c|c|c|}
\hline \multirow{2}{*}{ Pacientes } & \multicolumn{3}{|c|}{ AST1 } & \multicolumn{3}{|c|}{ AST2 } & \multicolumn{3}{|c|}{ AST3 } \\
\hline & PRE & $\begin{array}{c}\text { POS } \\
1\end{array}$ & POS2 & PRE & Pos1 & $\begin{array}{c}\text { POS } \\
2\end{array}$ & PRE & POS1 & $\begin{array}{c}\text { POS } \\
2\end{array}$ \\
\hline 1 & 0.45 & 0.36 & 0.40 & 1.41 & 0.55 & 0.50 & 2.58 & 0.64 & 0.52 \\
\hline 2 & 0.10 & 0.22 & - & 0.31 & 1.00 & - & 0.37 & 1.12 & - \\
\hline 3 & 0.72 & 0.87 & 0.57 & 0.77 & 1.51 & 0.47 & 0.98 & 1.64 & 0.69 \\
\hline 4 & 0.51 & 0.61 & 0.71 & 0.96 & 0.77 & 1.26 & 1.47 & 1.12 & 1.90 \\
\hline 5 & 0.22 & 0.42 & 0.44 & 0.56 & 0.28 & 0.60 & 0.96 & 0.38 & 1.00 \\
\hline 6 & 0.19 & 0.17 & 0.16 & 0.36 & 0.85 & 0.63 & 0.60 & 1.27 & 1.22 \\
\hline 7 & 0.45 & 0.33 & 0.32 & 0.74 & 0.31 & 0.88 & 1.34 & 1.31 & 1.40 \\
\hline 8 & 0.54 & 0.33 & 0.66 & 1.39 & 0.46 & 1.55 & 1.71 & 0.81 & 2.05 \\
\hline 9 & 0.25 & 0.25 & 0.38 & 0.77 & 0.82 & 0.82 & 1.10 & 1.01 & 1.30 \\
\hline 10 & 0.53 & 0.64 & 0.77 & 1.10 & 0.88 & 1.16 & 1.61 & 1.53 & 1.09 \\
\hline 11 & 0.4 & 0.44 & 0.37 & 0.67 & 1.10 & 0.72 & 1.71 & 2.23 & 1.35 \\
\hline 12 & 0.47 & 0.66 & 0.57 & 0.56 & 1.65 & 1.03 & 0.62 & 1.93 & 0.71 \\
\hline 13 & 0.16 & 0.37 & - & 0.31 & 0.60 & - & 0.45 & 0.91 & - \\
\hline 14 & 0.44 & 0.70 & 0.63 & 0.89 & 1.03 & 0.81 & 1.56 & 1.19 & 0.98 \\
\hline 15 & 0.16 & 0.42 & 0.55 & 0.38 & 1.24 & 1.13 & 0.60 & 1.43 & 1.51 \\
\hline 16 & 0.37 & 0.52 & 0.36 & 1.59 & 0.97 & 0.90 & 3.97 & 1.58 & 1.58 \\
\hline 17 & 0.47 & 0.67 & 0.77 & 0.47 & 1.03 & 0.80 & 0.79 & 1.32 & 1.09 \\
\hline 18 & 0.40 & 0.34 & 0.44 & 0.57 & 0.69 & 1.11 & 0.69 & 0.73 & 1.27 \\
\hline 19 & 0.08 & 0.34 & 0.39 & 0.18 & 0.65 & 0.75 & 0.36 & 1.04 & 1.38 \\
\hline 20 & 0.22 & 0.81 & - & 0.38 & 1.57 & - & 0.88 & 2.26 & - \\
\hline 21 & 0.20 & 0.25 & 0.18 & 0.57 & 0.72 & 0.72 & 0.69 & 1.10 & 1.01 \\
\hline$\overline{\mathbf{x}}$ & 0.35 & 0.46 & 0.48 & 0.71 & 0.89 & 0.88 & 1.19 & 1.26 & 1.23 \\
\hline$\pm \mathrm{DP}$ & 0.17 & 0.20 & 0.18 & 0.39 & 0.38 & 0.28 & 0.85 & 0.48 & 0.40 \\
\hline
\end{tabular}


Anexo 4B - Valores individuais e médios ( \pm desvio padrão) das áreas de secção transversa de três diferentes segmentos da cavidade nasal (AST1, AST2 e AST3), aferidas por rinometria acústica em 21 indivíduos com fissura de lábio e palato unilateral reparada, previamente (PRE) à rinosseptoplastia e no primeiro (POS1) e segundo (POS2) pós-operatório, do lado não-fissurado, antes da aplicação tópica de vasoconstrictor nasal. As áreas seccionais são expressas $\mathrm{em} \mathrm{cm}^{2}$.

\begin{tabular}{|c|c|c|c|c|c|c|c|c|c|}
\hline \multirow{2}{*}{ Pacientes } & \multicolumn{3}{|c|}{ AST1 } & \multicolumn{3}{|c|}{ AST2 } & \multicolumn{3}{|c|}{ AST3 } \\
\hline & PRE & $\begin{array}{c}\text { POS } \\
1\end{array}$ & POS2 & PRE & POS1 & $\begin{array}{c}\text { POS } \\
2\end{array}$ & PRE I & POS1 & $\begin{array}{c}\text { POS } \\
2\end{array}$ \\
\hline 1 & 0.38 & 0.53 & 0.53 & 1.02 & 2.63 & 2.30 & 1.41 & 2.23 & 2.66 \\
\hline 2 & 0.42 & 0.32 & - & 0.78 & 0.84 & - & 1.03 & 0.74 & - \\
\hline 3 & 0.34 & 0.31 & 0.38 & 0.42 & 0.6 & 0.79 & 0.60 & 0.96 & 1.19 \\
\hline 4 & 0.57 & 0.61 & 0.58 & 0.74 & 0.67 & 0.41 & 1.20 & 0.93 & 0.59 \\
\hline 5 & 0.74 & 0.69 & 0.85 & 1.04 & 0.89 & 1.33 & 1.66 & 1.39 & 1.90 \\
\hline 6 & 0.71 & 0.34 & 0.35 & 1.80 & 0.69 & 0.65 & 2.25 & 1.18 & 0.98 \\
\hline 7 & 0.37 & 0.38 & 0.23 & 0.82 & 0.97 & 0.53 & 1.59 & 1.18 & 0.84 \\
\hline 8 & 0.41 & 0.68 & 0.60 & 0.68 & 2.14 & 0.82 & 0.87 & 3.03 & 1.43 \\
\hline 9 & 0.60 & 0.50 & 0.30 & 1.68 & 1.77 & 0.53 & 2.29 & 2.25 & 0.81 \\
\hline 10 & 0.42 & 0.14 & 0.31 & 0.64 & 0.13 & 0.36 & 0.82 & 0.26 & 0.37 \\
\hline 11 & 0.28 & 0.42 & 0.40 & 0.67 & 0.53 & 1.41 & 1.08 & 1.02 & 3.44 \\
\hline 12 & 0.82 & 0.36 & 0.70 & 0.99 & 0.41 & 0.78 & 0.95 & 0.68 & 0.80 \\
\hline 13 & 0.54 & 0.3 & - & 1.70 & 1.52 & - & 1.48 & 1.64 & - \\
\hline 14 & 0.44 & 0.49 & 0.64 & 0.58 & 0.75 & 0.86 & 0.99 & 0.86 & 1.02 \\
\hline 15 & 0.75 & 0.4 & 0.34 & 1.73 & 1.34 & 0.67 & 2.40 & 1.47 & 0.92 \\
\hline 16 & 0.42 & 0.62 & 0.65 & 0.76 & 1.98 & 1.78 & 1.38 & 2.46 & 2.33 \\
\hline 17 & 0.52 & 0.56 & 0.51 & 0.66 & 0.9 & 1.00 & 0.85 & 2.04 & 2.29 \\
\hline 18 & 0.65 & 0.71 & 0.74 & 0.81 & 1.26 & 0.81 & 1.02 & 1.57 & 0.84 \\
\hline 19 & 0.30 & 0.17 & 0.15 & 0.68 & 0.42 & 0.46 & 1.24 & 0.81 & 0.85 \\
\hline 20 & 0.17 & 0.24 & - & 0.35 & 0.48 & - & 0.48 & 0.83 & - \\
\hline 21 & 0.51 & 0.32 & 0.36 & 1.11 & 0.84 & 0.86 & 1.33 & 0.76 & 0.85 \\
\hline $\bar{x}$ & 0.49 & 0.43 & 0.48 & 0.94 & 1.04 & 0.91 & 1.28 & 1.35 & 1.34 \\
\hline$\pm \mathrm{DP}$ & 0.17 & 0.17 & 0.19 & 0.44 & 0.65 & 0.51 & 0.53 & 0.70 & 0.83 \\
\hline
\end{tabular}


Anexo 4C - Valores individuais e médios ( \pm desvio padrão) das áreas de secção transversa de três diferentes segmentos da cavidade nasal (AST1, AST2 e AST3), aferidas por rinometria acústica em 21 indivíduos com fissura de lábio e palato unilateral reparada, previamente (PRE) à rinosseptoplastia e no primeiro (POS1) e segundo (POS2) pós-operatório, do lado fissurado, após a aplicação tópica de vasoconstrictor nasal. As áreas seccionais são expressas em $\mathrm{cm}^{2}$.

\begin{tabular}{|c|c|c|c|c|c|c|c|c|c|}
\hline \multirow{2}{*}{ Pacientes } & \multicolumn{3}{|c|}{ AST1 } & \multicolumn{3}{|c|}{ AST2 } & \multicolumn{3}{|c|}{ AST3 } \\
\hline & PRE & $\begin{array}{c}\text { POS } \\
1\end{array}$ & POS2 & PRE & Pos1 & $\begin{array}{c}\text { POS } \\
2\end{array}$ & PRE & Pos1 & $\begin{array}{c}\text { POS } \\
2\end{array}$ \\
\hline 1 & 0.39 & 0.42 & 0.52 & 1.02 & 0.72 & 1.26 & 1.80 & 1.38 & 1.34 \\
\hline 2 & 0.19 & 0.26 & - & 0.73 & 1.21 & - & 0.72 & 1.35 & - \\
\hline 3 & 0.84 & 0.83 & 0.96 & 1.98 & 1.86 & 1.72 & 2.70 & 2.24 & 2.54 \\
\hline 4 & 0.41 & - & 0.61 & 0.79 & - & 0.95 & 1.38 & - & 1.60 \\
\hline 5 & 0.21 & 0.46 & 0.52 & 0.60 & 0.44 & 1.36 & 1.13 & 0.64 & 1.98 \\
\hline 6 & 0.23 & 0.18 & 0.20 & 0.76 & 0.97 & 1.05 & 0.91 & 1.34 & 1.59 \\
\hline 7 & 0.43 & 0.40 & 0.33 & 1.56 & 0.69 & 1.19 & 2.21 & 2.53 & 1.42 \\
\hline 8 & 0.57 & 0.34 & 0.69 & 1.37 & 0.57 & 1.91 & 1.84 & 1.10 & 2.50 \\
\hline 9 & 0.25 & 0.25 & 0.51 & 1.07 & 0.94 & 1.60 & 1.64 & 1.19 & 2.07 \\
\hline 10 & 0.75 & 1.06 & 1.08 & 1.80 & 2.15 & 2.01 & 0.92 & 4.54 & 2.49 \\
\hline 11 & 0.35 & 0.39 & 0.37 & 0.75 & 1.15 & 0.97 & 1.43 & 2.49 & 2.35 \\
\hline 12 & 0.69 & 0.64 & 0.64 & 1.26 & 1.86 & 1.55 & 1.24 & 2.29 & 1.24 \\
\hline 13 & 0.25 & 0.50 & - & 0.98 & 1.17 & - & 0.88 & 1.57 & - \\
\hline 14 & 0.30 & 0.87 & 0.74 & 1.62 & 1.70 & 1.58 & 2.48 & 2.15 & 2.06 \\
\hline 15 & 0.32 & 0.39 & 0.66 & 1.10 & 1.58 & 1.33 & 1.22 & 1.72 & 1.77 \\
\hline 16 & 0.37 & 0.48 & 0.36 & 1.72 & 0.96 & 1.24 & 5.01 & 1.43 & 2.21 \\
\hline 17 & 0.28 & 0.60 & 0.76 & 0.81 & 1.30 & 1.15 & 1.03 & 1.99 & 1.78 \\
\hline 18 & 0.43 & 0.32 & 0.43 & 0.70 & 1.05 & 1.33 & 1.04 & 1.22 & 1.67 \\
\hline 19 & 0.10 & 0.38 & 0.39 & 0.40 & 1.10 & 1.31 & 0.66 & 1.73 & 2.07 \\
\hline 20 & 0.33 & 0.76 & - & 1.23 & 1.40 & - & 1.71 & 1.92 & - \\
\hline 21 & 0.23 & 0.23 & 0.20 & 0.99 & 0.99 & 0.82 & 1.46 & 1.62 & 1.39 \\
\hline$\overline{\mathbf{x}}$ & 0.38 & 0.49 & 0.55 & 1.11 & 1.19 & 1.35 & 1.59 & 1.82 & 1.89 \\
\hline$\pm \mathrm{DP}$ & 0.19 & 0.24 & 0.24 & 0.43 & 0.46 & 0.33 & 0.96 & 0.81 & 0.42 \\
\hline
\end{tabular}


Anexo 4D - Valores individuais e médios ( \pm desvio padrão) das áreas de secção transversa de três diferentes segmentos da cavidade nasal (AST1, AST2 e AST3), aferidas por rinometria acústica em 21 indivíduos com fissura de lábio e palato unilateral reparada, previamente (PRE) à rinosseptoplastia e no primeiro (POS1) e segundo (POS2) pós-operatório, do lado não-fissurado, após a aplicação tópica de vasoconstrictor nasal. As áreas seccionais são expressas em $\mathrm{cm}^{2}$.

\begin{tabular}{|c|c|c|c|c|c|c|c|c|c|}
\hline \multirow{2}{*}{ Pacientes } & \multicolumn{3}{|c|}{ AST1 } & \multicolumn{3}{|c|}{ AST2 } & \multicolumn{3}{|c|}{ AST3 } \\
\hline & PRE & $\begin{array}{c}\text { POS } \\
1\end{array}$ & POS2 & & POS1 & $\begin{array}{c}\text { POS } \\
2\end{array}$ & PRE & POS1 & $\begin{array}{c}\text { POS } \\
2\end{array}$ \\
\hline 1 & 0.62 & 0.59 & 0.54 & 2.39 & 2.90 & 2.63 & 3.18 & 2.43 & 2.87 \\
\hline 2 & 0.56 & 0.46 & - & 1.14 & 1.11 & - & 1.49 & 1.11 & - \\
\hline 3 & 0.55 & 0.37 & 0.43 & 1.15 & 1.34 & 1.43 & 1.71 & 1.43 & 1.87 \\
\hline 4 & 0.58 & - & 0.63 & 1.23 & - & 0.87 & 1.79 & - & 1.52 \\
\hline 5 & 0.84 & 0.79 & 0.84 & 1.62 & 1.48 & 1.99 & 2.40 & 2.29 & 2.51 \\
\hline 6 & 0.72 & 0.61 & 0.68 & 1.81 & 1.58 & 1.97 & 2.45 & 1.99 & 2.32 \\
\hline 7 & 0.42 & 0.43 & 0.38 & 1.33 & 1.10 & 1.47 & 2.02 & 1.50 & 1.51 \\
\hline 8 & 0.48 & 0.71 & 0.56 & 0.92 & 2.22 & 1.46 & 0.97 & 3.41 & 2.64 \\
\hline 9 & 0.69 & 0.57 & 0.63 & 1.77 & 2.06 & 1.63 & 2.55 & 2.63 & 2.37 \\
\hline 10 & 0.62 & 0.86 & 0.91 & 1.15 & 0.91 & 1.66 & 1.20 & 1.06 & 2.33 \\
\hline 11 & 0.36 & 0.40 & 0.40 & 1.36 & 1.03 & 2.17 & 1.77 & 1.71 & 4.37 \\
\hline 12 & 0.68 & 0.60 & 0.81 & 0.78 & 1.12 & 1.29 & 0.99 & 1.40 & 1.31 \\
\hline 13 & 0.60 & 0.32 & - & 2.03 & 1.67 & - & 1.84 & 1.71 & - \\
\hline 14 & 0.74 & 0.74 & 0.79 & 1.46 & 1.44 & 1.48 & 2.43 & 2.32 & 2.02 \\
\hline 15 & 0.72 & 0.45 & 0.42 & 1.95 & 1.67 & 1.24 & 2.39 & 2.02 & 1.54 \\
\hline 16 & 0.46 & 0.65 & 0.65 & 0.92 & 2.06 & 1.96 & 1.92 & 2.56 & 2.73 \\
\hline 17 & 0.51 & 0.58 & 0.52 & 0.85 & 1.19 & 1.00 & 0.97 & 1.57 & 1.16 \\
\hline 18 & 0.98 & 0.74 & 0.84 & 1.63 & 1.66 & 1.81 & 2.01 & 2.07 & 1.83 \\
\hline 19 & 0.55 & 0.27 & 0.32 & 1.33 & 1.11 & 1.31 & 2.10 & 1.70 & 1.87 \\
\hline 20 & 0.58 & 0.44 & - & 2.21 & 1.00 & - & 2.03 & 1.24 & - \\
\hline 21 & 0.57 & 0.43 & 0.43 & 1.47 & 1.66 & 1.36 & 1.95 & 1.79 & 1.55 \\
\hline$\overline{\mathbf{x}}$ & 0.61 & 0.55 & 0.60 & 1.45 & 1.52 & 1.60 & 1.91 & 1.90 & 2.13 \\
\hline$\pm \mathrm{DP}$ & 0.14 & 0.16 & 0.18 & 0.45 & 0.50 & 0.43 & 0.57 & 0.59 & 0.76 \\
\hline
\end{tabular}


Anexo 4E - Valores individuais e médios ( \pm desvio padrão) dos volumes de dois diferentes segmentos da cavidade nasal (V1 e V2), aferidos por rinometria acústica em 21 indivíduos com fissura de lábio e palato unilateral reparada, previamente (PRE) à rinosseptoplastia e no primeiro (POS1) e segundo (POS2) pós-operatório, do lado fissurado, antes da aplicação tópica de vasoconstrictor nasal. Os volumes são expressos $\mathrm{em}^{\mathrm{cm}^{3}}$.

\begin{tabular}{|c|c|c|c|c|c|c|}
\hline \multirow{2}{*}{ Pacientes } & \multicolumn{3}{|c|}{ V1 } & \multicolumn{3}{|c|}{ V2 } \\
\hline & PRE & POS1 & POS2 & PRE & POS1 & POS2 \\
\hline 1 & 1.44 & 1.19 & 1.32 & 6.75 & 2.21 & 1.98 \\
\hline 2 & 0.40 & 1.07 & - & 1.10 & 3.81 & - \\
\hline 3 & 1.99 & 2.57 & 1.70 & 3.30 & 5.93 & 2.04 \\
\hline 4 & 1.28 & 1.69 & 1.95 & 4.05 & 3.21 & 5.37 \\
\hline 5 & 1.20 & 1.14 & 1.34 & 2.32 & 1.25 & 2.81 \\
\hline 6 & 0.81 & 0.72 & 0.71 & 1.38 & 3.28 & 2.76 \\
\hline 7 & 1.30 & 1.03 & 1.14 & 3.02 & 1.17 & 3.55 \\
\hline 8 & 1.58 & 0.96 & 2.06 & 5.25 & 2.25 & 7.16 \\
\hline 9 & 0.95 & 0.96 & 1.24 & 3.13 & 3.22 & 3.93 \\
\hline 10 & 1.43 & 1.52 & 1.76 & 4.33 & 3.11 & 3.79 \\
\hline 11 & 1.08 & 1.36 & 1.33 & 4.83 & 5.56 & 4.43 \\
\hline 12 & 1.16 & 2.08 & 1.52 & 2.10 & 6.02 & 3.15 \\
\hline 13 & 0.77 & 1.32 & - & 1.21 & 2.56 & - \\
\hline 14 & 1.19 & 1.82 & 1.53 & 3.71 & 4.01 & 3.28 \\
\hline 15 & 0.79 & 1.56 & 1.82 & 1.47 & 4.48 & 4.43 \\
\hline 16 & 1.20 & 1.83 & 1.53 & 4.93 & 6.00 & 5.13 \\
\hline 17 & 1.11 & 1.96 & 1.90 & 2.37 & 4.41 & 3.50 \\
\hline 18 & 1.06 & 1.23 & 1.39 & 2.20 & 2.45 & 3.92 \\
\hline 19 & 0.54 & 1.19 & 1.27 & 0.82 & 3.01 & 3.36 \\
\hline 20 & 1.07 & 2.10 & - & 1.69 & 6.46 & - \\
\hline 21 & 0.86 & 0.84 & 0.73 & 2.07 & 2.60 & 2.80 \\
\hline$\overline{\mathbf{x}}$ & 1.11 & 1.44 & 1.46 & 2.95 & 3.67 & 3.74 \\
\hline$\pm \mathrm{DP}$ & 0.36 & 0.48 & 0.38 & 1.60 & 1.58 & 1.26 \\
\hline
\end{tabular}


Anexo 4F - Valores individuais e médios ( \pm desvio padrão) dos volumes de dois diferentes segmentos da cavidade nasal (V1 e V2), aferidos por rinometria acústica em 21 indivíduos com fissura de lábio e palato unilateral reparada, previamente (PRE) à rinosseptoplastia e no primeiro (POS1) e segundo (POS2) pós-operatório, do lado não-fissurado, antes da aplicação tópica de vasoconstrictor nasal. Os volumes são expressos $\mathrm{em} \mathrm{cm}^{3}$.

\begin{tabular}{|c|c|c|c|c|c|c|}
\hline \multirow{2}{*}{ Pacientes } & \multicolumn{3}{|c|}{ V1 } & \multicolumn{3}{|c|}{ V2 } \\
\hline & PRE & POS1 & POS2 & PRE & POS1 & POS2 \\
\hline 1 & 1.32 & 1.82 & 1.83 & 3.85 & 7.95 & 7.39 \\
\hline 2 & 1.18 & 1.19 & - & 2.98 & 2.84 & - \\
\hline 3 & 1.24 & 1.04 & 1.25 & 2.11 & 2.11 & 2.74 \\
\hline 4 & 1.58 & 1.53 & 1.30 & 3.09 & 3.11 & 1.97 \\
\hline 5 & 2.10 & 2.02 & 2.39 & 4.79 & 4.12 & 5.92 \\
\hline 6 & 2.11 & 1.18 & 1.17 & 6.74 & 3.12 & 3.17 \\
\hline 7 & 1.19 & 1.25 & 0.94 & 3.97 & 3.86 & 2.17 \\
\hline 8 & 1.54 & 2.16 & 1.59 & 2.69 & 7.65 & 3.14 \\
\hline 9 & 2.07 & 1.75 & 1.09 & 7.14 & 5.89 & 2.20 \\
\hline 10 & 1.22 & 0.60 & 0.97 & 2.32 & 0.48 & 1.12 \\
\hline 11 & 1.02 & 1.09 & 1.32 & 3.49 & 4.45 & 5.72 \\
\hline 12 & 2.33 & 1.14 & 1.73 & 3.31 & 1.88 & 3.03 \\
\hline 13 & 1.84 & 1.33 & - & 5.49 & 5.55 & - \\
\hline 14 & 1.35 & 1.50 & 1.75 & 2.44 & 2.95 & 3.11 \\
\hline 15 & 2.42 & 1.40 & 1.36 & 7.23 & 4.36 & 2.70 \\
\hline 16 & 1.43 & 2.24 & 2.11 & 3.63 & 8.11 & 7.24 \\
\hline 17 & 1.35 & 1.42 & 1.31 & 3.2 & 3.66 & 3.77 \\
\hline 18 & 2.17 & 2.27 & 2.22 & 3.12 & 5.00 & 2.93 \\
\hline 19 & 1.16 & 0.83 & 0.76 & 2.78 & 2.04 & 2.24 \\
\hline 20 & 0.89 & 1.08 & - & 1.33 & 2.13 & - \\
\hline 21 & 1.45 & 1.12 & 1.19 & 4.03 & 2.75 & 2.97 \\
\hline$\overline{\mathbf{x}}$ & 1.57 & 1.43 & 1.46 & 3.80 & 4.00 & 3.53 \\
\hline$\pm \mathrm{DP}$ & 0.46 & 0.46 & 0.46 & 1.63 & 2.08 & 1.81 \\
\hline
\end{tabular}


Anexo 4G - Valores individuais e médios ( \pm desvio padrão) dos volumes de dois diferentes segmentos da cavidade nasal (V1 e V2), aferidos por rinometria acústica em 21 indivíduos com fissura de lábio e palato unilateral reparada, previamente (PRE) à rinosseptoplastia e no primeiro (POS1) e segundo (POS2) pós-operatório, do lado fissurado, após a aplicação tópica de vasoconstrictor nasal. Os volumes são expressos $\mathrm{em}^{\mathrm{cm}^{3}}$.

\begin{tabular}{|c|c|c|c|c|c|c|}
\hline \multirow{2}{*}{ Pacientes } & \multicolumn{3}{|c|}{ V1 } & \multicolumn{3}{|c|}{ V2 } \\
\hline & PRE & POS1 & POS2 & PRE & POS1 & POS2 \\
\hline 1 & 1.23 & 1.30 & 1.75 & 5.32 & 3.70 & 4.55 \\
\hline 2 & 0.80 & 1.18 & - & 2.45 & 4.62 & - \\
\hline 3 & 2.52 & 2.69 & 2.90 & 8.12 & 7.42 & 7.82 \\
\hline 4 & 1.17 & - & 1.67 & 3.77 & - & 4.42 \\
\hline 5 & 1.20 & 1.18 & 1.57 & 2.46 & 2.12 & 5.41 \\
\hline 6 & 0.85 & 0.73 & 0.77 & 2.52 & 3.55 & 3.89 \\
\hline 7 & 1.21 & 1.28 & 1.23 & 5.48 & 2.90 & 4.20 \\
\hline 8 & 1.78 & 1.06 & 2.24 & 5.45 & 3.04 & 8.64 \\
\hline 9 & 0.97 & 1.01 & 1.71 & 4.36 & 4.03 & 6.30 \\
\hline 10 & 1.91 & 2.21 & 2.38 & 7.37 & 6.71 & 7.45 \\
\hline 11 & 1.05 & 1.68 & 1.43 & 4.37 & 7.51 & 6.44 \\
\hline 12 & 1.94 & 2.30 & 2.10 & 3.99 & 7.11 & 4.75 \\
\hline 13 & 0.97 & 1.69 & - & 3.10 & 4.93 & - \\
\hline 14 & 1.06 & 2.60 & 2.13 & 5.62 & 7.39 & 6.29 \\
\hline 15 & 1.08 & 1.63 & 2.06 & 3.65 & 5.77 & 5.22 \\
\hline 16 & 1.57 & 1.72 & 1.84 & 6.12 & 5.42 & 7.23 \\
\hline 17 & 0.95 & 1.93 & 2.02 & 3.21 & 5.56 & 5.09 \\
\hline 18 & 1.03 & 1.17 & 1.52 & 2.70 & 3.58 & 4.93 \\
\hline 19 & 0.59 & 1.58 & 1.50 & 1.68 & 5.04 & 5.76 \\
\hline 20 & 1.26 & 1.96 & - & 4.09 & 5.62 & - \\
\hline 21 & 0.96 & 0.92 & 0.82 & 4.04 & 4.25 & 3.68 \\
\hline$\overline{\mathbf{x}}$ & 1.24 & 1.59 & 1.76 & 4.28 & 5.01 & 5.67 \\
\hline$\pm \mathrm{DP}$ & 0.46 & 0.56 & 0.53 & 1.67 & 1.63 & 1.43 \\
\hline
\end{tabular}


Anexo 4H - Valores individuais e médios ( \pm desvio padrão) dos volumes de dois diferentes segmentos da cavidade nasal (V1 e V2), aferidos por rinometria acústica em 21 indivíduos com fissura de lábio e palato unilateral reparada, previamente (PRE) à rinosseptoplastia e no primeiro (POS1) e segundo (POS2) pós-operatório, do lado não-fissurado, após a aplicação tópica de vasoconstrictor nasal. Os volumes são expressos em $\mathrm{cm}^{3}$.

\begin{tabular}{|c|c|c|c|c|c|c|}
\hline \multirow{2}{*}{ Pacientes } & \multicolumn{3}{|c|}{ V1 } & \multicolumn{3}{|c|}{ V2 } \\
\hline & PRE & POS1 & POS2 & PRE & POS1 & POS2 \\
\hline 1 & 2.21 & 2.12 & 1.99 & 9.77 & 8.41 & 8.18 \\
\hline 2 & 1.79 & 1.58 & - & 4.76 & 4.04 & - \\
\hline 3 & 1.79 & 1.41 & 1.64 & 5.44 & 5.02 & 5.73 \\
\hline 4 & 1.80 & - & 1.67 & 5.10 & - & 4.46 \\
\hline 5 & 2.44 & 2.37 & 2.59 & 7.17 & 7.08 & 8.08 \\
\hline 6 & 2.03 & 1.93 & 2.12 & 6.86 & 5.72 & 6.38 \\
\hline 7 & 1.36 & 1.38 & 1.34 & 5.50 & 4.63 & 5.06 \\
\hline 8 & 1.69 & 2.17 & 1.74 & 3.32 & 7.81 & 6.07 \\
\hline 9 & 2.22 & 1.86 & 2.16 & 7.78 & 6.64 & 6.91 \\
\hline 10 & 1.62 & 2.05 & 2.42 & 3.88 & 3.18 & 6.32 \\
\hline 11 & 1.57 & 1.59 & 1.83 & 5.48 & 6.88 & 8.31 \\
\hline 12 & 2.01 & 1.82 & 2.29 & 3.04 & 5.05 & 4.94 \\
\hline 13 & 1.94 & 1.28 & - & 6.44 & 5.69 & - \\
\hline 14 & 1.90 & 2.13 & 2.04 & 5.91 & 6.37 & 5.92 \\
\hline 15 & 2.22 & 1.91 & 1.65 & 7.34 & 6.32 & 4.55 \\
\hline 16 & 1.52 & 2.32 & 2.22 & 4.74 & 8.44 & 8.13 \\
\hline 17 & 1.48 & 1.83 & 1.58 & 3.50 & 5.75 & 4.20 \\
\hline 18 & 2.45 & 2.47 & 2.52 & 6.12 & 6.65 & 6.46 \\
\hline 19 & 1.69 & 1.18 & 1.37 & 5.56 & 4.63 & 5.33 \\
\hline 20 & 1.80 & 1.57 & - & 6.68 & 3.68 & - \\
\hline 21 & 1.66 & 1.88 & 1.49 & 5.51 & 5.77 & 4.77 \\
\hline$\overline{\mathbf{x}}$ & 1.87 & 1.84 & 1.93 & 5.71 & 5.89 & 6.10 \\
\hline$\pm \mathrm{DP}$ & 0.31 & 0.37 & 0.39 & 1.61 & 1.47 & 1.37 \\
\hline
\end{tabular}


Anexo 4I - Valores individuais e médios ( \pm desvio padrão) da nasalância, aferida por nasometria, em 21 indivíduos com fissura de lábio e palato unilateral reparada, previamente (PRE) à rinosseptoplastia e no primeiro (POS1) e segundo (POS2) pós-operatório, na leitura do texto nasal e do texto oral. A nasalância é expressa em porcentagem (\%).

\begin{tabular}{|c|c|c|c|c|c|c|}
\hline \multirow{2}{*}{ Pacientes } & \multicolumn{3}{|c|}{ Texto Nasal } & \multicolumn{3}{|c|}{ Texto Oral } \\
\hline & PRE & POS1 & POS2 & PRE & POS1 & POS2 \\
\hline 1 & 45 & 37 & 42 & 10 & 6 & 6 \\
\hline 2 & 60 & 67 & - & 44 & 50 & - \\
\hline 3 & 54 & 62 & 42 & 34 & 47 & 21 \\
\hline 4 & 47 & 61 & 49 & 31 & 47 & 33 \\
\hline 5 & 64 & 64 & 65 & 42 & 51 & 51 \\
\hline 6 & 41 & 40 & 36 & 17 & 9 & 12 \\
\hline 7 & 42 & 51 & 56 & 16 & 14 & 29 \\
\hline 8 & 64 & 61 & 65 & 50 & 41 & 54 \\
\hline 9 & 51 & 47 & 41 & 28 & 25 & 13 \\
\hline 10 & 54 & 47 & 47 & 44 & 37 & 41 \\
\hline 11 & 55 & 54 & 49 & 23 & 17 & 22 \\
\hline 12 & 56 & 59 & 50 & 20 & 16 & 16 \\
\hline 13 & 48 & 53 & 60 & 10 & 15 & 22 \\
\hline 14 & 42 & 49 & 37 & 28 & 28 & 22 \\
\hline 15 & 31 & 50 & 40 & 13 & 31 & 15 \\
\hline 16 & 50 & 59 & 47 & 27 & 33 & 32 \\
\hline 17 & 47 & 45 & 46 & 11 & 9 & 13 \\
\hline 18 & 61 & 67 & 67 & 43 & 53 & 52 \\
\hline 19 & 56 & 60 & 61 & 39 & 43 & 46 \\
\hline 20 & 40 & 36 & - & 14 & 11 & - \\
\hline 21 & 50 & 42 & 38 & 26 & 20 & 21 \\
\hline$\overline{\mathbf{x}}$ & 50 & 53 & 49 & 27 & 29 & 25 \\
\hline$\pm \mathrm{DP}$ & 9 & 10 & 10 & 13 & 16 & 15 \\
\hline
\end{tabular}

